LONG-TERM EFFECIS OF SEXUAL VICTIMIZATION IN CHILDHCOD:

AN ATIRIBUTIONAL APPROACH

by

Erica R. Gold

Department of Psychology

\begin{abstract}
Submitted in partial fulfillment
of the requirements for the degree of

Doctor of Philosophy
\end{abstract}

Faculty of Graduate Studies

University of Manitoba

Winnipeg, Manitoba

January, 1985

(C) Erica Robin Gold 1985 
Permission has been granted to the National Library of Canada to microfilm this thesis and to lend or sell copies of the film.

The author (copyright owner) has reserved other publication rights, and neither the thesis nor extensive extracts from it may be printed or otherwise reproduced without his/her written permission.
L'autorisation a été accordée a Ia Bibliothèque rationale du Canada de microfilmer cette thèse et de prêter ou de vendre des exemplaires du film.

L'auteur (titulaire du aroit d'auteurl se réserve les autres droits de publication: ni la thèse ni de longs extraits de celle-ci ne doivent être imprimés ou autrement reproduits sans son autorisation écrite. 


\title{
LONG-TERM EFFECTS OF SEXUAL VICTIMIZATION IN CHILDHOOD: \\ AN ATTRIBUTIONAL APPROACH
}

BY

ERICA R. GOLD

\begin{abstract}
A thesis submitted to the Faculty of Graduate Studies of the University of Manitoba in partial fulfillment of the requirements of the degree of

DOCTOR OF PHILOSOPHY
\end{abstract}

() $\mathbf{1 9 8 5}$

Permission has been granted to the LIBRARY OF THE UNIVERSITY OF MANITOBA to lend or sell copies of this thesis, to the NATIONAL LIBRARY OF CANADA to microfilm this thesis and to lend or sell copies of the film, and UNIVERSITY MICROFILMS to publish an abstract of this thesis.

The author reserves other publication rights, and neither the thesis nor extensive extracts from it may be printed or otherwise reproduced without the author's written permission. 
Abstract

This study explored the relationship between childhood sexual victimization experience and adult functioning. One hundred and three adult women who were sexually victimized as children or adolescents served as subjects and eighty-eight women who were not victimized served as controls. All subjects completed a questionnaire which examined family background, victimization experiences and present social, psychological and sexual functioning. Sexually victimized women were also interviewed about their experiences. Victimized women differed significantly from nonvictims on measures of: (a) childhood family and social experiences; (b) adult attribution style, characterized by a tendency to employ characterological and behavioral self-blame and not other-blame, and a pattern of internal, stable, global attributions for bad events and external attributions for good events; (c) level of psychological distress, sexual problems and self-esteem. Results of the study suggest that the sexually victimized woman's adult functioning level is related most strongly to her attribution style for bad events. Perception of the victimization experience and social support are are also important factors related to adult coping. The implications of these findings for treating women who are experiencing problems related to their abusive experience are explored in addition to methodological issues and suggestions for future research. 


\section{Acknowledgements}

I would like to thank my advisor, Dr. Lillian Esses, for her support and contributions to this work. Her conscientiousness and thoroughness made the whole research process easier. Thanks are also due to the Examining Committee members, Dr. Derek Jenu, Dr. John Schallow and Mr. Walter Driedger for their contributions and support and to the External Examiner, Dr. Roxanne Silver for her thorough review of this work.

I am grateful to several professors at the UnIversity of Western Ontario where the bulk of the research was conducted. Dr. William McClelland found space for me to run the study, Dr. Richard Neufeld generously allowed me the use of his word processor, and Dr. Robert Gardner provided statistical advice.

The support of my family throughout my years in graduate school is gratefully acnowledged, especially that of my husband, Warren Nielson, whose patience, support, and editorial comments have been extremely valuable.

Finally, very special thanks are extended to the 191 women who took the time to participate in this study and made the effort to discuss some very personal matters with no reward except the hope that other women might be helped. 
ABSTRACT ..........................................

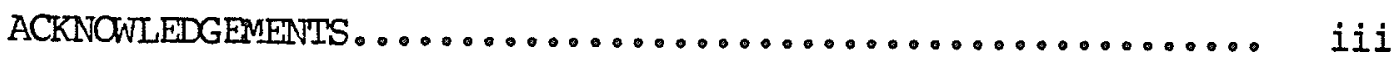

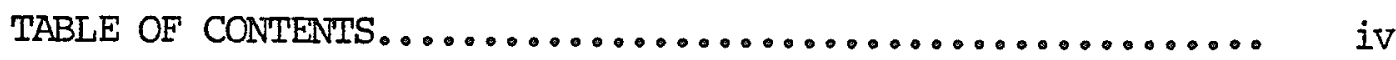

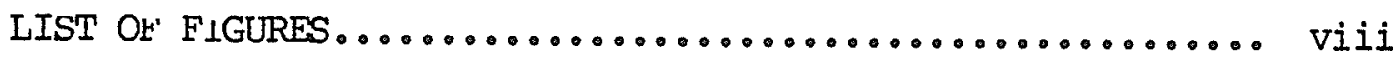

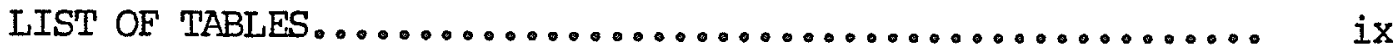

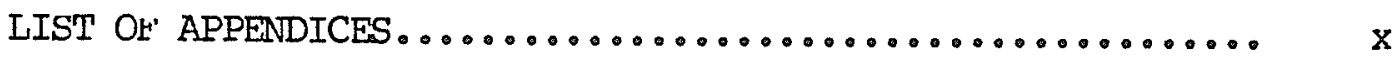

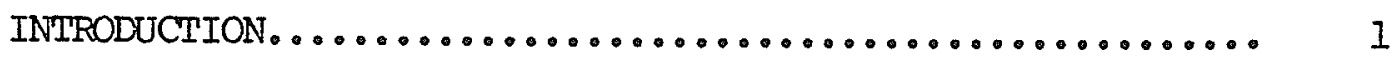

Incidence of Sexual Victimization in Childhood.......... I

Definition of Sexual Victimization in Childhood........ 1

Eftects of Sexual Victimization in Childhood........... 4

The Sexual Victimization Literature................. 9

Problems with the Sexual Victimization Literature....... 12

Definition of dependent variables............... 12

Retrospective studies........................ 13

Design and statistical problens................. 13

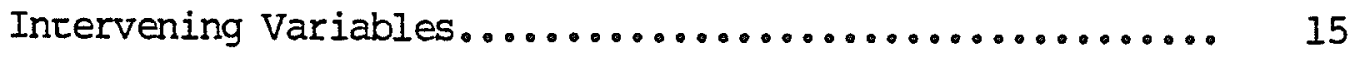

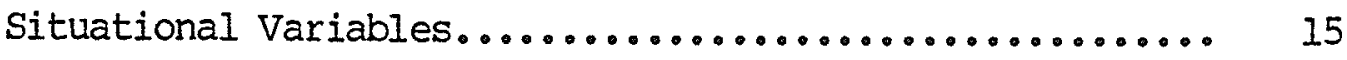

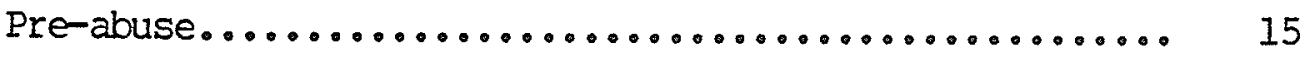

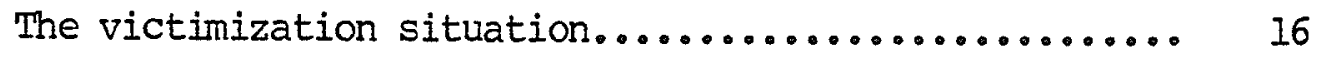

Victim-offender characteristics............... 16

Duration of molestation..................... 17

Use of force or physical coercion versus use of verbal

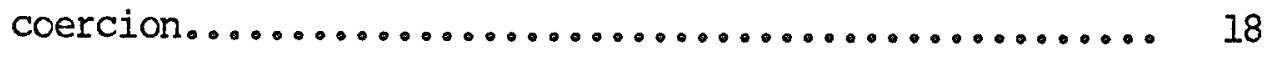

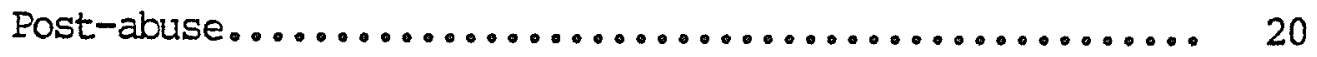


Intrapersonal Variables........................ 20

Pre-abuse ................................ 20

The victimization situation........................ 21

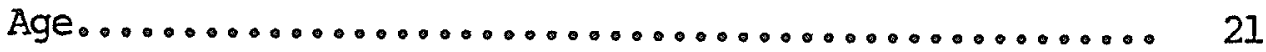

Passive compliance......................... 21

Victim's enotional response.................... 22

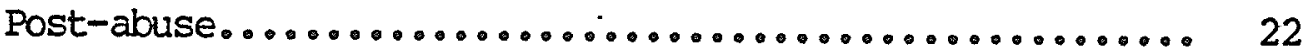

Implications of Intervening Variables for Understanding the

Eftects of Sexual Victimization in Childhood.......... 24

Attribution Theory and Learned Helplessness Theory....... 26

Research into Attribution Theory and Learned Helplessness

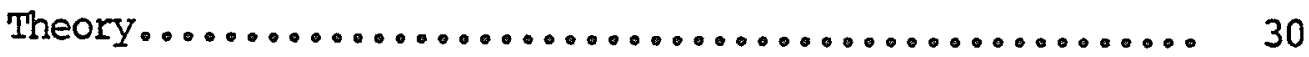

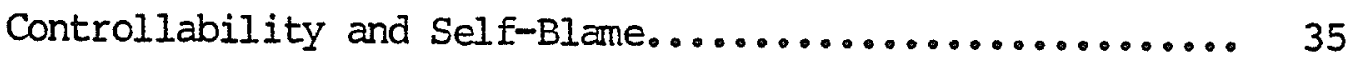

Research into Controllability and Self-Blame.......... 41

Factors Related to Coping Efficacy................. 44

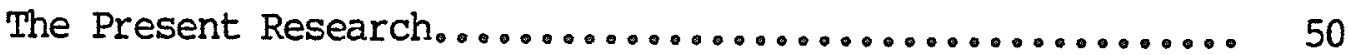

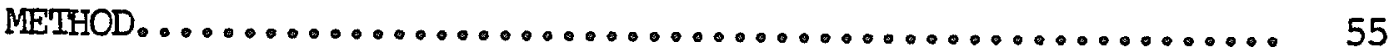

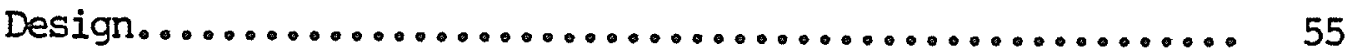

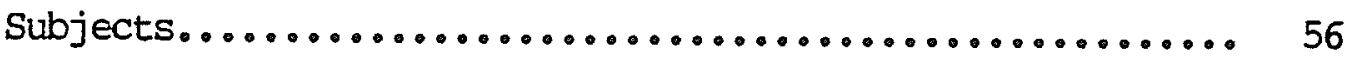

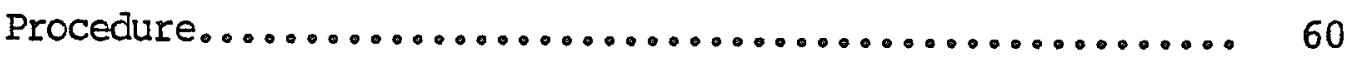

Measures.................................. 61

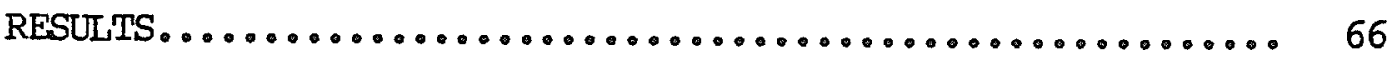

Comparability of the Groups..................... 66

The Victimization Experiences..................... 66

Length of victimization...................... 67 
Age of participants.......................... 67

Relationship of victim and offender............... 67

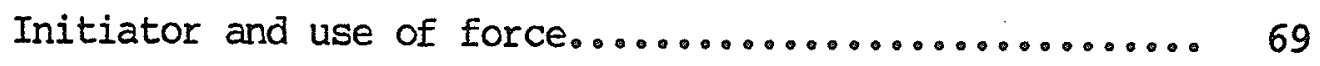

The type of sexual contact...................... 69

Victim's immediate reaction...................... 69

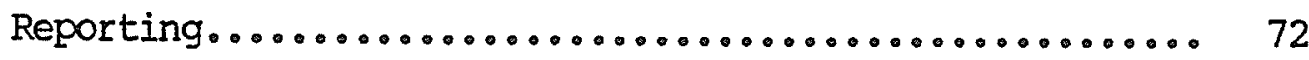

Parental response......................... 72

Overall victim response..................... 72

Between-Group Analyses............................ 74

Within-Groups Analyses: Victims.................... 79

Incest victims versus victims of nonfamilial abuse..... 79

Combination of variables....................... 80

Relationship Among Victimization Experience, Attribution,

Social Support and Coping Level Variables............ 84

Sexual victimization experience and other variables..... 84

Attribution style and coping level.................. 84

Social support and coping level................. 85

Attribution style and social support................ 88

Relationship of victimization experience, social support and attribution style with coping level........... 88

Within-Groups Analyses: Both Groups Combined............ 93

Relationship between social support variables and coping

level................................. 93

Relationship between attribution style and self-blane... 96 
Relationship between social support variables and locus

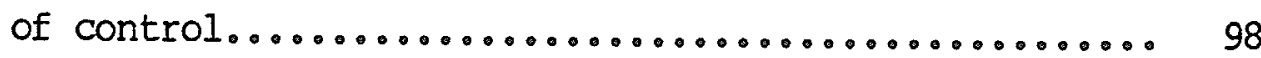

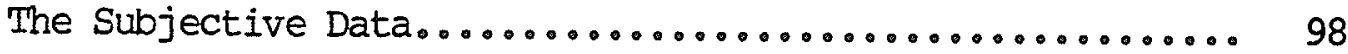

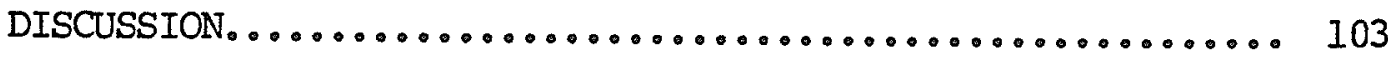

The Victimization Experiences..................... 103

Victimized Women Compared with Nonvictimized Women....... 107

The Role of the Victimization Experiences.............. 109

The Role of Attribution Style................... 111

The Role of Social Support...................... 116

Treatment Implications......................... 120

Limitations of the Present study.................... 123

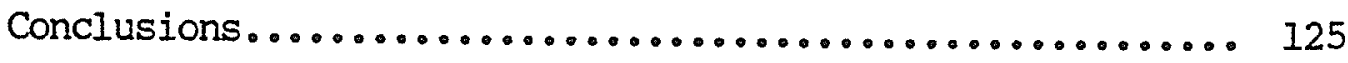

Future Directions............................ 128

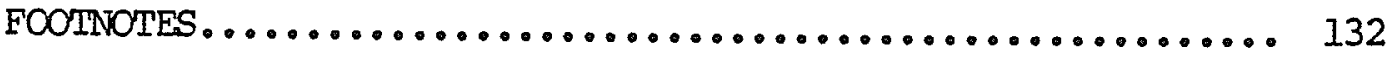

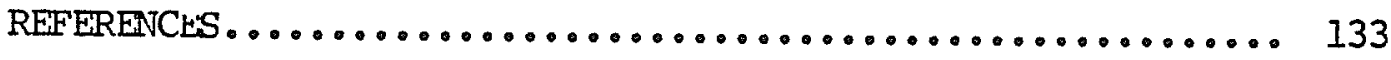

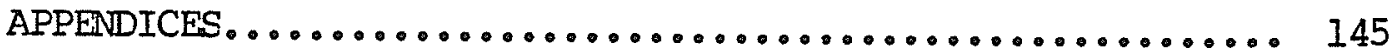




\section{LIST OF FIGURES}

Figure Description Page

1 General Model of Long-Term Response to Sexual

Victimization in Childhood 52 


\section{LIST OF TABLES}

Table

Description

Page

1 Demographic Characteristics of Subjects

2

Age at Victimization

68

3 Relationship to Offender

Sexual Contact Between Victim and Offender

71

5 Victim's Immediate Reaction to the Experience

73

6

Univariate F's from Multivariate Analysis of

Covariance between Victims and Nonvictims

Canonical Correlations Between Attribution Style and Coping Level

8 Canonical Correlations Between Social Support and Coping Level

9 Canonical Correlations Between Attribution Style and Sccial Support

10 Canonical Correlations Between Victimization, Attribution and Social Support and Coping Level

11 Correlations Between Social Support Variables and Coping Level Variables

12 Correlations Between ASQ Scores and Behavioral and Characterological Self-Blame Scores 


\section{IIST OF APPENDICES}

Appendix

Fage

A Advertisement and Description of the Study 145

B Informed Consent Form and Experimental

Questionnaire

C Open-Ended Questions About Sexual Victimization

Experiences

$\mathbb{D}$

Table of Means and Standard Deviations from

Multivariate Analysis of Covariance 


\section{Incidence of Sexual Victimization in Childhood}

Studies conducted during the past 30 years indicate that sexual victimization in childhood is a widespread phenomenon. Research suggests that as many as one of every four girls growing up in North America may be sexually victimized before she reaches adulthood (Finkelhor, 1979; Fritz, Stoll \& Wagner, 1981; Gagnon, 1965; Kinsey, Fomeroy, Martin \& Gebhard, 1953; Landis, 1956). The average age of the child at the time of victimization is about ten years old (Finkelhor, 1979).

It is likely that many of the above studies have underestimated the incidence of sexual victimization in childhood because they employed non-representative samples. For example, Finkelhor (1979), Fritz et al. (1981) and Landis (1956) sampled psychologically healthy, middle class college students. Kinsey et al. (1953) also suggested that they had a non-representative sample which may have decreased the incidence of sexual abuse reported. Therefore, the estimate that $25 \%$ of girls are sexually victimized during childhood or adolescence may be conservative.

\section{Definition of Sexual Victimization in Childhood}

Sexual abuse and victimization are generally defined as sexual contact between a child (12 years old and under) and an older person where there is an age difference of five years or 
more between the two parties and the older person is postpubertal (Berliner, 1982; Finkelhor, 1979; Gagnon, 1965; Kinsey et al., 1953). Some authors (e.g., Finkelhor, 1979) also consider sexual contact between an adolescent (age 13-16) and an adult who is ten or more years older to be sexual victimization. Sexual contact may include intercourse or genital touching and fondling of the. child by the adult or vice versa. The terms sexual abuse and sexual victimization may be differentiated as follows. Any situation in which force is used in sexual contact between the two parties would constitute sexual abuse (Berliner, 1982; Finkelhor, 1979). Sexual victimization more frequently refers to the situation in which a child is victimized by virtue of his/her age, naivete and/or relationship to the older person (Finkelhor, 1979). The present paper employs the definition given above and uses the terms sexual abuse and sexual victimization interchangeably although it is recognized that childhood sexual victimization may or may not involve physical aggression. As will be discussed later, the differential effects of physical versus verbal coercion are not clear. For the purposes of this review, sexual contact between an adolescent and adult at least ten years older will also be considered abuse.

Incest is related to sexual victimization, but is not identical to it. The term incest usually refers to sexual intercourse between family members who would not be permitted to 
marry by law. Finkelhor (1979), however, defines incest as "sexual contact between family members and relatives including those of the immediate and extended family" (po 18). This definition is broader than the other in that it includes any sexual contact and it is congruent with Finkelhor's definition of sexual victimization. There are instances when a relationship is incestuous but would not be considered victimization, as in the case of sexual contact between siblings close in age. Similarly, a relationship between a child and a non-related adult is sexual victimization but not incest. The area of overlap between sexual victimization and incest includes children who are involved in incestuous relationships with an adult. This situation will be included in the present discussion. No differentiation will be made between these incest victims and victims of other forms of childhood sexual abuse unless the literature suggests that differences exist.

While it is acknowledged that sexual victimization occurs to both boys and girls, the present paper focuses on the female victim - male offender dyad as this situation accounts for the majority of victimization occurrences and has been studied more than any other victimization situation. De Francis (1971) found that female victims outnumbered male victims 10 to 1 . In Finkelhor's (1979) study, 2.3 times as many female as male students reported that they had been sexually victimized as chilären and Fritz et al. (1981) reported that almost twice as 
many females as male students reported that they were sexually victimized as children。

\section{Effects of Sexual Victimization in Childhood}

There is evidence to suggest that many girls who are sexually victimized during childhood or adolescence experience psychological problems immediately following the event and/or later in life. Several recent studies have examined samples of girls and women who have received help in psychiatric hospitals or mental health clinics and have found that a large proportion of them were sexually abused as children (Benward \& DensenGerber, 1975; Briere, 1984; Carmen, Rieker \& Mills, 1984; Emslie \& Rosenfeld̄, 1983; Husain \& Chapel, 1983). Briere (1984) found that 67 of 153 (43.8\%) women seeking counseling in a community health centre had a history of sexual abuse in chilöhood, although less than $40 \%$ of these women listed the abuse as the presenting complaint. Carmen et al. (1984) examined the hospital records of 122 female adolescent and adult psychiatric patients and found that $27.9 \%$ had been sexually abused as children or adults. Unfortunately, they do not report how many of the women were victimized during childhood and how many as adults. In their investigation of adolescent and adult women who were receiving treatment for drug abuse in a "psychiatrically-oriented residential therapeutic community treatment modality", Benward 
and Densen-Gerber (1975, p. 325) found that 52 of 118 women sampled (44\%) had been involved in incestuous relationships with age peers or adults when they were children. Emslie and Rosenfeld (1983) reported that $34.6 \%$ of the 26 females admitted to an inpatient child and adolescent psychiatric unit in one six-month period reported that they had been sexually abused. Husain and Chapel (1983) studied 437 girls admitted to a child psychiatric facility and found that $13.9 \%$ had been involved in an incestuous relationship which they defined as overt intercourse only. Therefore, they have omitted cases of sexual abuse if no intercourse occurred or abuse occurred with non-family members. Thus, these studies suggest that $28-45 \%$ of female patients seen in both inpatient settings and mental health clinics may have been victims of childhood sexual abuse.

Female victims exhibit no specific pattern of response to childhood sexual abuse either in the short-term (Maisch, 1972) or long-term (Meiselman, 1978). The absence of a pattern of emotional response and variability in intensity of response has been observed both across and within various life crises (Silver \& Wortman, 1980). Sexual victimization experience may predispose a person to psychopathology or exacerbate pre-existing pathology, but the person's pattern of response appears to be determined by factors of the abusive situation itself and the cerson's history and personality (Maisch, 1972). Most controlled studies indicate that victims do not show different kinds of pathology than do 
control groups (Benward \& Densen-Gerber, 1975; Meiselman, 1978; 1980). However, there are certain classes of symptoms which are commonly observed in victims. The most common features observed among victims of chilahood abuse, both immediately upon discovery and in later life, are depression, accompanied by loss of selfesteem and negative self-image, guilt feelings, and interpersonal difficulties characterized by feelings of isolation and difficulty trusting others (Benward \& Densen-Gerber, 1975; Herman, 1981; Tsai \& Wagner, 1978). Acting out behavior such as suicide attempts, alcohol and/or arug abuse are often reported (Benward \& Densen-Gerber, 1975; Herman, 1981). Sexual dysfunctions (Becker, Skinner, Abel \& Treacy, 1982; Herman, 1981; Meiselman, 1978; Tsai \& Wagner, 1978), promiscuity (Tsai \& Wagner, 1978) and prostitution (James \& Meyerding, 1977) may also be associated with sexual abuse.

Briere (1984) recently suggested that women who were sexually victimized as children and seek counseling as adults, exhibit a different pattern of symptoms than other women seeking psychological help. Briere hypothesized that this pattern of "symptomatic behaviors. . .were originally coping mechanisms or conditioned reactions to a childhood characterized by victimization" (Briere, 1984, p. 12). On the basis of his findings he defined a "Post-Sexual Abuse Syndrome" (PSAS) consisting of a pattern of symptoms which include a history of 
substance addiction, being battered in an adult relationship, suicide attempts, dissociative periods, sleep disturbances, feelings of isolation, anxiety attacks, chronic muscle tension, anger problems, sexual dysfunctions, self-destructive desires, and fears of men and women. Briere suggested that the PSAS pattern resembles the diagnostic criteria for Borderline Personality Disorder as defined by the Diagnositic and Statistical Manual of Mental Disorders, Third Edition (DSM III; American Psychiatric Association [APA], 1980). However, he does not establish what proportion of the subjects in his study exhibitted sufficient symptoms of this disorder to meet the DSM III criteria for the diagnosis of Borderline Personality Disorder. Also, given that the subjects were all seeking treatment it is not clear whether the PSAS pattern is a general phenomenon among victims or is specific to clinical samples of victimized women. Thus, his conclusions must be considered speculative at the present time.

It should be recognized that a large proportion of women who were sexually victimized as children are able to cope adequately ana do not seek counseling. Fritz et al. (1981) sampled 952 college students and found that $7.7 \%$ of the females sampled had been victimized as children. Only $23 \%$ of those women reported that they experienced sexual problems. Gagnon (1965) found that about $25 \%$ of 333 women victimized before age 13 suffered lasting negative effects which ranged from minor to severe. Landis (1956) 
reported that of 360 female students who had sexual experience with an adult during childhood and adolescence, $30 \%$ felt that they had suffered temporary damage and $3 \%$ reported permanent damage due to the experience. Of a sample of 796 students, Finkelhor (1979) reports that $19.2 \%$ were sexually victimized by a much older partner (including by exhibitionists) and $66 \%$ considered the experience to be negative on a self-rating scale of trauma. These three studies suggest that 34 to $75 \%$ of victims may suffer no negative effects of sexual victimization. However, these studies may overestimate the number of victims who are able to cope adequately because studies of college students are particularly biased toward identifying victims who are able to function at a high level and are unlikely to identify persons with very severe pathology who may be institutionalized.

Regardless of the exact number of victims who are coping well, the question of interest is what determines how a person copes with abuse. If, as most data suggest, childhood sexual abuse does not produce a predictable pattern of response or consistent pathology in later life, what are the determinants of victim response? Are there specific factors which determine or predict the long-term effects of victimization? Would they be related to the victimization situation, the victim herself or her environment prior to and/or subsequent to the abuse? For the purposes of the present study, an attempt has been made to 
identify the intervening variables which mediate the long-term psychological effects of childhood sexual abuse for female victims who were involved with male offenders. These variables were examined in an exploratory study of the relationship between childhood sexual victimization experience and adult functioning. Before describing the study, a brief overview of the history of the literature on childhood sexual victimization will be presented and some of the problems with this literature will be discussed.

\section{The Sexual Victimization Literature}

Sexual victimization of children has only recently emerged as an issue of public and scientific concern. Neglect of such a serious social problem may be partially due to the perspective taken by Freud in the late 19th and early 20th centuries. Freud initially brought child sexual victimization to public attention and into the scientific sphere. His early theory attributed adult psychological problems (especially hysteria) to early sexual trauma. However, he later modified his theory and asserted that his patients' reports were based on fantasy not reality (Freud, 1954). Pychoanalytically-oriented therapists therefore discounted the reports of sexual victimization given by their clients and if such a situation could be proven, the child was considered to have been the initiator or a willing participant (e.g., Bender \& Blau, 1937). 
Another factor which may have influenced societal inaifference to sexual victimization of children is the patriarchal nature of society (Herman \& Hirschman, 1977). Patriarchical structure causes the prohibitions against fatherdaughter incest to be weaker than the prohibitions against mother-son incest. Men create and enforce the rules and therefore may break them more frequently. This may account for the preponderance of male offender - female victim dyads. It may also explain the lack of interest in the problem. As men have dominated the culture and are the major perpetrators of sexual victimization, the lack of interest in studying or reducing the situation becomes more understandable.

The Kinsey study of female sexuality (Kinsey et al., 1953) was the first to document that childhood victimization was more widespread than had previously been believed. At that time however, liberal thinkers, professionals and academics were lobbying for sexual reform and feared that bringing attention to this issue would interfere with their efforts (Finkelhor, 1979). Thus the issue of childhood victimization was ignored and its effects were downplayed by researchers (e.g., Gagnon, 1965; Kinsey et al., 1953; Weiner, 1962).

As the sexual revolution has taken hold and the woman's movement has developed, the problem of childhood sexual abuse has now become an issue of public concern. Recently, Masson (1984) 
has questioned the psychoanalytic view that a patient's reports of early seduction is fantasy. He suggests that Freud's retraction of his original theory that psychopathology could be related to sexual trauma in childhood was due to complex personal reasons rather than theoretical or clinical ones. It is Masson's opinion that "Freud had abandoned an important truth: that sexual, physical and emotional violence is a real and tragic part of the lives of many children" (Masson, 1984, p. 59).

Within the past seven years an increasing number of scientific studies of the effects of childhood sexual victimization have been published (e.g.r Finkelhor, 1979; Fritz et al., 1981; Meiselman, 1978; Tsai, Feldman-Summers \& Wagner, 1979). However, many problems still remain in this area of research. They will be discussed below.

The literature on rape has also developed during this same time span, in fact at a faster rate than the sexual victimization literature. This may be a function of the greater reluctance of society to delve into issues related to family functioning. Studies of rape victims may suggest viable methodologies and directions for future research in the area of sexual victimization of children. As Finkelhor (1979) has pointed out, there are many differences between rape and sexual victimization. The offenders who victimize children are more often known to their victims. The offense is usually repeated, often for years. Sexual victimization may involve less physical force than rape 
and more coercion, and the contact may not include sexual intercourse. Other people may be implicated indirectly when a child is sexually abused such as family members, and of course, the victim is a child and may be male. For these reasons the findings of rape studies cannot be automatically generalized to the victims of childhood sexual abuse.

\section{Problems with the Sexual Victimization Literature}

Definition of dependent variables. A major difficulty in assessing the research in this area is a result of the varying definitions and operationalizations of "long-term effects" of victimization. Some researchers try to assess negative effects or trauma on the basis of psychopathology exhibited by the victim (e.g., Gagnon, 1965; Herman, 1981; Maisch, 1972; Meiselman, 1978) but the diagnostic criteria employed and the level of pathology observed are usually vaguely defined. Others consider only specific types of pathology such as sexual dysfunctions (e.g., Becker et al., 1982; Fritz et al., 1981), homosexuality (e.g., Gundlach, 1977; Simari \& Baskin, 1982) or prostitution (e.g•p James \& Meyerding, 1977) in their articles. Assessment of trauma level or pathology is often left to the victim who provides a self-report on some variable le.g., Finkelhor, 1979; Fritz et al., 1981) or is considered to be experiencing negative effects by virtue of the fact that she is seeking therapy (e.g., Tsai et 
al., 1979). Thus there is a serious lack of uniformity in the outcome response being measured and the comparability of many of the studies is in doubt. The validity of some of these measures as indicators of long-term effects or pathology could also be called into question. For example, homosexuality is no longer considered to be pathological according to DSM III (APA, 1980).

Retrospective studies. Of necessity, most research into the effects of sexual victimization in childhood is retrospective. It would be impossible to identify potential victims prior to abuse unless an enormous study was undertaken. At best victims are identified when abuse is reported, but to date no longitudinal study has been undertaken using this population. As the majority of cases are not reported to the authorities (see Finkelhor, 1979; Gagnon, 1965) data from the victims who report abuse would not necessarily be generalizable to all victims.

Retrospective studies are plagued with many problems. There is some, if not total reliance on subjective data which may be purposefully or unknowingly distorted due to memory impairment or discomfort with the subject matter. Also, causality is difficult to establish in this type of research. That is, attribution of effects observed to the victimization experience could never be certain because so many events would have intervened between the time of abuse and assessment and the person's original level of functioning is unknown.

Design and statistical problems. As previously mentioned, 
studies of the long-term effects of childhood sexual abuse tend to focus on two populations, university students (e.g.r Finkelhor, 1979; Fritz et al., 1981) or clinical populations (e.g., Briere, 1984; Herman, 1981; Meiselman, 1978).1 It can be argued that studies involving such samples focus on extreme subgroups of a population and are likely not generalizable to the whole population of victimized women.

Similarly, studies do not always employ adequate control groups. Some studies (e.g., Herman, 1981; Maisch, 1972) are purely observational with no comparison groups at all and therefore their findings are of limited value in delineating the effects or sexual victimization. It was not until appropriate comparisons were made that the lack of response specificity in victims became obvious (Meiselman, 1978). Tsai et al. (1979) reported the only study in which a clinical sample of victims was compared with victims not seeking therapy and with non-victimized women not seeking therapy. This study would be more complete, however, if a fourth group of non-victimized women seeking therapy was included. This would allow a comparison of victims seeking therapy with nonvictims seeking therapy to determine if these two groups differ in any way. Many studies provide demographic intormation but do not employ statistical techniques (e.g., Herman, 1981; Maisch, 1972; Meiselman, 1978). Statistical analyses ot the data using techniques sucn as correlations or multiple regressions would clarify the findings and provide 
evidence of relationships among the variables of interest.

Given the methodological limitations of many studies in this area, conclusions reached by many authors must be considered tentative and much further research is needed.

\section{Intervening Variables}

The variables which may explain long-term victim response to sexual abuse in childhood can be categorized along several dimensions. Many researchers have looked at the situation in which sexual abuse occurs to determine which aspects of it may be related to victim response. However, there is some suggestion that factors outside this situation may be relevant to victim response including pre-abuse and post-abuse factors. It is also useful to categorize intervening variables as situational (i.e., related to the environment or the interaction of the victim and the environment) or intrapersonal (i.e., related to the victim alone). The present paper classifies intervening variables along these two dimensions.

\section{Situational Variables}

\section{Pre-abuse}

Meiselman (1978) studied the long-term effects of incest in 26 psychotherapy clients as compared with 50 control clients and concluded that a family background conducive to incest is almost certain to produce difficulties even if incest never occurs. She 
considers that the effects of incest cannot be isolated from effects of a disturbed family background. From their observations of 15 incest victims in therapy, Herman and Hirschman (1977) also suggest that the observable effects may be related to the degree of family disorganization and deprivation experienced by the child rather than the incest itself. Both Meiselman (1978) and Herman and Hirschman (1979) base their conclusions on clinical observations rather than hard data.

Finkelhor (1979) found that certain family backgrounds were associated with victimization in a college sample. These factors included social isolation, low income, absent, sick or poorly educated mothers, unhappy parental marriages and presence of a stepfather in the home. However, he did not find a relationship between these factors and negative impact of victimization.

\section{The victimization situation}

Victim-offender characteristics. Finkelhor (1979) employed a multiple regression technique to examine the variables which might predict trauma level (perceived negativity of victimization) in his college sample. One of the factors he found that significantly predicted trauma level was the victim-offender age difference. That is, the greater the age difference between victim and offender, the greater the perceived trauma of the abuse.

Researchers studying homosexual populations have found that 
women abused by a family member in childhood are more likely to become homosexual following the abuse than are women victimized by strangers (Gundlach, 1977). Finkelhor (1979) found that father-daughter incest was perceived as the most traumatic type of abuse, but his data do not indicate that a closer relationship with the offender is related to increased trauma. However, these two studies are not comparable due to the very different outcome measures used. Heterosexual incest has also been reported to be more aversive than homosexual incest (both nuclear family and extended family) by homosexual women regardless of whether they were lesbian prior to the assault (Simari \& Baskin, 1982). Finkelhor (1979) also found that experience with a male offender was considered to be more traumatic by both male and female victims, but did not predict trauma level.

Duration of molestation. Tsai and Wagner (1978) observed that the length of the molestation was related to the amount of guilt felt by their psychotherapy clients. This relationship was supported by their subsequent research (Tsai et al., 1979). A significant difference was found in the duration and frequency of molestation and the frequency of attempted intercourse, between victims seeking therapy and those not seeking help, such that the clinical sample had experienced greater duration and frequency of molestation. Becker et al. (1982) have also found that sexually dysfunctional women experienced more penetration during sexual 
abuse than did nondysfunctional women. Finkelhor's (1979) data do not support this relationship. However, it should be noted that since his sample was comprised of students it is more likely to resemble Tsai et al.'s nonclinical victim group and may not be directly comparable to their sample.

Use of force or physical coercion versus use of verbal coercion. The negative effects of the use of force, threats or promises by the offender are unclear. Finkelhor (1979) found that the use of force was the most important factor determining the level of trauma of a sexual victimization experience. This factor, with the age difference between victim and offender, accounted for $34 \%$ of the variance in the trauma experienced. It should be noted that this factor may have been affected by the inclusion of exhibitionist experiences in the data which accounted for $20 \%$ of the female victimization experiences. Experiences with exhibitionists would not involve force and are also less likely to have been traumatic than physical contact experiences. Therefore they may have inflated the regression weights for this variable.

Becker et al. (1982) found that the use of physical as opposed to verbal coercion differentiated sexually nondysfunctional from dysfunctional victims. They felt that guilt was minimal for victims who were physically coerced into participation and that they would experience fewer residual effects. Fritz et al. (1981) found that positive (reward) as 
opposed to negative (threats) coercion was correlated with selfperceived adult sexual maladjustment in college students. These authors also commented that the "guilt induced by succumbing to molestation without physical force is the basic identified factor compounding the trauma associated with molestation such that its effects are felt in adult life" (p. 58).

Other authors (e.g., Burgess \& Holmstrom, 1975; Gagnon, 1965; Herman, 1981; Paulson, 1978; Tsai \& Wagner, 1978) have noted that the effects of victimization may be related to pressures to keep the events secret, coercion or threats made by the perpetrator. Benward and Densen-Gerber (1975) observed that if the victim passively consented to incest she tended to react strongly to it and show residual effects.

Thus the effects of physical versus verbal coercion on the victims remains in dispute. The confusion may be a function of the differing definitions of trauma employed by the authors, the different types of acts considered to be victimization, or it could be accounted for by intrapersonal factors such as the victim's attributions of responsibility for the abuse and/or methods of coping with the situation. The latter possibility will be discussed in later sections of this paper, but clearly more research is needed in this area to clarify the effects of the two kinds of coercion. 


\section{Post-abuse}

Several authors have observed that the symptoms exhibited by victims may be related to the reactions of others after abuse is reported (Burgess \& Holmstrom, 1975; James, 1977; Kaufman, Peck \& Tagiuri, 1954; Maisch, 1972; Meiselman, 1978). However, no data are reported to support these observations and Finkelhor's (1979) data indicate that reporting is not related to trauma level years later.

Tsai et al. (1979) suggest that post-abuse adjustment may be related to social support received from others including the victim's partner. Studies of rape victims have also found that strong social support systems are useful in reducing rape impact (Norris \& Feldman-Summers, 1981), depression (Atkeson, Calhoun, Resnick \& Ellis, 1982) and length of recovery (Burgess \& Holmstrom, 1979).

\section{Intrapersonal Variables}

\section{Pre-abuse}

Meiselman (1978) indicates that of 11 incest victims seen within one year of the termination of abuse, half appeared to have disturbances (e.g., character disorders, neuroses or psychoses) which predated the incest. She further concludes that the specific reaction of the victim probably depends upon her underlying personality structure. In their review of treatments 
of sexual assault, Becker and Abel (1981) also conclude that preexisting pathology was one factor which contributed to impact of the event on children. No data are presented by these authors and no other authors comment on pre-incest intrapersonal factors which may affect outcome. This is an important potential confound in the research which may affect susceptibility to victimization as well as outcome of victimization. However, as previously mentioned, it is extremely difficult to assess these factors in retrospective studies.

\section{The victimization situation}

Age. Some authors suggest that response to sexual abuse in childhood is a function of the child's age or developmental level at the time of the abuse (e.g., Paulson, 1978). Tsai et al. (1979) found that their clinical sample of incest victims was significantly older at the time of the last molestation than was the nonclinical sample and they suggest that the older children blame themselves for the abuse while the younger children feel less responsibility for the event. Finkelhor (1979) also found that earlier abuse experiences were associated with less or equal trauma, but as this factor did not preaict trauma level, he hypothesized that the younger children may have been subjected to less force than the older children and that the force variable was actually determining this finding.

Passive compliance. This factor was discussed in relation to 
verbal coercion. However, it has been reported that some victims experience physical pleasure from sexual abuse and thus feel conflict about whether to end it. These women are thought to experience a great deal of guilt and shame later in life because of their self-perceived complicity (Herman \& Hirschman, 1977; Paulson, 1978; Tsai \& Wagner, 1978). No objective data are presented to support this view.

Victim"s emotional response. Tsai et alo's (1979) clinical sample perceived their emotional response at the time of the abuse to be more negative than the response of the nonclinical sample. These authors suggest that these victims may have experienced more pressure, pain and guilt, which resulted in more stimulus generalization and more long-term effects than the other group. Atkeson et al. (1982) found that the extent of rafe victims' immediate problems and life style changes (such as nightmares, breaking up with a boyfriend, moving, etc.) following the assault were predictive of depression four and twelve months later. No other authors discuss the effects of emotional response at the time of victimization on later adjustment.

\section{Post-abuse}

Herman and Hirschman (1977) implicate the victim's low selfesteem as a factor in her impaired ability to develop friendships with women. In their study of long-term adaptive 
strategies of rape victims over a four to six year period, Burgess and Holmstrom (1979) assess four categories of coping. One category, self-esteem, is "the evaluative component of an individual's self-concept and implies a personal assessment of worth or competence" (p. 1278). They found that positive selfesteem was related to short.recovery time and negative selfesteem was related to long recovery time. Direction of causality was unknown as self-esteem could not be measured prior to the rape and so it could not be established whether prior high level of self-esteem produces good coping or adaptive coping causes high self-esteem.

Burgess and Holmstrom also found that use of defense mechanisms such as explanation, minimization, suppression or dramatization to reduce anxiety produced by rape was associated with shorter recovery time as was increased action (i.e., moving, travel, visiting friends, etc.). Maisch (1972) also suggests that incest victims' attempts at mastery influence the psychological effects of the experience.

Libow and Doty (1979) have reported that their small sample of rape victims tended to attribute responsibility for the rape to themselves eight weeks after the event, but it is not clear whether this was a normal or pathological response. Norris and Feldman-Summers (1981) found that rape victims who were "vulnerable to claims of responsibility" for the assault by virtue of their behavior were less likely to be reclusive (i.e., 
avoid bars) than victims low on this measure.

Thus there is some evidence to support the contention that victims' self-esteem and the coping strategies that they employ are related to their later functioning. However, it should be noted that most of the support comes from the rape literature which focuses on adolescent or adult victims and hence it may not be directly generalizable to discussions of child victims.

\section{Implications of Intervening Variables for Onderstanding the Effects of Sexual Victimization in Childhood}

The available research indicates that there is a great deal of response variability to sexual victimization in childhood. Factors associated with the victimization situation such as the age difference between the victim and offender, possibly their relationship, and the use of force and/or verbal coercion by the offender are determinants of victim response. Reaction of others to disclosure of the event and the social support provided are other situational determinants of victim response. The victim's age at the time of the abuse, her emotional response to it, her self-esteem and the coping strategies that she employs following victimization are thought to be related to her later functioning. It is not clear whether a history of family and/or personal problems may also contribute to later pathology. More research is definitely needed to clarify the aforementioned relationships and 
a theoretical explanation for the findings should be developed to account for some of the research findings.

The following questions remain unanswered. Why would the age difference between victim and offender be important in determining long-term effects? Why do some victims respond more negatively to physical force and others to verbal coercion? How does social support ease the negative effects of abuse? What coping strategies are effective and why? What determines the victim's emotional response to the event?

To date the major focus of research has been on the effect of variables associated with the victimization situation on the victim's later functioning. Many authors have pointed out that examination of the person by situation interaction is a more accurate conceptualization of behavior than observation of either separately (e.g., Bowers, 1973; Miller \& Norman, 1979). Intrapersonal variables, specifically those related to the victim's attributions, self-esteem and coping style may provide a theoretical explanation for victimization effects. Some authors have proposed that the victim's guilt feelings and selfblame might explain the effects of certain intervening variables. For example, verbal coercion, pleasure derived from the victimization experience, emotional response to the abuse, age at victimization, and duration of victimization have all been linked to later pathology through the "mechanism" of guilt or self-blame (e.g., Becker et al., 1982; Tsai et al., 1979). 
An alternative approach would be to more thoroughly examine the victim's tendency to blame herself. A victim may have had a self-blaming response style prior to the abusive situation or may develop such a style in response to victimization.

The following sections review some of the literature on attribution theory and coping. An attempt is made to integrate this area with the sexual victimization literature and to develop hypotheses about the relationship between attributional style and coping in adult women who were sexually victimized as children.

\section{Attribution Theory and Leamed Helplessness Theory}

Attribution theory (e.g., weiner, 1972) and the learned helplessness model of depression (Abramson, Seligman \& Teasdale, 1978) may provide a useful conceptual framework for study of the effects of sexual victimization. "A number of investigators have presented theory and evidence suggesting that people's beliefs about the causes of events in their lives have important, sometimes profound, implications for their psychological wellbeing" (Metalsky \& Abramson, 1981, p. 16). Metalsky and Abramson (1981) describe attribution as a process whereby people draw upon both situational information and generalized beliefs and motivations to deal with ambiguity about the causes of life events. At times beliefs may take precedence over situational information in influencing causal inferences.

Research in the area of attribution theory began with the 
study of achievement motivation by Weiner (1972). He argued that the locus of control (internal or external) and stability (stable or unstable) dimensions were most relevant to perceptions of causality. Internal attributions are attributions of outcomes to oneself and external attributions are attributions of outcomes to environmental factors. Stable attributions are persistent and unchanging, whereas unstable ones are likely to change over time. The stability factor is related to the magnitude of expectancy of future success. Internality relates to self-esteem。Differences in attributions between high and low self-esteem subjects, which support Weiner's theories, have been observed by Ickes and Layton (1978). These authors report three findings: (a) high self-esteem subjects tended to internalize success and externalize failure outcomes, low self-esteem subjects tended to show the reverse pattern; (b) males tended to resemble high self-esteem subjects and females resembled low self-esteem subjects; (c) all subjects chose unstable causes more frequently than stable causes, especially for negative outcomes or those perceived as internally caused.

The learned helplessness model of depression (Abramson, Garber \& Seligman, 1980; Abramson et al., 1978) postulates that a person's causal attributions and expectancies mediate response to uncontrollable situations. The attribution made for noncontingency determines subsequent expectations for future 
noncontingency and the expectation determines the chronicity, generality and intensity of the resulting deficits. Attributions are categorized according to three dimensions, internal-external, stable-unstable and global-specific. Attributions to internal factors, or personal helplessness, are characterized by the beliet that there are responses that would produce the desired outcome, but the individual does not have the response in his/her repertoire (i.e., the events are caused by the person). This attribution results in self-esteem deficits. Attributions to external factors, or universal helplessness, is the situation in which the person believes that the outcome is independent of his/her responses and the responses of others (i.e., the events are caused by the situation). This attribution does not produce self-esteem deficits.

After the person makes attributions about the cause of noncontingency of outcomes and responses, s/he develops expectations about future response-outcome relations which determine the chronicity and generality of the resulting deficits. Attributions to stable factors are expected to produce more performance deficits than would attributions to unstable factors, while attributions to global factors (i.e., across situations) would lead to more generalized deficits than attributions to specific (i.e., situational) factors. Severity of deficits in particular situations is thought to increase with the strength of the expectation of noncontingency. 
The learned helplessness model is limited in that it does not specify the conditions under which particular attributions are made or the properties of the attribution process. The model also concentrates on depressive or helplessness reactions rather than on the full range of emotional reactions and coping styles (Abramson et al., 1978; Silver \& Wortman, 1980).

Many authors have observed the child victim's perceived loss of control (Bailey, 1982), powerlessness (Berliner, 1982; Herman \& Hirschman, 1977) and helplessness to disengage herself from sexual involvement (Benward \& Densen-Gerber, 1975; Herman \& Hirschman, 1977; Maisch, 1972). If childhood sexual abuse is conceptualized as a helplessness experience (i.e., an uncontrollable event), then learned helplessness theory would predict that the victims would develop motivational, cognitive, emotional and self-esteem deficits which, depending upon the victims' attributions, could be relatively enduring. Observed effects of sexual abuse such as depression, guilt, interpersonal problems, low self-esteem and feelings of isolation may result from internal, stable, global attributions made by victims who expect to have no control of their environment.

Helplessness theory suggests that there are individual differences in attributional style which affect susceptibility to pathology. This approach supports the observation that victimization experience may be associated with various levels of 
negative effect (Gagnon, 1965). Identification of victims' attributional styles and their expectations of control may prove useful in explaining some of the aforementioned relationships between mediating variables and effects of victimization.

Research into Attribution Theory and Learned Helplessness Theory Examination of research into attribution theory and learned helplessness theory may help to determine the suitability of applying these concepts to the study of childhood sexual abuse. Given that the learned helplessness model focuses on depressive and helplessness reactions, it is not surprising to find that most of the research which has been conducted in this area has also focused on persons with mild or severe depression. The research may be roughly divided by samples and situations. As will be discussed below, some studies utilize student samples and others employ clinical samples. Researchers have examined attributional styles of subjects on achievement tasks, through responses to attributional questionnaires which focus on hypothetical situations, and in response to real life stresses. Thus few studies which have been reviewed are directly comparable because they vary on one or both of these dimensions.

Several studies of college students have found that depressed students tend to make internal attributions for failure 
or bad outcomes and nondepressed students make external attributions on the same tasks (Garber \& Hollon, 1980; Kuiper, 1978; Rizley, 1978). Rizley (1978) reported that depressed students attributed success to external causes more frequently than did nondepressed students. However, Kuiper (1978) found that both groups made internal attributions for success and he found no difference between groups on the stability dimension. More specifically, a study by Seligman, Abramson, Semmel and von Baeyer (1979) suggested that depressed students made internal, stable, global attributions for bad outcomes on an attributional questionnaire and external, stable attributions for good outcomes. Golin, Sweeney and Shaefter (1981) found that internal attributions for bad outcomes were correlated with depression in students but there was no evidence that these attributions were causally related to depression. This surprising result may have been due to unreliability of the measures, spuriousness of the correlation or due to a reciprocal causal relationship between such attributions and depression. These authors did find evidence to suggest that predisposition to make stable or global attributions for bad outcomes may be a cause of depressive symptoms, but they caution that the methodology that was employed (cross-lagged panel correlation) in no way provides positive proof of causation. It has been pointed out that these studies were all of college students in the laboratory or responding to 
hypothetical situations and thus the results may not be generalizable to other situations (Gong-Guy \& Hammen, 1980).

Student responses to life stresses have provided more equivocal data. Harvey (1981) found differences between the attributions of depressed and nondepressed female students on the internal-external attribution dimension for both positive and negative life events that support the learned helplessness model. However, no differences were found for the stability dimension. Hammen, Krantz \& Cochran (1981) assessed student responses to life stresses and found that mildly depressed students tended to view the stresses as less controllable and more upsetting than did nondepressed students. The depressed students tended to make more global attributions, but did not differ from nondepressed students on attributions of internality or stability. Hammen \& Cochran (198I) found no difference between depressed and nondepressed students' attributions of life stresses. Depressed students tended to find the life stresses more upsetting and uncertain than did nondepressed students.

Two studies of clinical samples have found that the attribution pattern of unipolar depressives differs from that of psychiatric and normal groups on achievement tasks (Abramson, Garber, Edwards \& Seligman, 1978) and from psychiatric and medical patients on an attribution scale (Raps, Peterson, Reinhard, Abramson \& Seligman, 1982). The latter study found that the male depressives tended to attribute bad events to internal, 
stable, global factors. However, Gong-Guy \& Hammen (1980) found no difference between the attributions of control, stability, locus of causality or globality for depressed and nondepressed clients rating stressful life events. When the most upsetting events were rated, the depressed clients made more internal, intended attributions, that is, they considered events to be intentionally caused by their personal qualities. Lewinsohn, Steinmetz, Larson \& Franklin (1981) found no differences on attributional measures between depressed and nondepressed people in a community-oriented longitudinal study. Depressives did have higher expectancies for negative events, lower expectancies for positive events, tended to have irrational beliefs and had low self-esteem.

Thus the evidence relating attributional theory and learned helplessness theory, specifically regarding depressed persons, is weak. Depressed people tend to make more internal attributions for failure than do nondepressed people, for most samples and situations studied (see Coyne \& Gotlib, 1983). However, studies of real life stresses tend not to provide much support for this finding. The remaining predictions of the learned helplessness model, regarding the stability and globality dimensions, have received little support.

It has been suggested that rather than postulating a helpless, depressive attributional style, patterns of 
attributions may vary as a function of the population sampled or events studied (Gong-Guy \& Hammen, 1980). Coyne and Gotlib (1983) offer several possible explanations of the data. First they raise the possiblity that there are two types of depression, one characterized by helplessness, another by guilt, that result in different attributional styles. Thus the data from one group may wash out the data from the other. If this is occurring, experimenters could readily identify the problem by examining their raw data. However, Abramson and Sackeim (1977) have stated that existing data do not support this position. Another possible problem identified by these authors and others (e.g., Raps et al., 1982) is the use of unreliable measures of attributions.

The implications of this research for the study of childhood sexual abuse are as follows. First, given the weak support of the learned helplessness model in the area of depression, specifically response to real life stresses, it may not be appropriate to apply this model in its entirety to response to childhood sexual abuse. However, the internal-external dimension does seem to differentiate depressed and nondepressed individuals, and therefore may prove to be an important mediating factor for victims as well, considering that depression is common among victims. That is, victims who are coping well may make external attributions for stressful life events whereas victims who are coping poorly may make internal attributions and have low self-esteem. Also, victims in general may tend to make internal 
attributions for bad events more than do nonvictims. The victim's attributional style may be related to her response to other factors of the abusive situation such as the age difference, the use of force, reactions of others and may explain her own emotional reaction and the coping strategies which she employs.

\section{Controllability and Self-Blame}

Abramson et al. (1980) indicate that there are several other attributional dimensions which may be relevant to helplessness besides the three main ones. These dimensions may therefore also be useful in the study of childhood sexual abuse. One such dimension is controllability-uncontrollability. Abramson et al. (1980) suggest that attributions of failure to controllable factors may be related to self-blame, self-criticism and guilt. Harvey's (1981) study partially supports this contention. He found that depressed female students assumed more responsibility and attributed negative events to controllable causes more frequently than did nondepressed students.

Wortman (1976) notes that many studies have found that people often exaggerate their control over "uncontrollable" life events. They seem uncomfortable with the idea that such outcomes may be due to chance. She reports that many apparently innocent victims appear to feel guilty, but little is known about what conditions elicit self-blame. Some authors have suggested that 
self-blame may be an adaptive response to rape (e.g., Libow \& Doty, Iy7y; Medea \& Thompson, 1974) and physical disability (e.g., Bulman \& Wortman, 1977). Medea and Thompson (1974) describe the rape victim's adaptation as follows:

What appears to be guilt... may be tne way the woman's mind interprets a positive impulse, a need to be in control of her life. If the woman can believe that somehow she got herself into the situation, if she can make herself responsible for it, then she's established a sort of control over the rape. It wasn't someone arbitrarily smashing into her life and wreaking havoc. The unpredictability of the latter situation can be too much for some women to face. If it happened entirely without provocation, then it could happen again. This is too horrifying to believe, so the victim creates an illusion of safety by declaring herself responsible for the incident (p. 105-106).

Similarly, Bulman and Wortman (1977) found that good coping with spinal cord injury (paraplegia and quadriplegia) was associated with self-blame and perceived unavoidability of the activity in which they were engaged at tne time of injury, whereas poor coping was associated with blame of others and perceived avoidability of the activity. They interpret this to mean that good copers perceived themselves as in control of their actions at the time of injury and poor copers did not. Further, 
and perhaps more important, good copers impose order and meaning onto their world. Control through avoidance of reccurrence is not a crucial issue in this particular situation, but ascribing meaning to the situation is important.

Janoff-Bulman (1979) has postulated that there are two types of self-blame, one adaptive and one maladaptive. The two forms of self-blame differ in the focus of blame. The "adaptive, controloriented" form focuses on the person's behavior and is therefore called "behavioral" self-blame. The "maladaptive, selfdeprecating response" focuses on the person's character and is labelled "characterological" self-blame. These two responses may be described as distinct on the basis of the perceived controllability dimension. In the behavioral self-blame situation the person peceives that the outcome is controllable, but when characterological self-blame is employed, the outcome appears to be uncontrollable. The distinction between the two forms of selfblame also parallels the attributional dimensions discussed by Weiner (1972) and Abramson et al. (1978). Behavioral self-blame corresponds to internal, unstable attributions and characterological self-blame to internal, stable attributions. Similarly, the two differ on the global-specific dimension dimension discussed by Abramson et al. (1978). However, JanoffBulman (1979) considers the significant dimension differentiating the two forms of self-blame to be perceived controllability and 
postulates that the importance of the other dimensions is their contribution to the controllability dimension. Contrary to Abramson et al. (1978), Janoff-Bulman asserts that characterological self-blame results from attributions to uncontrollable, not controllable factors. She found support for this claim in a study that indicated that characterological self-. blame was related to attributions to uncontrollable factors (Janoff-Bulman, 1979). Persons employing this strategy had an external locus of control and low self-esteem.

Behavioral and characterological self-blame are further differentiated on the basis of time orientation. The person employing behavioral self-blame is concerned with avoiding the negative outcome in the future. The person employing characterological self blame is concerned with his/her "deservingness for past outcomes" (Janoff-Bulman, 1979, p. 1800).

Perceived controllability is based on the locus of control construct described by Rotter (1966). Belief in external control is the situation in which a person perceives that reinforcement follows his/her actions, but is not entirely contingent upon those actions. That is, events are determined by luck, fate or others. When events are perceived as contingent on the person's behavior or personality characteristics, the person is considered to believe in internal control. Women appear to be more external than men in late adolescence, but a drop in the female externality score seemed to have reversed this 
relationship in a group ten years older (Feather, 1967).

Generally, internal locus of control is associated with good adjustment and external locus of control with poor adjustment (e.g., Janoff-Bulman, 1979; Joe, 1971). Externals, in contrast to internals, appear to be more anxious, aggressive, dogmatic, less trustful and more suspicious of others, lack self-confidence and insight, and have low needs for social approval (Feather, 1967; Joe, 1971). It is not known "whether the belief in external control produces anxiety or whether anxiety produces a belief in external control" (Joe, 1971, p. 626). Internals tend to make more efforts to control their environments and impulses than do externals. Internals also seem to seek information and behave in a manner which facilitates personal control over their environments. However, as some authors have pointed out (e.g.r Joe, 1971; Lefcourt, 1980; Rotter, 1966), the relationship between locus of control and adjustment may be nonlinear. Individuals at the extreme ends of the continuum might be more maladjusted than individuals in the middle. There may also be interactions between internal control and other factors such as success experiences.

For individuals who are favored with success experiences, internal control expectancies could result in a sense of pride, positive affects and assertive, striving behavior. However, for individuals who are more likely to experience 
setbacks and failure, an internal locus of control could result in depression, self-denigration and a surrender of ambition (Lefcourt, 1980, p. 249).

Zuroff (1980) notes that perceived locus of control and attributions are conceptually and operationally distinct. Internal and external attributions refer to causes that are physically within or outside the person. Internal and external locus of control refer to skill-controlled and non-skillcontrolled (chance or other-controlled) causes. Therefore, one can believe in external control and yet make an internal attribution in a particular situation, or vice versa. For example, a woman may not believe that avoiding rape depends on skill (i.e., external locus of control), but in this particular instance may feel that she provoked the attack (i.e., internal attribution). Also, attributions and locus of control differ in that locus of control is generally assessed prior to an event, whereas attributions are assessed after the event.

Controllabibility, self-blame and locus of control may be relevant to the study of victims of sexual abuse since selfblame and guilt are frequently noted characteristics of rape. victims (e.g., Benward \& Densen-Gerber, 1975; Herman, 1981; Tsai \& Wagner, 1978). However, it is not clear whether such a response is adaptive or maladaptive. Perhaps, as suggested by Janoff-Bulman (1979) and Medea and Thompson (1974), the rape victim attempts to regain control of her life by blaming herself 
for the rape (i.e., using a behavioral self-blame strategy) and has an internal locus of control. On the other hand, the woman with a maladaptive approach to victimization may utilize the characterological self-blame strategy, see herself as a chronic victim, and have an external locus of control. People who work closely with victims of childhood sexual abuse often note that the women seem to take on a victim role and suffer from other kinds of abuse (e.g., Herman, 1981).

\section{Research into Controllability and Self-Blame}

A review of the research into controllability and self-blame may provide information which will help clinicians predict which victims of childhood sexual abuse will cope adaptively and maladaptively. Studies of students have suggested that depressed students tend to employ more characterological self-blame than do nondepressed students (Janoff-Bulman, 1979; Peterson, Schwartz \& Seligman, 1981). Peterson et al. (1981) found that for female students characterological attributions for bad outcomes were associated with helplessness and guilt, with more stable, global, uncontrollable attributions and with more bad life events during the past year than were behavioral attributions. Gong-Guy and Hammen (1980) found that the attributions of depressed and nondepressed clients differed for the most upsetting life events. The depressed clients appeared to employ characterological self- 
blame when they considered bad events to be intentionally caused by their personal qualities.

Characterological attributions for bad events have not been found to be predictive of depressive symptoms six to twelve weeks later (Peterson et al., 1981), therefore they may be a concomitant but not a cause of depression. This position is supported by Lewinsohn et al.'s (1981) study which suggested that depression-related cognitions may be consequences of depression which are reversed once depression lifts. These authors found no evidence that depressive cognitions are antecedents of depression or are permanent residuals of a depressive episode.

Research with rape victims and rape crisis workers suggests that rape victims tend to employ behavioral self-blame strategies (Janoff-Bulman, 1979; Libow \& Doty, 1979). It is not clear whether this pattern was associated with good or poor coping since neither author investigated the relationship between selfblame and coping. Frieze (1979) reports data which suggests that initially battered women blame themselves for the battering and tend to make unstable attributions. That is, they use a behavioral self-blame strategy. The best predictors of "severe levels of violence were being unfamiliar with other women who had been battered, seeing the cause of one's own violence as stable factors within oneself, and believing that wife-battering was a relatively frequent occurrence" (p. 102). Thus, lack of social supports, characterological self-blame and acceptance of violence 
as normal are related to severe battering. Frieze further found evidence that battered women attempt to gain control over their situation.

The research into self-blame, internal-external attributions and controllability suggests that depressed individuals tend to employ more characterological self-blame than do nondepressed individuals, victims of rape tend to employ behavioral selfblame, and victims of battering may employ behavioral self-blame in less severe situations and characterological self-blame when battering is more severe. These data suggest that attempts to cope with and control the stress may be associated with behavioral self-blame strategies, that is, internal, unstable, controllable attributions, whereas poor adjustment, helplessness, and/or depression may be associated with characterological selfblame, that is, internal, stable, uncontrollable attributions. Admittedly, these conclusions must be considered tentative as they are based on a small number of studies. However, they raise some interesting questions for research with victims of childhood sexual abuse. For example, can victims be differentiated on the basis of the type of self-blame that they employ? Is one pattern of self-blame adaptive, and the other maladaptive? To date there has been no research conducted exploring attributional styles of victims of childhood sexual abuse. However some predictions might be made. For example, good coping may be associated with 
behavioral self-blame, that is, internal, unstable attributions and perceived control and poor coping may be associated with characterological self-blame, that is, internal, stable attributions and perceived lack of control.

\section{Factors Related to Coping Efficacy}

What exactly defines good coping and what determines whether a person is able to cope effectively with a life crisis? Pearlin and Schooler (1978) define coping efficacy as "the extent to which a coping response attenuated the relationship between the Iife-strains people experience and the emotional stress they feel" (p. 8). Richard Lazarus (e.g., Lazarus \& Launier, 1978) has developed a model of coping with stress which focuses on the person-environment transaction as discussed by Pearlin and Schooler. This approach takes into account individual responses to the same situation, such as the fact that what one person views as a threat another sees as a challenge and a third considers irrelevant. It also considers the variation in experiences at different points in a person's life which are unrelated to personality factors. A central component of Lazarus' model is the ongoing process of cognitive appraisal of the situation. The perceived threat or benefit (primary appraisal) and perceived ability to cope (secondary appraisal) are thought to determine whether or not stress arousal will occur in a particular situation. Stress is defined as "any event in which 
environmental or internal demands (or both) tax or exceed the adaptive resources of an individual, social system, or tissue system" (Lazarus \& Launier, 1978, p. 296). Stress arousal is thus dependent upon the balance between the appraised threat and the individual's ability to cope with it.

Lazarus and Launier (1978) note the distinction between threat and challenge. They suggest that these different appraisals may depend upon the configuration of environmental events and the individual's beliefs about their potential for mastery. Implicit in their discussion of this issue is the assumption that appraisal of challenge is more adaptive than appraisal of threat.

A second crucial component of the Lazarus model is coping. Lazarus and Launier (1978) point out that "the ways people cope with stress are even more important to overall morale, social functioning, and health/illness than the frequency and severity of episodes of stress themselves" (p. 308). They define coping as "efforts, both action-oriented and intrapsychic, to manage (i.t, master, tolerate, reduce, minimize) environmental and internal demands, and conflicts among them, which tax or exceed a person's resources" (p. 311).

Evidence suggests that many people do not cope effectively with a serious 1 ife crisis and do not accept or recover from it (Silver \& Wortman, 1980). For example, Burgess and Holmstrom 
(1978) found that $26 \%$ of rape victims in their sample did not feel that they had recovered four to six years after the assault. Even when people appear to have recovered, problems may develop later. Some rape victims show silent rape reactions and their unresolved feelings may surface years later (Burgess \& Holmstrom, 1974). Notman and Nadelson (1976) feel that anxiety and depression can reemerge years after a rape precipitated by some apparently unrelated events.

After reviewing the literature on coping with life crises, Silver and Wortman (1980) suggest four conceptual variables that may help us understand "people's responses to stressful outcomes and increase our ability to predict the nature, sequence, duration and intensity of their reactions" (p. 309). These are: (a) perceived social support; (b) opportunity for ventilation or free expression of feelings; (c) ability to find meaning in the crisis; and (d) experience with other stressors. Pearlin and Schooler (1978) discuss three dimensions of coping in their study of responses to everyday strains (i.e., stressors). These are the person's: (a) social resources which are represented in their interpersonal networks and are a potential source of support; (b) psychological resources; and (c) specific coping responses. Psychological resources represent the personality characteristics which a person employs to help withstand threats or stressors from his/her environment. They include such resources as selfesteem, self-denigration and mastery (i.e., sense of control), 
some of which were discussed in the previous sections of this paper. Specific coping responses are defined as the behaviors, cognitions and perceptions in which people engage when dealing with life problems. These responses may be divided into three categories: (a) responses that modify the situation causing the strain; (b) responses that change the meaning of the stressor after it occurs but before stress develops; and (c) responses that control the stress after it occurs.

Both Silver and wortman (1980) and Pearlin and Schooler (1978) identify social support as one of the most important variables related to coping with stress. "Social support is usually defined as the existence or availability of people on whom we can rely, people who let us know that they care about, value, and love us" (Sarason, Levine, Basham \& Sarason, 1983). Social support may provide a climate in which self-identity changes can occur more easily (Cobb, 1979), may increase selfconfidence and adaptability and act as a buffer against stress (Sarason et al.p 1983).

Gottlieb (1983) has outlined three sets of variables which may be employed to distinguish between social networks which provide adequate levels of social support and those which are deficient. These variables are: "(a) the structural properties of the network as a whole; (b) the norms members subscribe to regarding their rights to receive, and their obligations to 
extend help to others on certain occasions; and (c) qualitative aspects of the relationships that the focal individual maintains with network members" (p. 281). Large numbers of social supports and high levels of satisfaction with social supports have been found to be related to optimism, high self-esteem, internal locus of control, and fewer psychological problems (i.e.; anxiety, depression and hostility). Low levels of social support and low levels of satisfaction with social supports have been related to pessimism, material concerns, external locus of control, unhappiness, introversion, unpleasant memories of early parentchild relationships, dissatisfaction with life and difficulty persisting with difficult tasks (Sarason et al., 1983). Some authors (e.g., Cobb, 1979; Silver \& Wortman, 1980) have also observed that social support can have negative effects such as interfering with development of coping skills. The mechanism by which social support functions as a buffer against stress and how it influences subsequent coping is unknown (Gottlieb, 1983; Sarason et al., 1983).

Silver and Wortman (1980) also suggested that ability to find meaning in a crisis may be a factor in a person's response to stress. In an investigation of incest victims' search for meaning in the experience, Silver, Boon and Stones (1983) reported that women who found some meaning in the experience coped more effectively than those women who had not found meaning in the experience, although both groups of women still appeared 
to cope significantly more poorly than population norms. Specifically, women who found meaning in the victimization experience reported less psychological distress, better social adjustment, higher self-esteem and better resolution of the experience. The authors suggest that having an opportunity to ventilate one's feelings about the victimization to a conficant was related to finding meaning in the experience. Apparently, the critical factor was making sense of the experience regardless of the specific answer that was found.

There is much evidence to suggest that different people respond differently to exactly the same stressor (e.g., silver \& Wortman, 1980), for example, sexual victimization. This variability across people may reflect different coping processes or levels of coping efficacy which are affected by aspects of the person's environment (e.g., social support, opportunity for ventilation), their personality characteristics (e.g., ability to find meaning in the situation, self-esteem, self-denigration, sense of control), their behavior (e.g.r appraisals, cognitions, attributions) and the interactions anong these factors.

The variability of response to childhood sexual abuse noted by several authors (e.g., Maisch, 1972; Meiselman, 1978) may reflect these differences in coping processes and efficacy. Elucidation of the social resources, personality characteristics and behaviors which are associated with good and poor coping in 
childhood sexual abuse victims would provide much insight into the coping of victims and would suggest some methods of ameliorating the functioning of poor copers. On the basis of the research previously presented (i.e., Cobb, 1979; Pearlin \& Schooler, 1978; Sarason et al., 1983; Silver \& Wortman, 1980; Silver et al., 1983), one might make the following predictions: (a) high levels of social support and opportunity to express feelings would be associated with high self-esteem, internal locus of control and good coping, whereas low social support would be associated with external locus of control and poor coping; (b) ability to find meaning in the situation would be associated with high self-esteem and good coping; (c) appraisal of challenge would be associated with better coping than appraisal of threat.

\section{The Present Research}

The present study was designed to explore the relationship between childhood sexual victimization experience and adult coping. Factors of the victim's personality, social environment and the victimization situation were explored as possible mediating variables. Coping was assessed through measures of psychological distress, depression, sexual functioning, selfesteem and antisocial behavior. Personality factors investigated included attribution style for good and bad events, self-blame, locus of control and response to victimization. Aspects of the 
social environment studied were size of social network, qualitative aspects of the social network (helpfulness and reciprocity), opportunity for ventilation through therapy, and relationship with parents. The differences between the personality, social environment and coping efficacy of victimized and nonvictimized women were also explored. Through the use of an extended questionnaire and assessment battery, adult women who were sexually victimized as children provided information about their past experiences and their present functioning. Adult women who were not victimized completed the same questionnaire and served as controls.

Figure 1 presents a model of the hypothesized relationships between the variables. The victimization situation was seen as a stressor which might directly affect adult coping. It was hypothesized that the effects of the victimization on coping might be moderated by the person's personality style and/or her social environment. The possibilty that there might be some reciprocal relationships between the person's personality style and her social environment was also considered.

Insert Figure I About Here

The data were employed to test the following hypotheses:

1. Victims would be coping more poorly than nonvictims, particularly they would have more psychological symptoms, lower 
Figure 1

General Model of Long-Term Response to Sesual Victimization in Childhood

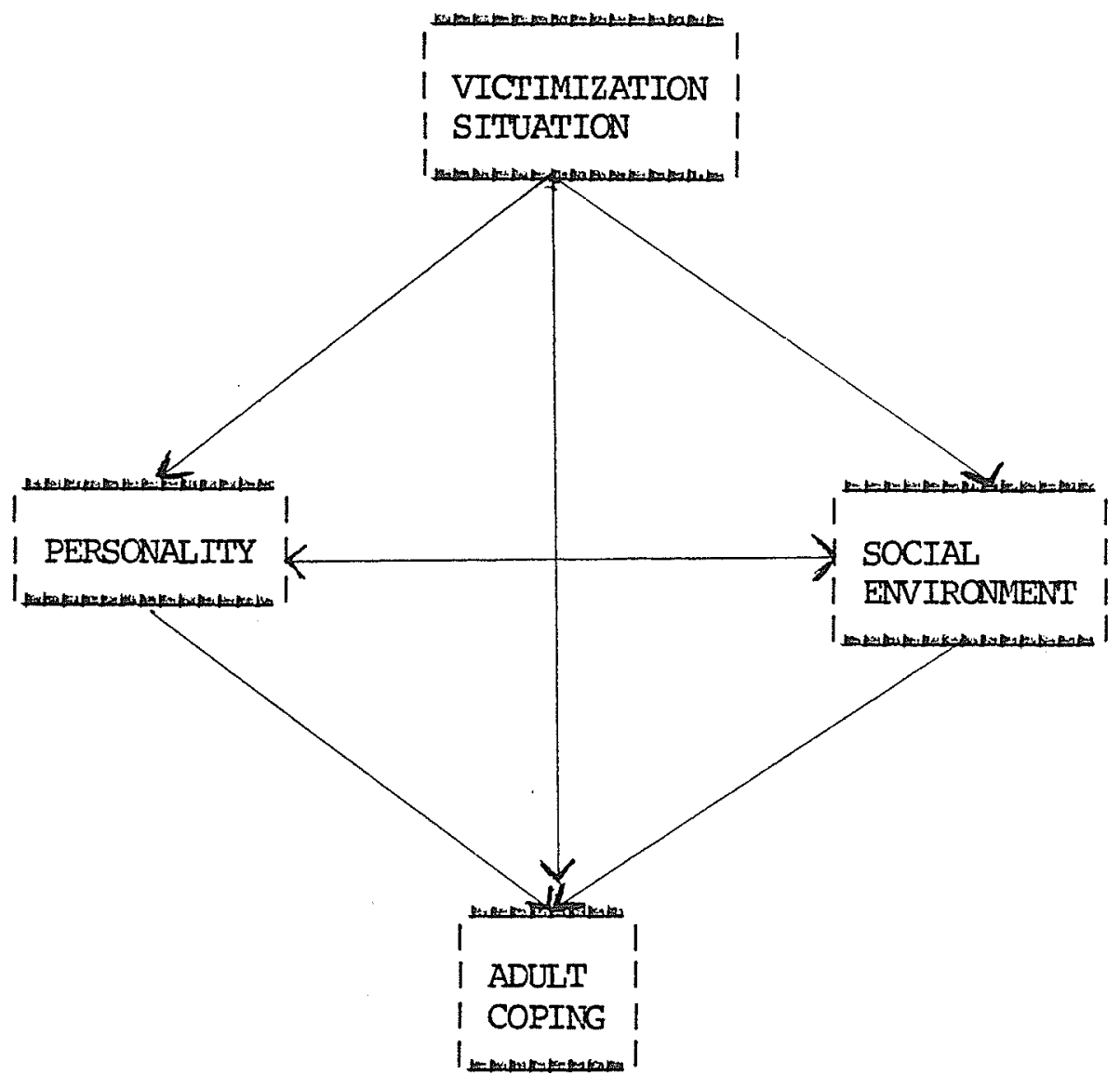


self-esteem and more sexual problems than the non-victims. Victims would have different attribution styles than nonvictims and would make internal attributions for bad events more frequently than nonvictims.

2. Poor coping among victims would be associated with several aspects of the victimization situation: (a) a greater age difference between the participants; (b) the victim knowing the assailant and having a close relationship with him; (c) use of force or coercion by the offender during victimization; and (d) older age of the victim at the time of the abuse.

3. External attributions for bad events would be related to good coping and internal attributions for bad events and low self-esteem would be related to poor coping. Behavioral selfblame would be associated with better coping than characterological self-blame. Good coping would be associated with internal locus of control and poor coping with external locus of control. Ascription of meaning to the victimization experience, appraisal of challenge rather than threat in that situation and attribution of blame for the event to other people, would be related to good coping.

4. There would be a positive relationship between the amount of social support and therapy received in the past and at present and present coping, particularly self-esteem level, for both groups.

5. Attributional style would mediate the relationship 
between characteristics of the victimization situation and coping adequacy. That is, factors of the person's attributional style would account for any observed relationship between characteristics of the victimization situation and adult coping.

6. High levels of social support would be related to internal locus of control and low social support would be associated with external locus of control, for all subjects.

7. Behavioral self-blame would be associated with internal, unstable attributions for bad events, and characterological selfblame would be associated with internal, stable attributions for bad events, for all subjects. 


\section{Method}

\section{Design}

The present study employed a passive observational design (Cook \& Campbel1, 1979). That is, an attempt was made to infer causal processes from observations of concomitancies in natural settings. No manipulations were undertaken. Aspects of the victimization experience were employed as if they were independent variables but were not manipulated. Dependent variables were aspects of social support and personality and the coping measures. As described below, subjects were volunteers who responded to advertisements in newspapers and to other forms of publicity. It is recognized that a large segment of the population of victimized and nonvictimized women chose not to participate in the study or were not reached by the publicity. Therefore, subject selection was nonrandom and the study must be considered to be quasi-experimental.

For the purposes of the study sexual victimization was defined as: (a) sexual contact (i.e., physical.touch) between a child (12 years old and under) and a postpubertal person at least five years older than the child; (b) sexual contact between an adolescent (age 13 to 16) and an adult at least ten years older; or (c) sexual contact between any child or adolescent under 16 years old and another person or persons which involved use of physical force by the perpetrator (see Berliner, 1982; Finkelhor, 1979). 
subjects

Two groups of subjects were employed in the present study. One hundred and three women who had been sexually victimized as children, as defined above, were drawn from the populations of sexually victimized women in London, Ontario $(n=83)$ and Winnipeg, Manitoba $(n=20)$. The women ranged in age from 18 to 56 years old with a mean age of 30.4 years. Eighty-eight women who had not been sexually victimized as children were drawn from the populations of nonvictimized women in London, Ontario $(n=81)$ and Winnipeg, Manitoba ( $n=7)$. These women ranged in age from 18 to 57 years old with a mean age of 29.8 years. The marital status, education levels and personal incomes of the two groups of women are shown in Table 1.

10.

Insert Table 1 About Here

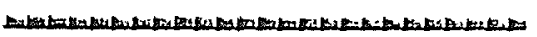

The participants were solicited for participation using the following methods:

1. Advertisements were placed in local and campus newspapers specifying the need for research participants, the nature of the research and the type of persons required to participate (see Appendix A). Advertisements were also placed on local Cable Television networks. Sixty-eight of the victimized women (66\%) and $62(70.48)$ of the nonvictimized women were recruited in this manner. 
Table 1

Demographic Characteristics of Subjects

\begin{tabular}{|c|c|c|c|c|}
\hline \multicolumn{3}{|c|}{ Victims ${ }^{\mathrm{a}}$} & \multicolumn{2}{|c|}{ Nonvictims ${ }^{b}$} \\
\hline Variables & Frequency & Percent & Frequency & Percent \\
\hline \multicolumn{5}{|c|}{ 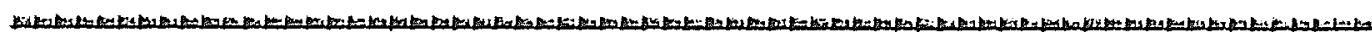 } \\
\hline \multicolumn{5}{|l|}{ Marital Status } \\
\hline Single & 45 & 43.7 & 38 & 43.2 \\
\hline Married & 31 & 30.1 & 26 & 29.5 \\
\hline Separated/divorced & 26 & 25.2 & 22 & 25.0 \\
\hline Widowed & 1 & 1.0 & 2 & 2.3 \\
\hline
\end{tabular}

Education Level

\begin{tabular}{|c|c|c|c|c|}
\hline Grade School & 2 & 1.9 & 1 & 1.1 \\
\hline Some High School & 10 & 9.7 & 2 & 2.3 \\
\hline Completed High School & 9 & 8.7 & $I$ & 1.1 \\
\hline $\begin{array}{l}\text { High School and } \\
\text { Other Training }\end{array}$ & 11 & 10.7 & 11 & 12.5 \\
\hline Some College & 34 & 33.0 & 36 & 40.9 \\
\hline Completed College & 21 & 20.4 & 12 & 13.6 \\
\hline Some Graduate School & 4 & 3.9 & 2 & 2.3 \\
\hline $\begin{array}{l}\text { Graduate or } \\
\text { Professional Degree }\end{array}$ & 11 & 10.7 & 23 & 26.1 \\
\hline Missing Data & 1 & 1.0 & 0 & 0.0 \\
\hline
\end{tabular}

(table continues) 
Table 1 continued

\begin{tabular}{|c|c|c|c|c|}
\hline & Victim & (2) & 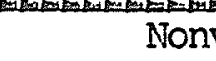 & $\operatorname{tims}^{\circ}$ \\
\hline $\begin{array}{l}\text { Variables } \\
\text { Vables }\end{array}$ & Frequency & Percent & Frequency & Percent \\
\hline Income Level & & & & \\
\hline Not Employed & 23 & 22.3 & 21 & 23.9 \\
\hline under $\$ 10,000$ & 38 & 36.9 & 25 & 28.4 \\
\hline$\$ 10,000-\$ 20,000$ & 24 & 23.3 & 22 & 25.0 \\
\hline$\$ 20,000-\$ 30,000$ & 12 & 11.7 & 15 & 17.0 \\
\hline$\$ 30,000-\$ 40,000$ & 4 & 3.9 & 2 & 2.3 \\
\hline Missing Data & 2 & 2.0 & 3 & 3.4 \\
\hline
\end{tabular}


2. Notices regarding the need for research participants were placed in various locations in London, Ontario and Winnipeg, Manitoba. These locations included hospitals, mental health clinics, the Universities and Community Colleges, battered womens' shelters, womens' counselling centres, the Y.W.C.A. p the libraries in London, and other locations where women would be likely to see them. Eighteen (17.5\%) victimized women and eight (9.18) nonvictims were recruited through these notices.

3. Clinicians and agencies who were known to be working with clients who were sexually victimized as children were contacted by telephone and/or letter by tue researcher or a research assistant and were asked to approach their clients to determine whether they would be willing to participate in this research. A written description of the study was provided for the clinician or agency to give to the client (see Appendix A). Clients who were willing to participate in the study then contacted the researcher or research assistant. Nine $(8.7 \%)$ of the victimized women and three $(3.4 \%)$ of the nonvictimized women participated in the study after hearing about it from a clinician.

4. Scudents in several introductory psychology classes at the University of Western Ontario and the University of Manitoba were invited to participate in the study and were given research credit for their participation. Eight (7.8\%) victimized women and fifteen ( $17 \%$ ) nonvictimized women were recruited from these classes. 


\section{Procedure}

Prospective subjects contacted the researcher or research assistant by telephone and an appointment was scheduled. A brief description of the study was provided to all subjects during this initial contact (see Appendix A). Subjects were introduced to the research in greater detail when they met individually with the experimenter. They were advised that they could terminate their participation at any time and assured of the confidentiality of their responses. Informed consent was obtained (see Appendix B). Each respondent was assigned a number which was used in lieu of their name on all experimental materials. Only the experimenter had access to the list of names of the participants.

Participation in the research included completion of the experimental questionnaire by all subjects. The victimized women, identified on the basis of their responses to the questionnaire, were also asked a series of open-ended questions about their experiences to provide more information about the victimization experience and their responses to them (see Appendix C). The purpose of the study was described in greater detail after the tasks were completed and subjects had an opportunity to ask questions and discuss their responses to the study.

Feedback was provided to interested subjects, the participating agencies and clinicians after completion of the study. 


\section{Measures}

Demographic information about the subject's family background, personal history, and about any victimization experiences was collected using a modified version of the questionnaire developed by Finkelhor (1979) for his study of 796 university students. The questionnaire consists of 113 questions which collect demographic information, information about family life during childhood, childhood sexual experiences, violence in the home and present sexual activities. Items have been changed, added or deleted to make the questionnaire applicable to a broader sample of women than the university sample employed in Finkelhor's research. Specifically, items related to marital history and sexual functioning, acting out behavior, therapeutic involvement, and attribution of responsibility for victimization have been added to the questionnaire. Some of the items which collect details of family background and relationships were deleted as they were not relevant to the present study (see Appendix B).

The following measures were included in the experimental questionnaire to assess the subject's present level of functioning:

1. The Beck Inventory (BDI; Beck, 1978), a clinicallyderived 21 item self-report scale, was used to assess depression level. Split-half reliability is .86 and concurrent validity of the scale is .66 to .82 (Beck, 1972; 1974). Beck (1972) reports 
that trere is "reasonable evidence that the inventory reflects to an acceptable degree that ill-defined construct, depression" (p. $300)$.

2. To assess self-esteem or social competence, the Texas Social Behavior Inventory - Short Form (TSBI; Helmreich \& Stapp, 1974) was employed. This measure has been found to be unrelated to intelligence, but is related to social desirability for females, to achievement and to masculinity-femininity measures.

3. Sexual functioning was assessed using questionnaire items which were selected from the Index of Sexual Satisfaction (Hudson, Harrison \& Crosscup, 1981), and from the Sexual History Form (Schover, Friedman, Weiler, Heiman \& LoPiccolo, 1982). Reliability of the full Index of Sexual Satisfaction is .92 and the test-retest reliability is .93 . No rellability information is provided by the authors of the Sexual History Form.

4. The Hopkins Symptom Checklist (HSCL; Derogatis, Lipman, Rickels, Uhlenhuth \& Covi, 1974) provided a self-report of number and intensity of symptoms experienced. The HSCL measures five dimensions of symptoms: somatization, obsessive-compulsive, interpersonal sensitivity, depression and anxiety, through ratings on a four-point scale. Internal consistency for each dimension ranges trom .84 to .87 and test-retest reliabilities range from .75 to .84 over a one-week period.

The measures listed below were employed to assess 
attribution style.

1. Self-blame was assessed using the scenarios employed by Janoff-Bulman (1979). Subjects are asked to imagine themselves as the target person in each of four scenarios and to respond to five questions about the scene. Questions assess locus of blame (self, other, world and chance), characterological and behavioral self-blame and deservingness. Reliability for the avoidability measure is .50 , for self and other attributions reliability is between .50 and .60 , and for tre other five measures reliability ranges from .62 to .74 . Because of its low reliability, the avoidability item was not included.

2. Attributional style was measured using the Attributional Style Questionnaire (ASQ) developed by Peterson, Semmel, von Baeyer, Abramson, Metalsky and Seligman (1982). The scale asks "subjects to generace a cause themselves for each of a number (12) of events and rate the cause along seven point scales corresponding to the internality, stability and globality dimension" (Peterson et al., 1982, p. 289). Half of the events are positive and half negative. Test-retest reliabilities for the good and bad events are .70 and .64 and range from .57 to .69 for the six individual dimensions (internal- good, stable-good, global-good, internal-bad, stable-bad and global-bad). Internal reliabilities are .75 for good events and .72 for bad events and range from .44 to .69 for the individual dimensions.

3. Locus of control expectancy was measured using the 
Internal-External Locus of Control Scale (Rotter, 1966). This scale is a 29 item forced-choice test (including 6 filler items). Internal consistency is .65 to .76 . Test-retest reliability at one month ranged from .60 to .83 . The scale may not be independent of a social desirability response set (Joe, 1971). Correlations between internal-external locus of control and social desirability reported by Rotter (1966) ranged from -.07 to -.35 and Feather (1967) found a significant correlation of -.43 between external locus of control and social desirability for females.

Social support was measured using part of the Social Relationship Scale (SRS; McFarlane, Neale, Norman, Roy \& Streiner, 1981). The respondent is presented with two categories of life stress: home and family, and personal and social stresses. The respondent is asked to list the people with whom she has discussed these issues and the relationship of these people to her. She then rates how helpful the discussions have been with each person on a seven-point scale and whether the relationship is reciprocal. Subjects are also asked to list the key people to whom they would turn in times of crisis and whether these people reciprocate. Test-retest reliability for the number of individuals listed over a one-week period is from .62 to .99 with a median of .91. Average helpfulness test-retest reliability is .84 for home and family and .94 for personal and social 
issues. The SRS does not appear to elicit a socially desirable response.

The Marlowe-Crowne Social Desirability Scale (Crowne \& Marlowe, 1960; 1964) was employed to assess the tendency of the subjects to seek social approval by responding in a culturally appropriate manner. This 33 item scale has minimal pathological implications. The internal consistency is .88 and test-retest reliability is .89 . 
Results

\section{Comparability of the Groups}

To assure that the two groups of women employed in the present study did not differ on essential characteristics such as age, education level, personal and spouse's income, and social desirability set (as measured by the Marlowe-Crowne), t-tests were conducted on these variables. The results of the t-tests indicated that there was a significant difference between the groups on education level, $t(188)=-3.02$, $p<.003$, but no significant differences between the groups were evident for any of the other variables. Therefore, in subsequent between group analyses, education level was employed as a covariate.

To assure that the subjects from Winnipeg did not differ from the subjects from London in age, education level, income and social desirability set, t-tests were conducted on these variables. No significant differences emerged between these two groups.

\section{The Victimization Experiences}

The 103 women who were sexually victimized as children or adolescents reported a total of 191 victimization situations with different offenders which met the criteria for inclusion in this study. The number of different offenders involved with each victim ranged from 1 to 5 with a mean of 1.84 (SD=1.02). 
Length of victimization. The women were not always able to report the exact length of time that the abuse continued. This information was missing for $15(7.85 \%)$ of the 191 situations. In $44.9 \%$ of the cases for which data is available, the situation reported was an isolated incident. For the remaining $55.1 \%$ of the situations, the average length of time that the victimization continued was 3.33 years, the range of these occurrences was from one week to fifteen years.

Age of participants. The age of the victim at the time of the abuse ranged from two to sixteen years. The mean age was 9.74 years ( $S D=3.79$ ). Table 2 describes the age of the victims at

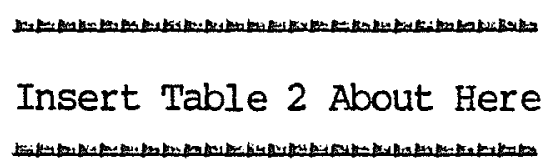

the time each abusive experience began in greater detail. The average age of the offender, as reported by the victims was 32.69 , with a range of 12 to 82 years. It should be noted that the victims were not always aware of the exact age of the offender, especially if he was a stranger, and therefore this information may not be accurate.

Relationship of victim and offender. In 12.28 of the incidents reported, the offender was a stranger to his victim. In $51.3 \%$ of the cases the offender was an acquaintance and in $36.3 \%$ of the cases he was a family member. In the cases of victimization by family members, 31.98 occurred with the 
Table 2

\section{Age at Victimization}

$\begin{array}{lccc}\text { Age in Years } & \text { Frequency } & \text { Percent } & \begin{array}{r}\text { Cumulative } \\ \text { Percent }\end{array} \\ 2-6 & 48 & 25.1 & 25.1 \\ 7-11 & 77 & 40.3 & 65.4 \\ 12-16 & 66 & 34.6 & 100.0 \\ & & & \\ \text { Total } & 191 & 100.0 & \end{array}$


victim's father, $21.7 \%$ with an uncle, $17.4 \%$ with a brother and $13 \%$ with a grandfather. Table 3 describes the relationship between victim and offender in greater detail.

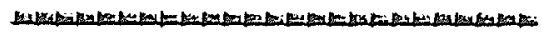

Insert Table 3 About Here

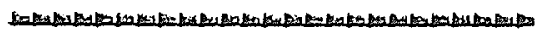

Initiator and use of force. In $96.3 \%$ of the incidents the victims reported that the abusive situation was initiated by the other person. In $2.1 \%$ of the cases, the victim shared the responsibility for initiation with the other person and in $1.6 \%$ of the cases the woman reported that she had initiated the situation. In $77.5 \%$ of the cases the women reported that the offender had used threats or force to obtain their participation.

The type of sexual contact. In the majority of cases, the victimization event involved sexual contact between victim and offender, but not intercourse. In $22 \%$ sexual intercourse occurred. Table 4 describes the type of sexual contact that occurred more fully.

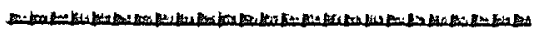

Insert Table 4 About Here

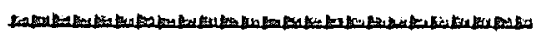

Victim's immediate reaction. The women reported that in $64.1 \%$ of the victimization situations their immediate reaction was fear, which at times was accompanied by other emotions such as shock, surprise and/or interest. Shock alone, or combined with surprise and interest, was reported in $17.6 \%$ of the situations. 
Table 3

\section{Relationship to offender}

$\begin{array}{lcc}\text { Relationship } & \text { Frequency } & \text { Percent } \\ \text { Stranger } & 23 & 12.0 \\ \text { Acquaintance } & 97 & 50.7 \\ \text { Family } & 69 & 36.3 \\ \text { Missing data } & 2 & 1.0 \\ & 191 & 100.0 \\ \text { Total } & & 1\end{array}$

Relationship to Offender who is a Family Hember

$\begin{array}{lcc} & \text { Frequency } & \text { Percent } \\ \text { Relationship } & 22 & 31.9 \\ \text { Father } & 15 & 21.7 \\ \text { Uncle } & 12 & 17.4 \\ \text { Brother } & 9 & 13.0 \\ \text { Grandfather } & 5 & 7.2 \\ \text { Stepfather } & 4 & 5.8 \\ \text { Cousin } & 1 & 1.4 \\ \text { Mother } & 1 & 1.4 \\ \text { Brother-in-law } & 69 & 99.8 \\ \text { Total } & 1 & \end{array}$

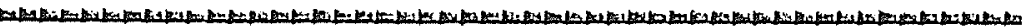


Table 4

Sexual Contact Between Victim and offender

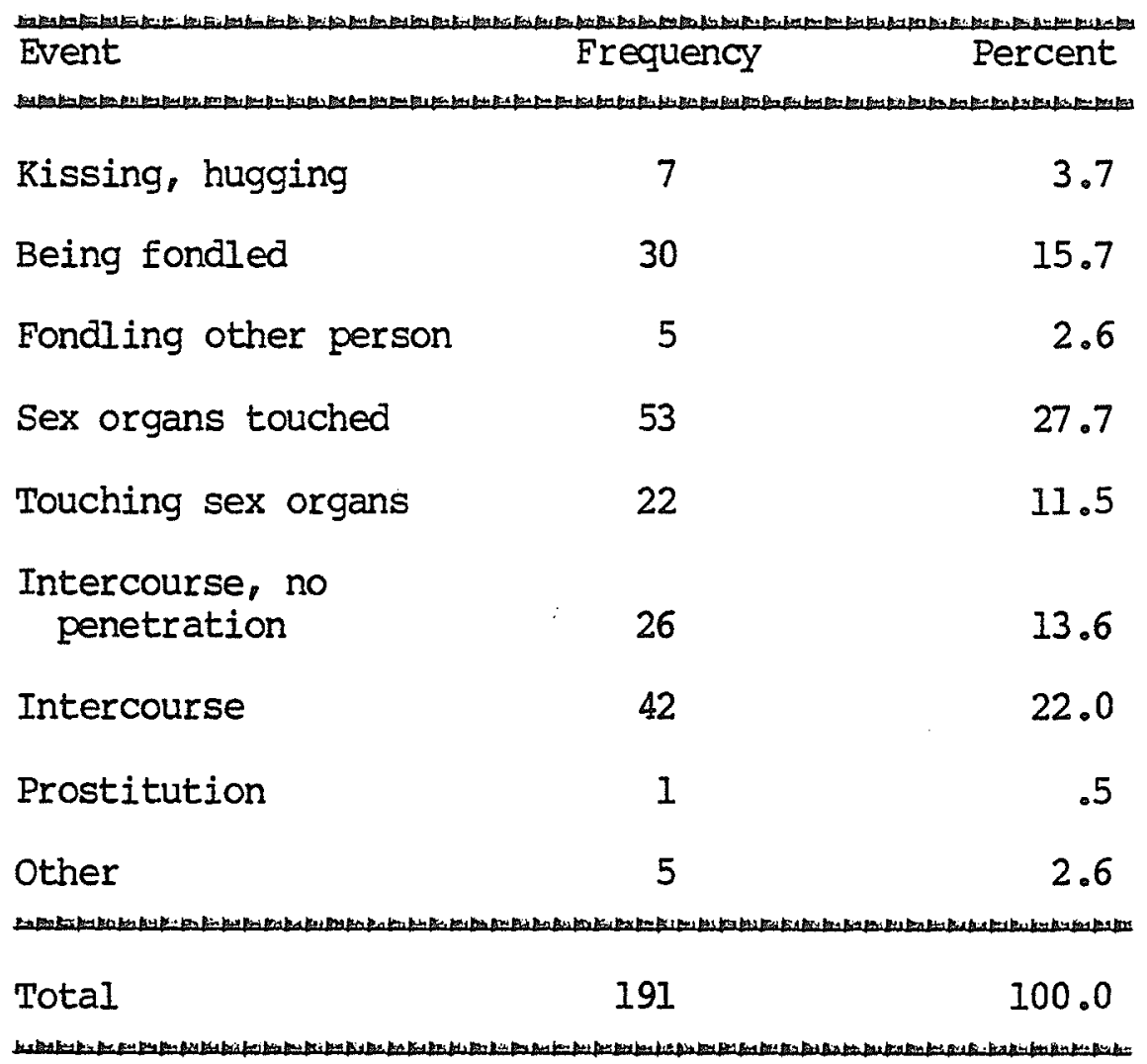


Surprise alone was reported in $8 \%$ of the cases. Interest alone was also reported in $8 \%$ of the cases and pleasure alone was reported in 2.18 of the situations. (See Table 5).

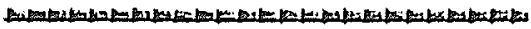

Insert Table 5 About Here

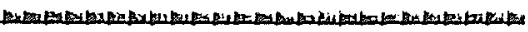

Reporting. In $58.6 \%$ of the situations the victim told no one of her experience after it occurred. Less than $15 \%$ of incicients were shared with parents and $5.7 \%$ were reported to the police. Eleven percent of the incidents were shared with friends, $3.7 \%$ with a sibling and $6.3 \%$ with a therapist or other adult.

Parental response. The women were asked to describe their parents' response to the victimization when they were informed of it or to describe how they expected their parents would have responded had they been told. In $51.2 \%$ of the situations for which data was available (which is $44 \%$ of the total number of incidents), mothers were or were expected to be very or mildly angry with the daughters. In $55.2 \%$ of the situations for which data is available ( $38.7 \%$ of the total sample), the fathers were or were expected to be very or mildly angry with the daughters. In $47.7 \%$ of cases (44.9\% of the total sample) mothers were or were expected to be supportive and in $37.5 \%$ of cases $(28.38$ of the total sample) fathers were or were expected to be supportive.

Overall victim response. Looking back on the situation years later, the victims perceive $84.2 \%$ of the situations as mostly 
Table 5

Victim ${ }^{\text {S }}$ Immediate Reaction to the Experience

\begin{tabular}{|c|c|c|}
\hline Reaction & Frequency & Percent \\
\hline Fear & 98 & 51.3 \\
\hline Shock & 30 & 15.7 \\
\hline Surprise & 15 & 7.9 \\
\hline Interest & 15 & 7.9 \\
\hline Pleasure & 4 & 2.1 \\
\hline Fear and Shock & II & 5.8 \\
\hline $\begin{array}{l}\text { Fear and Surprise and/or } \\
\text { Interest and/or Pleasure }\end{array}$ & 7 & 3.7 \\
\hline Fear, Shock, Surprise & 4 & 2.1 \\
\hline Shock, Surprise, Interest & 3 & 1.6 \\
\hline Missing Data & 4 & 2.1 \\
\hline Total & 191 & 100.0 \\
\hline
\end{tabular}

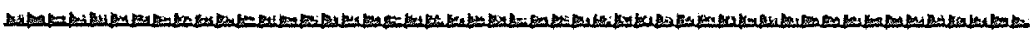


negative or negative. They perceive $12.6 \%$ of the situations as neutral and only $3.1 \%$ of the situations were described as positive or mostly positive. The event was seen as a threat in $81.2 \%$ of the situations and as a challenge in $12.6 \%$ of the situations. No differentiation was made in the remaining $6.3 \%$ of the situations. In $55.3 \%$ of the cases the victims have been able to attach some or very much meaning to the event, in $44.7 \%$ of the cases no meaning has been found.

Twenty-seven percent of the victims blamed themselves for the victimization. Two percent blamed themselves and the other person. In $53.2 \%$ of the cases the other person was blamed. Fathers were blamed in $11.5 \%$ of cases (which corresponds to the percent of situations in which they were the offender). Mothers were blamed in $2.1 \%$ of the situations and someone else was blamed 3.18 of the time.

\section{Between-Group Analyses}

A Multivariate Analysis of Covariance, with education level as the covariate, was conducted to compare the victimized women with the nonvictims on 42 measures of family violence, social support, attribution style, and coping level. Data from 167 subjects, 91 victims and 76 nonvictims for whom no relevant information was missing, were included in the analysis. There was a significant main effect for group, $E(1,123)=2.285, g<.0002$. Univariate F-tests indicated significant differences between the 
groups for the variables listed in Table 6 .

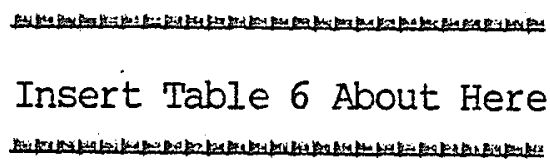

The results indicate that the victimized women have received more psychological help from therapists and have had more psychiatric hospitalizations than have the nonvictims. The victimized women had fewer friends at age 12 than did the nonvictims and they were less close to their parents when they last lived with them. At the time the participants were 12 years old, the families of tne victimized women were marked by more violence and these women received more spankings from their parents than did the nonvictimized women. At present the victims are more likely to attribute bad events to global factors and to internal, stable, global factors than are nonvictims. The victims are more likely to blame their character and behavior for bad events, are less likely to blame other people and are more likely to attribute good events to external factors. Victimized women have more negative sexual symptoms than nonvictims. The victimized women say they are less likely to respond positively to sexual invitations and are less satisfied with their present sexual relationship. The victims are more depressed, have a greater number of and more intense psychological symptoms and have lower self-esteem than do the nonvictimized women. 
Table 6

Univariate $\mathbb{F}^{\mathrm{S}}$ from Multivariate Analysis of Covariance between Victims and Nonvictims

\begin{tabular}{|c|c|}
\hline Variables & $F(1,164)$ \\
\hline \multicolumn{2}{|l|}{ Attribution style } \\
\hline Global - Bad Events (ASQ) & $11.82 * * *$ \\
\hline Internal, Stable, Global - Bad Events (ASQ) & $6.80 * *$ \\
\hline Characterological Blame & $10.23 * *$ \\
\hline Internal - Good Events (ASQ) & $5.79 *$ \\
\hline Other Blame & $4.19 *$ \\
\hline Behavioral Blame & $3.98 *$ \\
\hline Internal - Bad Events (ASQ) & 1.59 \\
\hline Stable - Bad Events (ASQ) & 1.84 \\
\hline Stable - Good Events (ASQ) & 1.21 \\
\hline Global - Good Events (ASQ) & .03 \\
\hline Internal, Stable, Global - Good Events (ASQ) & 1.98 \\
\hline Chance Blame & 2.53 \\
\hline Self-Blame & .47 \\
\hline Envirorment-Blame & .29 \\
\hline Deservingness & .00 \\
\hline Locus of Control & .65 \\
\hline
\end{tabular}

(table continues) 
Table 6 continued

\begin{tabular}{|c|c|}
\hline Variables & $\mathrm{F}(1,164)$ \\
\hline \multicolumn{2}{|l|}{ Coping Level } \\
\hline Depression (BDI) & $17.33 * * * *$ \\
\hline Psychological Symptoms (HSCL) & $11.44 * * *$ \\
\hline Intensity of Symptoms (HSCL) & $11.63 * * *$ \\
\hline Negative Sexual Symptoms & $11.16 * * *$ \\
\hline Sexual Responsiveness & $7.70 * *$ \\
\hline Self-Esteem (TSBI) & $5.97 *$ \\
\hline Sexual Satisfaction & $5.11 *$ \\
\hline Heterosexual Behavior & .49 \\
\hline Homosexual Behavior & 2.01 \\
\hline Sexual Desire & 2.82 \\
\hline Masturbation & 3.32 \\
\hline Sexual Arousal & .64 \\
\hline Orgasmic Ability & .39 \\
\hline Number of Sex Partners & .02 \\
\hline Criminal Behavior & 1.99 \\
\hline Alcohol and Drug Use & .26 \\
\hline
\end{tabular}

(table continues) 
Table 6 continued

$\begin{array}{lc}\text { Variables } & F(1,164) \\ \text { Social Support } & 18.96 * * * * \\ \text { Psychological Help received } & 16.06 * * * * \\ \text { Number of Friends (age 12) } & 14.70 * * * \\ \text { Closeness to Mother } & 7.97 * * \\ \text { ClosenesS to Father } & .44 \\ \text { Reciprocity of Social Supports (SRS) } & .26 \\ \text { Helpfulness of Social SupportS (SRS) } & .04 \\ \text { Number of Social Supports (SRS) }\end{array}$

Family Violence

Spanking by Mother

$7.27 * *$

Overall Family Violence

$7.90 * *$

Spanking by Father

$6.56 *$

5 $\mathrm{n}=92$ for victims $\quad \mathrm{n}=75$ for nonvictims

$* \mathrm{p}<.05 \quad * * \mathrm{p}<.01 \quad * * * \mathrm{p}<.001 \quad * * * * \mathrm{p}<.0001$ 
No differences were found between the groups on measures of the amount of social support they receive, the helpfulness or the reciprocity of these social relationships (see Appendix D). There was no difference found in locus of control for the two groups, their tendency to attribute responsibility for good events to global versus specific factors, stable versus unstable factors, or their total attribution pattern for good events. Attribution of blame to self, the environment or chance was not significantly different for the two groups. The groups were similar in the amount of sexual activity in which they engage, the number of sexual partners they had during the past year and their sexual arousal and ability to experience orgasms. Their alcohol and drug use and their history of arrests did not differ significantly.

\section{Within Groups Analyses: Victims}

Incest victims versus victims of nonfamilial abuse. To assess the homogeneity of the group of victims, a Multivariate Analysis of Variance was conducted between incest victims and victims of nonfamilial abuse. Thirty-four measures of family violence, social support, attribution style and coping level were included in the analysis. Data from 91 subjects, 51 incest victims and 40 victims of nonfamilial abuse, for whom no relevant information was missing, were included in the analysis. There was 
no significant main effect for group, $F(1,55)=1.10, \mathbf{p}<.50$. Univariate $F$ tests indicated significant differences between the groups for the following six variables: closeness to mother, $F(1$, 88) $=6.95, \mathbf{p}<.01$; closeness to father, $\mathbb{F}(1,88)=8.90, \mathbf{p}<.01$; negative sexual symptoms, $F(1,88)=7.64, p<.01$; number of social supports, $F(1,88)=5.46$, p<.02; attribution style, global - good events, $\mathbf{F}(1,88)=5.08, \mathbf{p}<.05$; and behavioral blame, $\mathbf{F}(1$, 88) $=4.02$, p.05. That is, although incest victims and victims of nonfamilial abuse did not differ overall, incest victims had poorer relationships with their parents when they last lived with them, had fewer social supports as adults, tended to attribute good events to global factors, to employ more behavioral selfblame and to experience more negative sexual symptoms than did victims of nonfamilial abuse.

Combination of variables. Prior to assessing the relationship between the four groups of variables: the victimization experience, attribution style, social support, and coping level, the number of variables within each category was reduced to provide a smaller number of more stable measures of like constructs.

Six victimization variables were developed to be employed in subsequent analyses:

1) The age of the child the first time she was sexually abused.

2) The relationship between the victim and the offender(s) 
by whom she was sexually abused.

3) The average age difference between the victim and the offender ( $s$ ).

4) The number of incidents of victimization by different offenders reported by the victim.

5) The average amount of force used by the offender(s) to elicit the victim's cooperation.

6) The average negativity rating of the experience(s) given by the victim.

Four attribution style measures were developed as follows:

1) The ASQ total score for good events was employed as a measure of attribution style for good events.

2) The ASQ total score for bad events and the Janoff-Bulman scores for behavioral and characterological self-blame were standardized and the z-scores were combined to provide a measure of attribution style for bad events.

3) The Internal-External Locus of Control scale was employed as a measure of locus of control.

4) Eacn subject's responses to the three items which assessed to whom the victim assigned blame for the victimization experience (self or other person), whether each experience was seen as a threat or a challenge and whether the person found meaning for the experience, were averaged and combined to provide a measure of response to victimization. This combination was made 
since attribution of blame to self, seeing the experience as a threat, and not finding meaning for the experience were all considered to be related to poor coping. It was expected that this factor would provide an exploratory measure of the contribution of these attributions regarding the victimization experience to adult coping.

The following five social support measures were developed:

1) Each subject's responses to the items which assessed whether they had ever seen a therapist, whether they were presently in therapy and whether they had ever been hospitalized for a psychological problem, were combined to provide a measure of psychological help received.

2) Each subject's responses to the items which assessed whether their mother responded angrily and/or supportively to each victimization experience were averaged. The anger response was rescored so that a high score indicated less anger. These two scores along with the victim's response to the item assessing her closeness to her mother when she last lived wich her, were standardized and the z-scores combined to provide a measure of closeness to mother in the past.

3) The same procedure was followed with the items related to father to provide a measure of closeness to father in the past.

4) The item assessing the number of friends the woman had at age 12 was rescored so that a high score represented many friends 
and a low score represented few friends. This score and the total number of people listed for the SRS were standardized, and the two $z$-scores were combined to provide a measure of number of social supports past and present.

5) The SRS scores for helpfulness of social supports and reciprocity of social relationships were standardized and the zscores were combined to provide a measure of reciprocity and helpfulness of supports.

Four coping level measures were developed in the following way:

1) The TSBI was employed as a measure of self-esteem.

2) The scores on the BDI, the total number of symptoms reported on the HSCL and the total intensity of symptoms score of the HSCL were standardized and the three $z$-scores were combined to produce a measure of psychological distress.

3) The scores on sexual satisfaction and negative sexual symptoms were rescored so that high scores indicated greater distress. The scores for total amount of sexual behavior, amount of positive sexual response, and responsiveness to sexual invitations had been scored in the same direction. All five scores were standardized and the $z$-scores were combined to provide a measure of sexual problems.

4) Eacn subject's response to the items about alcohol and drug consumption were combined to provide one score. These scores 
were standardized as were the scores for history of arrest for criminal behavior. The two z-scores were combined to provide a measure of antisocial behavior.

Relationships Among Victimization Experience, Attribution, Social Support and Coping Level Variables

Canonical correlations were conducted among each pair of variables to assess their relationships. Significance of the canonical correlations was assessed by apportioning the familywise error rate in the manner suggested by Marascuilo and Levin $(1983) ; \alpha \mathrm{p}=[2(\mathrm{P}-\mathrm{p}-1)] /[\mathrm{P}(\mathrm{P}+1)]$.

Sexual victimization experience and other variables. Canonical correlation analysis revealed no significant relationships between the following sets of variables: (a) sexual victimization experience and attribution style, $r(24)=.42, p<.18$; (b) sexual victimization experience and social support, $r(30)=.47, p<.05 ;$ and (c) sexual victimization experience and coping level, $r(24)=.48, p<.05$.

Attribution style and coping level. Two significant canonical correlations were evident between attribution style and coping level. The first was highly significant, $\mathbf{r}(16)=.78$, p $\times 0001$. For this relationship the attribution style variable is largely composed of a high positive loading on attribution style for bad events and the coping level variable has a high positive loading on psychological distress and a high negative loading on 
self-esteem (see Table 7). The second relationship, $r(9)=.42$, $\mathrm{p}<.005$, is defined by an attribution style variable largely composed of a high positive loading on attribution style for good events and a coping level variable with high positive loadings on self-esteem and psychological distress and a high negative loading on sexual problems (see Table 7).

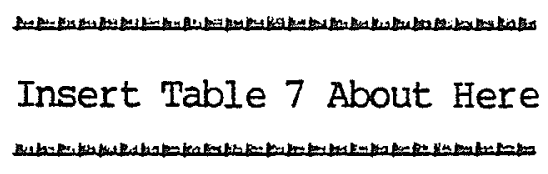

Social support and coping level. Two significant canonical correlations were apparent between social support and coping level. The first was highly significant, $r(20)=.62$, $p<.0001$, and demonstrated a relationship between the social support variable which had high negative loadings on number of social supports and reciprocity and helpfulness of supports and a high positive loading on psychological help, with the coping level variable which had high positive loadings on psychological distress and sexual problems (see Table 8). The second relationship, $r(12)=.45, p<.005$, was between the social support variable composed of high positive loadings on closeness to mother and psychological help and the coping level variable composed of a high positive loading on psychological distress and a negative loading on sexual problems (see Table 8). 
Table 7

Canonical Correlations Between Attribution Style And Coping Level Standardized Coefficients

\begin{tabular}{|c|c|c|}
\hline Variable & $\begin{array}{l}\text { First } \\
\text { cal Variable }\end{array}$ & $\begin{array}{c}\text { Second } \\
\text { Canonical Variable }\end{array}$ \\
\hline \multicolumn{3}{|l|}{ Attribution Style } \\
\hline Locus of Control & .169 & -.142 \\
\hline Attribution - Good & -.212 & .907 \\
\hline Attribution - Bad & .880 & .460 \\
\hline Response to Vict. & -.041 & .359 \\
\hline \multicolumn{3}{|l|}{ Coping Level } \\
\hline Self-Esteen & -.487 & .843 \\
\hline Sexual Problems & -.095 & -.578 \\
\hline Distress & .641 & .987 \\
\hline Antisocial Behavior & -.092 & .118 \\
\hline
\end{tabular}

(table continues) 
Table 7 continues

Canonical Variable Ioadings

\begin{tabular}{|c|c|c|}
\hline Variable & $\begin{array}{l}\text { First } \\
\text { cal Variable }\end{array}$ & $\begin{array}{c}\text { Second } \\
\text { Canonical Variable }\end{array}$ \\
\hline \multicolumn{3}{|l|}{ Attribution Style } \\
\hline Locus of Control & .374 & -.154 \\
\hline Attribution - Good & -.430 & .810 \\
\hline Attribution - Bad & .961 & .242 \\
\hline Response to Vict. & .004 & .370 \\
\hline \multicolumn{3}{|c|}{ - } \\
\hline Self-Esteem & -.880 & .405 \\
\hline Sexual Problems & .239 & -.525 \\
\hline Distress & .908 & .301 \\
\hline Antisocial Behavior & -.141 & .491 \\
\hline
\end{tabular}




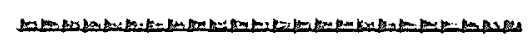

Insert Table 8 About Here

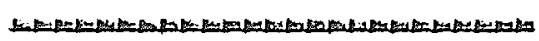

Attribution style and social support. One significant relationship emerged between attribution style and social support, $\mathbf{r}(20)=.55, p<.0001$. The attribution style variable had a high positive loading on attribution style for bad events and a high negative loading on attribution style for good events and the social support variable had high positive loadings on psychological help and closeness to father and a high negative loađing on number of social supports (See Table 9).

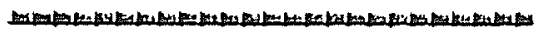

Insert Table 9 About Here

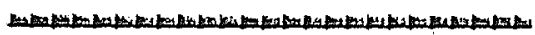

Relationship of victimization experience, social support and attribution style with coping level. Three significant relationships emerged between these variables. The first was highly significant, $r(40)=.80, \quad \mathbf{p}<.0001$, and was virtually identical to the first relationship that emerged between attribution style and coping level. That is, there was a high positive loading on attribution style for bad events which was related to the coping variable which had a high positive loading on psychological distress and a high negative loading on selfesteem (see Table 10). The second relationship, $r(27)=.59$, p .0001 , was defined by a set of victimization, attribution and social support variables which had high positive loadings on 
Table 8

Canonical Correlations Between Social support And Coping Level Standardized Coefficients

$\begin{array}{lcc} & & \\ V & & \end{array}$

Social Support

Psychological Help $\quad .400 \quad .529$

$\begin{array}{ll}\text { Reciprocity/helpfulness - }-.459 & .088\end{array}$

Closeness to Father $\quad .224 \quad-.348$

Closeness to Mother $\quad-.258 \quad .859$

Number of Supports $\quad-.558 \quad .381$

上.

Coping Level

$\begin{array}{lll}\text { Self-Esteem } & -.188 & .603\end{array}$

$\begin{array}{lll}\text { Sexual Problems } & .468 & -.588\end{array}$

$\begin{array}{lll}\text { Distress } & .501 & 1.175\end{array}$

$\begin{array}{lll}\text { Antisocial Behavior } & -.343 & .017\end{array}$

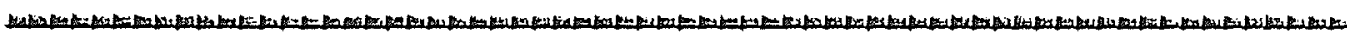


Table 8 continued

Canonical Variable Loadings

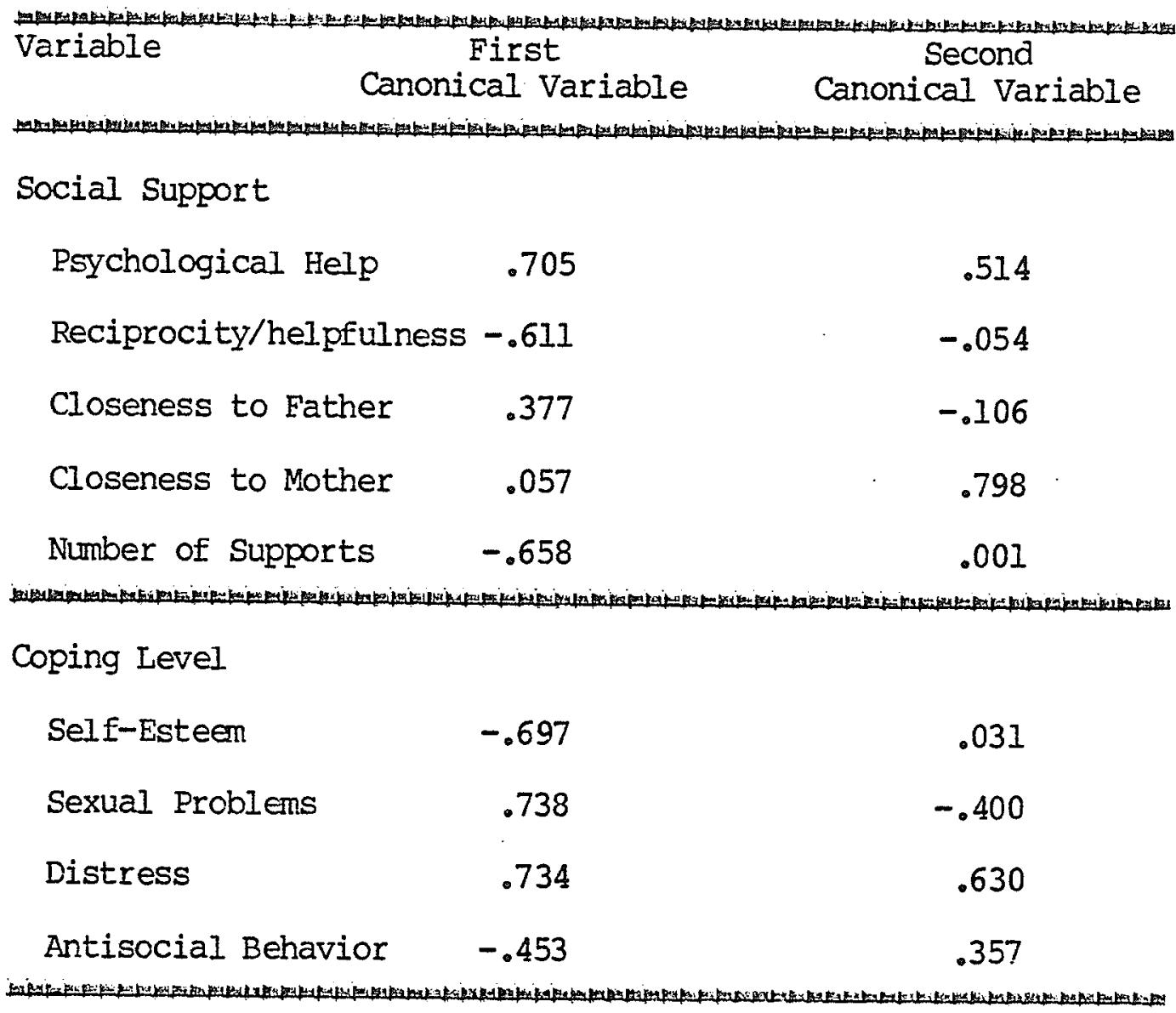


Table 9

Canonical Correlations Between Attribution style and Social Support

Standardized Coefficients

$\begin{array}{lc}\text { Variable } & \begin{array}{c}\text { First } \\ \text { Canonical Variable }\end{array} \\ \text { Attribution Style } & -.353 \\ \text { Locus of Control } & -.438 \\ \text { Attribution - Good } & .793 \\ \text { Attribution - Bad } & .159 \\ \text { Response to Vict. } & \\ \text { Social Support } & .535 \\ \text { Psychological Help } & -.159 \\ \text { Reciprocity/helpfulness } & -.361 \\ \text { Closeness to Father } & -.021 \\ \text { Closeness to Mother } & -.458 \\ \text { Number of Supports } & -.35\end{array}$


Table 9 continued

Canonical Variable Loadings

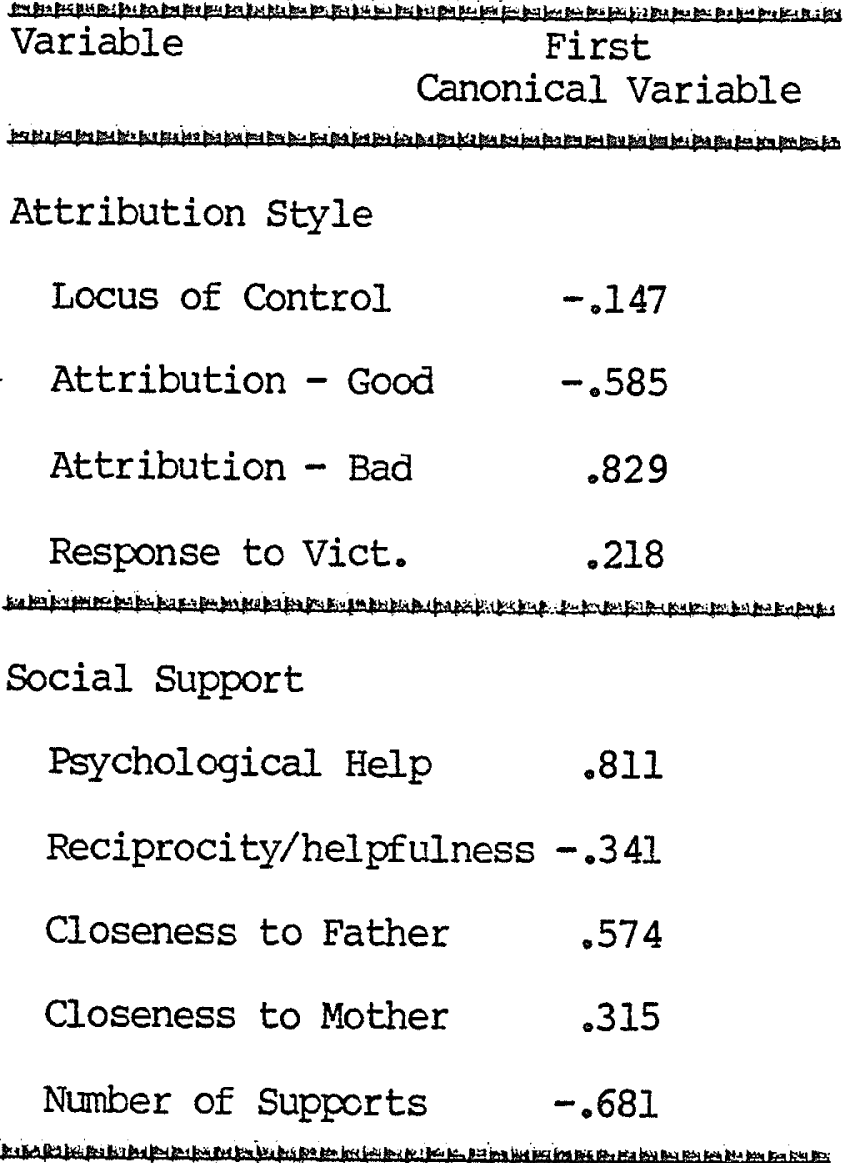


negativity of victimization experience and attribution style for good events. The coping level variable in this relationship had high positive loadings on both psychological distress and selfesteem (see Table 10). The third relationship, $r(16)=.54, p<.002$, was between the victimization, attribution and social support variable which was highly negatively loaded on reciprocity and helpfulness of supports and closeness to mother and highly positively loaded on negativity of victimization experience, and the coping level variable defined by a high positive loading on sexual problems (see Table 10).

Insert Table 10 About Here

and

\section{Within Groups Analyses: Both Groups Combined}

Relationships between social support variables and coping

level. Pearson product-moment correlations were conducted to examine the relationships between the social support variables and the coping level variables. The Dunn-Bonferroni procedure was employed to determine the appropriate significance level to reduce the Type I error rate. The results, as shown in Table 11, indicate that scores on the two SRS scores which measure number and helpfulness of social supports are significantly positively correlated with self-esteem scores. Number of social supports is also significantly negatively correlated with depression level. 
Table 10

Canonical Correlations Between Victimization, Attribution and Social Support and Coping Level

Standardized Coefficients

\begin{tabular}{|c|c|c|c|}
\hline \multicolumn{2}{|c|}{$\begin{array}{l}\text { First Canonical } \\
\text { Variable }\end{array}$} & $\begin{array}{l}\text { Second Canonical } \\
\text { Variable }\end{array}$ & $\begin{array}{l}\text { Third Canonical } \\
\text { Variable }\end{array}$ \\
\hline \multicolumn{4}{|c|}{ 1. } \\
\hline \multicolumn{4}{|c|}{ Victumization, Attribution Style, Social Support } \\
\hline Age Difference & -.143 & .026 & .110 \\
\hline Negativity & .003 & .597 & .482 \\
\hline Attribution-Good & -.168 & .509 & -.096 \\
\hline Attribution-Bad & .755 & .092 & -.535 \\
\hline Response to Vict. & -.058 & .269 & .044 \\
\hline Psychological Help & .086 & .332 & .192 \\
\hline Reciprocity/helpful. & -.188 & -.115 & -.555 \\
\hline Closeness to Father & .042 & -.346 & .085 \\
\hline Closeness to Mother & -.016 & .215 & -.559 \\
\hline Number of Supports & -.227 & .361 & -.276 \\
\hline \multicolumn{4}{|c|}{ - } \\
\hline \multicolumn{4}{|l|}{ Coping Level } \\
\hline Self-Esteen & -.404 & 1.064 & .376 \\
\hline Sexual Problems & .003 & -.092 & .997 \\
\hline Distress & .672 & 1.077 & -.055 \\
\hline Antisocial Behavior & -.173 & .158 & -.151 \\
\hline
\end{tabular}


Table 10 continued

Canonicat Variable Loadings

\begin{tabular}{|c|c|c|c|}
\hline $\begin{array}{rr}\text { Variable } & \text { First Car } \\
\text { Variar }\end{array}$ & $\begin{array}{l}\text { onical } \\
\text { le }\end{array}$ & $\begin{array}{l}\text { Second Canonical } \\
\text { Variable }\end{array}$ & $\begin{array}{l}\text { Third Canonical } \\
\text { Variable }\end{array}$ \\
\hline Viccımization, Attribu & tion St & e, Social Support & \\
\hline Age Difference & .038 & .028 & .299 \\
\hline Negativity & .223 & .539 & .359 \\
\hline Attribution - Good & -.443 & .468 & -.308 \\
\hline Attribution - Baa & .920 & .151 & -.237 \\
\hline Response to Vict. & .002 & .315 & .015 \\
\hline Psycholoyical Heıp & . 553 & .281 & .247 \\
\hline Reciprocity/helpful. & -.370 & -.133 & -.504 \\
\hline Closeness to Father & .273 & -.224 & .063 \\
\hline Closeness to Mother & .236 & .358 & -.451 \\
\hline Number or Supports & -.488 & .215 & -.192 \\
\hline
\end{tabular}

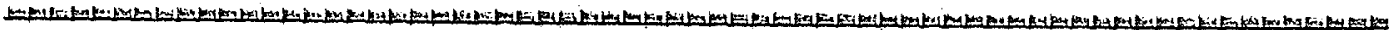

Coping Leve,

$\begin{array}{lrrr}\text { Self-Esteem } & -.800 & .456 & .121 \\ \text { Sexual Problems } & .342 & -.077 & .915 \\ \text { Distress } & .912 & .400 & -.002 \\ \text { Antisocial Behavior } & -.221 & .486 & -.275\end{array}$

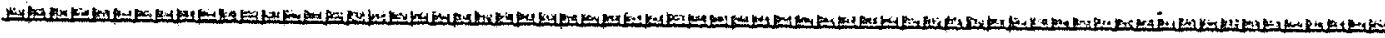


Greater reciprocity of the person's social supports is significantly correlated with less depression, fewer psychological symptoms, fewer sexual problems and greater sexual arousal.

Reports of having had close relationships with one's mother when last living with her was related to lower depression scores. Reports of a close relationship with father was related to fewer negative sexual symptoms and increased self-esteem.

Psychological help received was related to higher levels of depression, greater numbers of and more intense psychological symptoms, low self-esteem and fewer sexual problems.

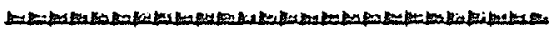

Insert Table 11 About Here

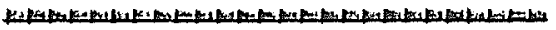

Relationship between attribution style and self-blame As Table 12 indicates, the Janoff-Bulman scores for behavioral and characterological self-blame were significantly correlated with all the measures on the ASQ, except for the measure of global attributions for good events. The two self-blame measures were highly correlated with each other $(r=.74, p<.001)$ and therefore showed the same relationship pattern to attribution style. That is, both behavioral and characterological self-blame were related to internal, stable and global attributions for bad events and external, unstable attributions for good events. 
Table 11

Correlations Between Social Support Variables and Coping Level Variables

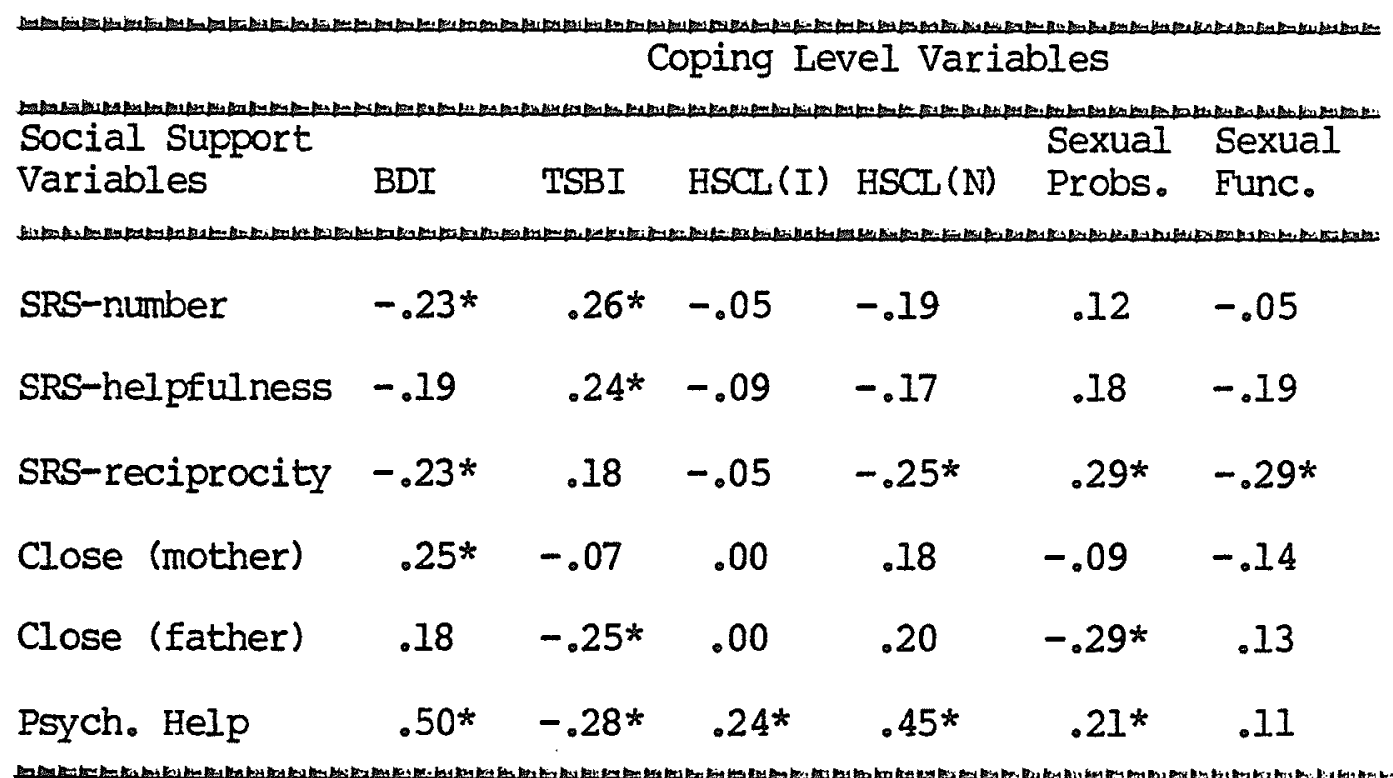

${ }^{*} p .001$ 
Eas

Insert Table 12 About Here

-10 a

Rellationship between social support variables and locus of control. No significant correlations were found between any of the social support measures and the locus of control measure.

\section{The Subjective Data}

Each victimized woman was asked a series of open-ended questions after she completed the questionnaire to provide more information about her perceptions of her experiences. The most common responses to these questions are discussed below.

1. The women's most frequent immediate reactions to the abuse, as they recalled them, were fear, reported by $69.1 \%$ of the respondents, and guilt, reported by 36.18 of the respondents. Many women (17.5\%) were aware that they had become depressed or had withdrawn after the incident cccurred. Others were confused and/or felt they did not understand what had occurred to them (13.4\%). More than ten percent of the women (10.3\%) felt that somehow they must have caused the situation or been bad for having allowed it to continue. About $10 \%$ of the women were disgusted by what had happened. Less than $10 \%$ of the respondents felt that they did not have an adverse response to the situation.

2. A large proportion of the women (35.7\%) attribute their present sexual aifficulties to their childhood victimization 
Table 12

Correlations Between ASQ Scores and Behavioral and Characterological Self-Blame Scores

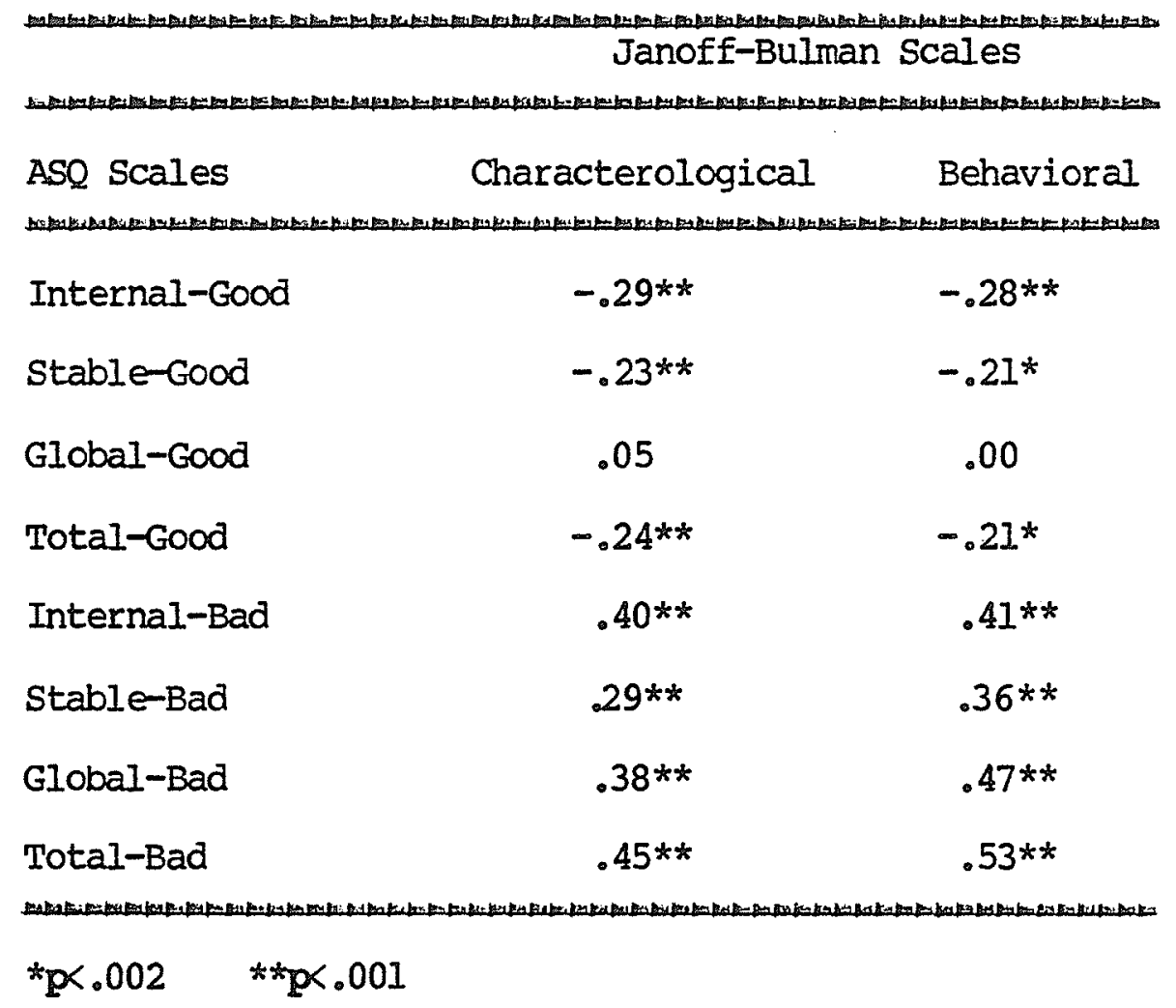


experiences. Thirty percent of the women felt that the victimization caused them to have difficulty trusting people, especially men. Many women saw themselves as fearful (13.3\%) and/or angry (9.2\%) now as a result of their experiences. Over $12 \%$ of the women felt that they had experienced no adverse longterm etfects from their experiences and $4 \%$ identified some positive effects.

3. In their opinion, over $20 \%$ of the women felt that their problems were due to the helplessness and powerlessness that they felt during the abuse. Many of the women also identified the fear they felt at the time of the victimization (16.3\%) and the force that was usea on them (14.1\%) as significant contributers to their present difficulties. The guilt that the women felt (15.2\%) and the sense of betrayal and broken trust (10.2\%) which were a part of the victimization were also seen as contributing to their problems.

4. When asked what helped them to cope with their experience(s), $27.6 \%$ of the women pointed to the supportiveness of their spouses, friends and family as an extremely important factor. Many of the women have purposely tried not to think of their experiences (19.1\%) and some try to bury themselves in work or other interests (9.6\%). Therapy has been helpful to $11.7 \%$ of the women. Other important coping methods mentioned by the women include learning not to take responsibility for what happened (11.7\%), trying to take control of their lives $(9.6 \%)$, trying to 
understand what happened $(7.4 \%)$, and feeling a strong need to survive $(6.4$ \% $)$.

5. Wren asked what interferes with their ability to cope, $29.8 \%$ of the women cited feelings of isolation and lack of support from others. Many women ( $18.2 \%$ ) pointed to memories of the event(s), nightmares and contact with the perpetrator as stressors. Media coverage of child molesting, rapes and incest are also distressing to $9.1 \%$ of tne women. Ten percent of the women still find that guilt feelings interfere with their ability to cope with their experiences. Feelings of powerlessness are problematic for $78 \%$ of the women.

6. Those women who had had therapy to deal with the victimization experience(s) were asked which aspects of the therapy were helpful to them. Close to half of the women (48.1\%) felt that having someone listen to them in a non-judgemental, empathic way was very therapeutic. Learning to absolve themselves of guilt was important to $21.1 \%$ of the women and group therapy was helpful to $19.2 \%$ to reduce their feelings of isolation. Developing trust was considered important by $9.6 \%$ of the women and overcoming their negative response to sex was therapeutic for the same number of women.

7. Wren asked which aspects of therapy were not helpful, $10 \%$ of the women who responded to this item $(n=40)$ felt that their therapists were not understanding and blamed them for the 
victimization. Some women (12.5\%) felt that their therapist did not understand their need to explore the past and did not allow them to focus on the event but encouraged them to get on with the present. Some of the women (12.5\%) had difficulty relating to and trusting a male therapist. A similar number found that the usual one hour session per week was too structured and did not meet their need for support at times of crisis. 
Discussion

This study demonstrates that as a group, sexually victimized women have had different family and social experiences while growing up, have different attribution styles and experience more psychological, self-esteem and sexual problems than do the nonvictimized women. For the first time aspects of the victimization experience, the woman's attribution style and social support network were related to her present coping level to provide clues to the factors which may influence her present level of functioning. The results suggest that it is the woman's perceptions of the bad events in her life, not factors of the victimization experience, which are most closely associated with her current functioning level. Social support variables were also found to be related to present coping level, although they account for less of the variance than does attribution style.

\section{The Victimization Experiences}

The sexual experiences reported by the participants in this study are somewhat similar to those reported by Finkelhor's (1979) subjects. On average, though, the participants in this study appeared to experience more severe types of sexual victimization than did the women who participated in the Finkelhor study. That is, they experienced more force and coercion (77.5\% versus 55\% reporting force used), more frequent 
victimization (45\% versus $60 \%$ reporting single occurrences), and were more likely to have experienced sexual intercourse during the abuse (22\% versus $4 \%$ ). The women who participated in the present study were also more likely to have responded negatively to the experience than were the participants in Finkelhor's study. These differences may reflect the fact that Finkelhor's sample was comprised of college students who tend to be young and psychologically healthy. Also, $20 \%$ of the incidents reported in the Finkelhor study were experiences with exhibitionists, which are probably less serious and more likely to be single events than other forms of sexual abuse. Such incidents were not included in the present study.

The mean ages of the victims and offenders at the time of the abuse were comparable in both studies 19.74 years old in the present study, 10.2 years old in the Finkel hor study). However, triere were more women in the present study who reported that they were victimized under the age of 6 and over the age of 12, which may be a function of the broader sample of victims who participated in the present study. In both samples the vast majority of incidents were initiated by the offender but the relationships between victim and offender differed in the two studies. Subjects in the Finkelhor study reported most incidents with family members (43\%), and the remainder with acquaintances (33\%) and strangers (24\%). In the present study the majority of 
incidents occurred with acquaintances (51.3\%), a large proportion were with family members (36.3\%) and few were with strangers (12.2\%). The significance of this finding is not clear, but may be related to sample differences. The experiences with exhibitionists inflate tne stranger category in the Finkelhor study. It is also possible that incest victims are more reluctant to present themselves for this type of research than are victims of non-family sexual abuse. On the other hand, it could be argued that the results of this study present a more accurate picture of the distribution of abuse than the Finkelhor study as a greater cross-section of people were sampled.

The initial reactions of the victims in the two studies were similar although the women in the Finkelhor study tended to report more positive reactions as well as the negative ones. This difference may reflect the fact that the participants in the present study experienced more force and indeed did have more negative experiences. Similar patterns of not reporting the abuse to anyone were evident in both samples of victims. Parental reactions (or expected parental reactions), as reported by participants in the present study, were divided between anger and support. Slightly more fathers were (or were expected to be) angry and more mothers were (or were expected to be) supportive. Thirty percent of the women have blamed themselves for the victimization whereas about $65 \%$ blamed the cffender or their fathers (who were probably the offenders in the situation). 
Slightly more women have been able to find some meaning for the event than have not found any meaning for it. These findings are contrary to the expectation that victimized women would blame themselves for bad events. It is encouraging to find that most women were able to place the blame where it belonged. However, even though may of the women absolved themselves of blame for the victimization, many of them had coping problems. This suggests that simply learning to attribute responsibility externally for a victimization experience may not be sufficient to improve coping. The woman's general attribution style may require examination and modification.

Neither the present study nor the Finkelhor (1979) study can claim to provide information about the "typical" sexual victimization experience. Finkelhor's sample was limited to university students who are uniform in age and are generally high functioning. Although the women who participated in the present study were more representative of a cross-section of the population, they represent a sample of research volunteers. Data from a random sample of the population are needed to provide information which is representative of most sexually victimized women. Uniform definitions of sexual victimization are also necessary to assure that the results of different studies are comparable. 


\section{Victimized Women Compared with Nonvictimized Women}

As hypothesized, comparison of victims and nonvictims on measures of attribution style, social support levels and coping level indicated that the women were indeed significantly different in these areas. The victimized women were from families marked by more violence and physical punishment; they were less close to their parents when they last lived with them, had fewer friends and have received more psychological help than the nonvictimized women. The victimized women tended to be more depressed, had more psychological symptoms and more intense symptoms than did the non-victimized women。 They had lower self esteem, more sexual problems and were less satisfied with their sex lives. These findings are congruent with previous reports of the types of problems experienced by victims of sexual abuse in childhood (e.g., Benward \& Densen-Gerber, 1975; Herman, 1981; Tsai \& Wagner, 1978).

The victims tended to have an attribution style marked by attribution of bad events to global factors, to internal, stable and global factors, and to their character and behavior. They also tended not to blame others for bad events and attributed good events to external factors. The attribution pattern of the victims is similar to the pattern commonly exhibited by depressed individuals (e.g., Seligman et al., 1979), but not identical to it. Contrary to the prediction made, there was no significant difference between the groups in their tendency to make internal 
attributions for bad events. When examining the attribution style data it must be recognized that $52 \%$ of the victimized women did not show evidence of depressed mood (BDI $<10)$, and almost $30 \%$ of the nonvictims did show evidence of depressed mood (BDI>9). Therefore tnere is no reason to expect that the victims, as a group, would exhibit the same attribution style as would depressed people, or that nonvictims as a group, would exhibit the same attribution pattern as nondepressed individuals. Overall, the women who were sexually victimized exhibited an attribution pattern more like that exhibited by depressed individuals and women who had not been victimized exhibited a pattern more like that of nondepressed individuals.

It is interesting to note that there were no differences between the groups in the amount of social support that they receive or the helpfulness and reciprocity of their social relationships. There was also no difference in their locus of control. The women were similar in the amount of sexual activity in which they engage and their sexual arousal and ability to achieve orgasm. The latter finding is supported by the results of a study by Becker and colleagues (1982) who found that rape and incest victims were more likely to report fear reactions, arousal and desire dysfunctions at least one year post assault, than any disturbances in physiologic responding. These authors report that victims "perceive sexual stimuli as anxiety provoking or relabel 
their sexual feelings as either reduced or inhibited" (p. 73). Contrary to reports of other studies le.g., Benward \& Densen-Gerber, 1975; Herman, 1981), victims and nonvictims did not differ in the amount of alcohol and drugs that they consume or their history of arrests. These findings may be a function of the method of selecting subjects and/or the communities from which they were drawn. It may be that women experiencing problems with drugs, alcohol and/or the law do not readily respond to advertisements requesting their participation in research. The Benward and Densen-Gerber study was conducted on a sample of women who were in treatment for drug abuse and therefore the researchers had a sample of women with these specific problems.

\section{The Role of the Victimization Experiences}

The victimized women reported that they now experience sexual problems and trust problems which they attribute to the abuse, particularly to their helplessness and powerlessness while it occurred. These subjective reports are similar to the findings of Becker et al. (1982) that coercion in the victimization experience is related to later sexual problems. The victims often felt that the perpetrator had betrayed them and broken their trust. They also reported that the fear they experienced at the time of the occurrence and the force that had been used on them were significant factors in their long-term problems.

Contrary to the prediction of the present study, the 
canonical correlation of the victimization and coping variables found no significant relationship between them. The only victimization variable which was found to contribute significantly to coping level, when combined with the attribution style and social support variables, was the victim's perception of the negativity of the event. The social support variable closeness to mother, which was partially composed of the woman's expectation of her mother's reaction to the victimization, also contributed significantly to coping level. Thus, only the woman's present perception of the victimization and her perception of her mother's response to it are related to her present coping level, the actual events which occurred do not appear to be important contributers to the woman's present coping level. This finding is contrary to the predictions made on the basis of Finkelhor's (1979) report that trauma level (negativity of victimization experience) is related to the amount of force used by the offender and the age difference between victim and offender. However, close examination of Finkelhor's data reveals that these factors only account for $34 \%$ of the variance in negativity rating. The present study has gone a step beyond Finkelhor's study by relating negativity of experience to present coping, and it appears that the impact of force and age difference on coping level individually are not sufficiently large relative to the other variables to make significant contributions. 


\section{The Role of Attribution Style}

The most significant relationship found in this study is that the victim's attribution style is closely related to her present level of coping. The canonical correlation defined mainly by the relationship between attribution style for bad events and distress and low self-esteem accounts for 648 of the variance in the relationship between the two sets of variables. These results indicate that women who were sexually victimized in childhood and who are experiencing distress $\left(i_{0} e_{0}\right.$, large numbers of intense psychological symptoms and depression) and have low self-esteem tend to display an attribution style marked by internal, stable, global attributions for bad events and behavioral and characterological self-blame. The results raise the possibility that the observed coping difficulties of victims, especially distress and low self-esteem, may be due to their attribution style. of course, causal relationships cannot be implied from this data.

A second relationship was found between attribution style and coping, which at first glance seems difficult to explain. That is, positive attribution style for good events was related to psychological distress and high self-esteem. Further, when all variable sets were combined, negativity of victimization experience and positive attribution style for good events were related to psychological distress and high self-esteem. This finding might be explained if one assumes that there is a 
subgroup of victims who are coping somewhat better than the previously discussed group of women who show distress and low self-esteem. This group of women may be distressed but have higher self-esteem and may be differentiated from the first group by virtue of the fact that they are able to make internal, stable, global attributions for good events, regardless of whether they consider that the sexual experience that they had as a child was negative. When understood in this way, this finding provides further evidence that attribution style is an important factor related to adult coping in victims of childhood sexual abuse.

As discussed earlier in the present paper, a review of the literature had indicated that support for the learned helplessness model of depression was weak. Therefore, the specific predictions that were made related only to the internalexternal dimension. It was expected that victims would make internal attributions for bad events, especially victims who were not coping well. In fact, in the present study the internalexternal dimension of the ASQ for bad events did not discriminate between victims and nonvictims, whereas the globalspecific dimension and the total internal, stable, global dimensions for bad events did discriminate between the groups. This may be due to the instability of the ASQ individual dimensions and the greater stability of the total dimensions 
(Peterson et al., 1982). For example, the internal reliability of the internal-bad dimension is .49 whereas the for the total-bad dimension the internal reliability is .72 . This finding may also be explained by the fact that, as previously mentioned, in the present study not all victims were depressed. If the internalexternal attribution dimension most strongly discriminates between depressed and nondepressed individuals then it would not be expected to discriminate differences between victims and nonvictims particularıy well.

The behavioral and characterological self-blame measures were significantly correlated with each other. Both were also correlated with psychological distress and low self-esteem and did not show the differential pattern that was suggested by Janoff-Bulman (1979). Both behavioral and characterological selfblame were related to all the ASQ measures except global attributions for good events. It appeared that either the subjects in this study could not differentiate between the two items on the self-blame measure or the characterological and behavioral self-blame items are not differentially measuring internal, stable, global attributions in a situation of perceived uncontrollability and internal, unstable, specific attributions in a situation of perceived control, but are in fact measuring the same thing. From the review of the controllability and selfblame literature, it was suggested that victims who were coping well might be differentiated from those who were not coping well 
on the basis of the type of self-blame that they employ. Given that the two scores are so highly correlated and that both behavioral and characterological self-blame are related to maladaptive patterns of coping, this construct was not found to be useful for the purpose suggested in this study. Further research is in order with this construct to determine whether it is useful in other contexts or with other subjects.

The internal-external locus of control measure was correlated with the self-esteem measure as had been predicted. That is, there was a correlation between low self-esteem and external locus of control. The locus of control measure was not correlated with any of the other coping measures or with the social support measures. It should be noted that the mean locus cf control score for victims $(X=10.9)$ and nonvictims $(X=10.2)$ indicated that on average the women in both groups reported a more external locus of control than the college women in the studies reported by Rotter (1966). The samples in the present study resembled the 28-29 year old group studied by Feather (1967) in age, but their locus of control scores were similar to those of his 18-19 year old sample. There is no obvious explanation for these findings. They may reflect differences in samples studied or changes in locus of control norms during the past 20 years. Since the two groups in the present study did not differ in locus of control but did differ in other aspects of 
attribution style and coping level, and since locus of control was not related to adult coping, the relationship between locus of control and coping which has been discussed by others ( $e_{\circ} g_{\circ}$, Joe, 1971) is called into question.

Contrary to the prediction made based on the findings of Silver and Wortman (1980), Pearlin and Schooler (1978) and Lazarus and Launier (1978), ascription of meaning and challenge, and attribution of blame for the victimization situation to others, were unrelated to the coping measures and were not significantly related to the coping level variables in the canonical correlations. The lack of significance may be a function of the weakness of these measures which were dichotomous, unitary measures. Further study of these variables is in order.

Attribution style variables highly loaded on internal, stable, global attributions for bad events and external, unstable, specific attributions for good events were related to the social support variables which indicated that the person had received psychological help, had few social supports and had not been close to her father and perceived him as angry and not supportive about the victimization. This finding raises several questions about the effects of the attribution style and social support variables on each other. For example, does a negative attribution style influence the level of social support a person receives and/or the level of closeness they experience with their 
father? Do low levels of social support and a poor relationship with father influence a person's attribution style? or, more likely, do these variables interact in some way; and what is the effect of this interaction on their coping level? Unfortunately, the present data do not provide information about causal relationships. However, it does seem reasonable to speculate that the relationship between the amount of psychological help received and attribution style reflects the attempt of a person with a negative attributional style to seek relief from the psychological distress that tends to accompany it.

\section{The Role of Social support}

The victimized women felt that having social supports was extremely important to them to help them cope with their victimization experience(s). The data support these subjective reports and the predictions made on the basis of the sexual abuse, rape and social support literature. That is, a high level of social support was found to be significantly correlated with higher self-esteem and less depression. Increased helpfulness of social supports was correlated with high self-esteem, and reciprocity of the supportive relationships was correlated with less depression, fewer psychological symptoms, fewer sexual problems and greater sexual arousal. When both groups of subjects were combined, a similar pattern of relationships was found. 
The canonical correlations also indicate that social support variables are related to coping level. A pattern of coping which included psychological distress and sexual problems was related to social support patterns which included low levels of social support, little reciprocity and helpfulness of the social support network and high levels of psychological help received. A second weaker correlation indicated that a pattern of psychological distress without sexual problems was related to less close relationship with mother and much psychological help received. When combined with some of the victimization and attribution style variables, the social support variables contribute to the third set of canonical correlations between victimization and social support variables. That is, sexual problems were related to closeness to mother, little reciprocity and helpfulness of supports and a negative perception of the victimization experience. It should be reiterated that victims considered their social support systems to be as large and effective as those of the nonvictims, therefore these relationships may not be specific to victims of sexual abuse. Overall, these results suggest that people who have strong relationships with their social networks may have fewer sexual problems. This is particularly true for women who feel that their relationships are reciprocal. The reciprocity variable may be measuring the ability of these women to have intimate or close relationships with other people which is then related to and reflected in the measures of 
their ability to have satisfactory sexual relationships.

There is also some suggestion that a victimized woman's relationships with her parents in the past are differentially related to coping level in the present. There are significant correlations between having a close relationship with mother and less depression, and between having a close relationship with father and increased self-esteem and fewer sexual problems, both for victims and when both groups are combined. The relationship between a victim of childhood sexual abuse, especially an incest victim, and her parents should be explored further. Data suggest that incest victims are more likely to have poor relationships with their parents as children than are victims of nonfamily abuse. Particular attention should be paid to these relationships during the girl's childhood and adolescence to determine which elements of the parent-child relationship are related to adult coping problems.

There appears to be a specific relationship between closeness to parents and adult sexual functioning which also warrants further examination. Closeness to father appears to be related to good sexual functioning whereas closeness to mother appears to be related to poor sexual functioning. There are several possible explanations of these relationships. One might speculate that victims who have negative perceptions of their experience and who are supported mainly by their mother, may have 
difficulty with separation from her. This may cause problems with individuation and interfere with the normal developmental process, including peer and sexual relationships. It is also possible that the mothers of these women were sexually or physically abused themselves. As a result, they may have difficulty with their sexual functioning and with their mothering skills. In such cases the victim would not have an appropriate role model for positive social and sexual functioning and might have difficulty in these areas. These issues cannot be examined in the present study because many of the relevant variables confuse important elements, for example, present and past relationships with each parent were combined into a single variable. Expectation of parents' behavior and parents' actual behavior has also been confounded, therefore further study of these important relationships is indicated.

Psychological help received is also related to the coping patterns previously described. Contrary to the predictions made, for both groups of subjects this measure is correlated with distress, sexual problems and low self-esteem, not with successful resolution of problems. This may be due to the fact that this measure was constructed of three items which asked whether the person had ever been in therapy, was presently in therapy and had ever been hospitalized for a psychological problem. No qualitative aspects of therapy were examined such as length of treatment, successful completion of therapy, perception 
of helpfulness of therapy, etc. Also, it may be that those women who sought help were most severely affected by the experience and although their level of distress may have decreased, it is still significant.

\section{Treatment Implications}

The victims were well aware of the areas in which they have problems today: sexual relationships, interpersonal relationships (trust and intimacy), and feelings of guilt. The present research supports their perceptions in that sexual problems and guilt (as measured by attribution style for bad events) were common among victims. Trust was not measured directly, but the findings that: (a) the victims' perceptions that their social supports were not reciprocal or helpful to them was related to sexual problems; and (b) victims were more likely to have had poor relationships with their parents when they last lived with them than were nonvictims, suggest that the victims have interpersonal and intimacy problems.

The first step in therapy with a woman who was sexually abused as a child is probably to help her develop a trusting relationship with the therapist by providing a supportive environment and listening to her in an empathic and nonjudgmental way. Many of the women felt that they needed to explore the past, but this need was not always understood by 
their therapist. The results. of this study suggest that if the therapist listens to the woman's story about her experiences, especially her perception of the negativity of tne event, s/he will have an indication of the severity of the woman's problems.

Given that victimized women showed a pattern of blaming themselves for bad events which occur, the therapist should help the woman to recognize this self-defeating pattern of thoughts which feeds into her low self-esteem. Cognitive therapy techniques such as identification of the woman's automatic thoughts, reattribution of responsibility for events when they are not realistic by reviewing the facts, identifying double standards and challenging beliefs could be very helpful (see Beck, Rush, Shaw \& Emery, 1979). Group therapy techniques seem to be most useful to reduce the woman's feelings of isolation, to reduce her guilt feelings, increase her self-esteem and to help her to develop an ability to trust other people (e.g., Tsai \&. Wagner, 1978)。

One avenue which may be important for the therapist to explore with the client is her relationship with her parents both in the past and at present. It may be necessary for the therapist to help the woman separate from her mother if this has not been accomplished. It is also important for the woman to develop her ability to distance herself from the victimization experience and to realize that it is no longer necessary to feel responsible for it or to continue to feel and act like a victim. $A$ useful way to 
conceptualize this point is to realize that by taking responsibility for the abuse the woman in fact coped with it as best she could at the time. Accepting responsibility for the event gave her a feeling of control over her life and kept her from feeling helpless and giving up. If the offender was a family member, directing blame externally might have led to rejection and/or family disintegration. Also, the girl's coping style was congruent with her developmental level at the time. That is, she may not have been sufficiently cognitively sophisticated at the time to assess the behavior of the other person. For these reasons many women who were sexually abused prefer to refer to themselves as "survivors" rather than "victims". The essential point, however, is that the woman is no longer a child and has many more functional coping options available to her now. The therapist should therefore help her to separate past responses, which may have been adaptive at the time but are no longer adaptive and in fact may be interfering with functioning, from what responses can be nów.

It should be recognized that many sexually victimized women experience sexual problems, especially negative emotional reactions, lack of physiological arousal, and little sexual satisfaction. These symptoms appear to be related to trust and intimacy problems, and may be improved through the normal ccurse of therapy. Becker and colleagues (1982) suggest that the 
therapist focus on the cognitive factors which affect the victim's perception of sexual stimuli rather than on physiological responses per se.

\section{Limitations of the Present Study}

The results of the study appear to provide strong support for some of the hypotheses that were made. However, several limitations of the design should be recognized. First, although the sample is large and an attempt was made to recruit a crosssection of women to participate in the study, it is possible that the women who volunteered were not representative of either the populations of victimized or nonvictimized women. For example, the victims who participated in the study might be those women who are most severely affected by the abuse and want to have their cases heard and prevent others from sharing their misfortune. On the other hand, they may also represent women who have resolved some of their problems associated with the abuse through therapy and are now feeling strong enough to tell their stories and to try to help others. Similarly, the nonvictims may be a bright, well-educated subgroup of nonvictimized women who feel a desire to contribute to science and/or to help other women. Should the samples be biased in some way, then the generalizability of the findings to other sexually abused women is limited.

A second limitation of the study relates to the nature of 
the statistical procedures employed to analyze the data. It should be recognized that correlations and canonical correlation procedures cannot provide evidence of causal relationships among the variables. Although it would be helpful to present evidence that the victim's present level of distress and problems is "caused" by her attribution style, in fact only the association of these variables is suggested by the analyses, and an equally strong argument could be made that distress causes a negative attribution style (e.g., see Golin et al., 1981).

It asso must be recognized that in a retrospective study such as this one it is not possible to control for the effects of events which intervened between the victimization and the present assessment or for pre-existing psychological disturbances. There is evidence to suggest that pre-existing symptoms may be more important predictors of psychological symptoms than is social support level. Monroe (1983) demonstrated that al though social support appears to be related to psychological symptoms when a retrospective design is employed, and also in a prospective study when social support is related to follow-up symptoms without controlling for the effects of prior symptoms, in fact when prior symptoms are entered into a regression equation first, they alone predict follow-up symptoms. This problem again precludes making causal attributions about the factors which are related to present coping level. 
The confound of a retrospective design is acknowledged, but as discussed previously, the only obvious solution to this problem when studying the effects of childhood sexual victimization, is to undertake an enormous prospective study to evaluate who is at risk for abuse and for severe effects of it.

In this study, victimized women showed certain attribution styles and coping problems which differentiated them from the control group. However, because the groups also differed in the amount of psychological help which they received in the past, an argument could be made that the pattern of behavior displayed by the victims would not differentiate them from other clinical samples of women (i.e. $e_{\circ}$ women who had received similar amounts of therapy). Depression and low self-esteem are extremely common symptoms in clinical popoulations. Thus, no conclusions can be drawn about the types of problems displayed by these women without comparing them to a control group matched on this variable. Only the amount of distress displayed by the two groups can be meaningfully compared.

\section{Conclusions}

Evidence from the present study suggests that women who were sexually victimized as children or adolescents experience more coping problems, including depression and other psychological symptoms, low self-esteem and sexual problems, than do women who were not sexually victimized as children, and they have received 
more psychological help. Further, the victimized women experienced more violence at home as children and were more socially isolated from family and friends. They have have an attribution style which differs from that of the nonvictims and is marked by global and internal, stable, global attributions for bad events, external attributions for good events and a tendency to blame their character and behavior for bad events and not to blame others.

Results of the study indicate that the only factor of the victimization experience which is related to later coping is perception of the negativity of the experience. The actual events which occurred, the use of force by the offender, and aspects of the victim and/or offender (i.e., their ages or relationship) are not significantly related to later coping. Perceptions of mother's reactions or expected reaction also contributes to coping. Thus, the woman's perceptions about the abuse are the only victimization variables which affect later coping.

Social support, as measured by level of support from friends and family, amount of psychological help received, relationship to mother, reciprocity and helpfulness of social supports, is related to coping level. Interestingly, the social support variables appear to be specifically related to distress (depression and psychological symptoms) and to sexual problems, but not to self-esteem. Victimized women reported similar levels, 
reciprocity and helpfulness of social support as did nonvictims.

Attribution style appears to make the strongest contribution to coping level of any of the three variable sets. The combination of variables which loads most heavily on attribution style for bad events accounts for $64 \%$ of the variance in coping level. The attribution style variables tend to contribute to patterns of coping which are related to both distress and selfesteem, but not to sexual problems. Thus, although the results cannot be considered to be definitive, evidence suggests that the coping problems of women who were sexually victimized during childhood or adolescence (especially a pattern of distress and low self-esteem) are related to their attribution style. Particularly implicated is a woman's tendency to make internal, stable, global attributions for bad events and to blame her character and behavior for them.

At this point one cannot determine whether the woman's attribution style developed prior to the abuse or in response to it or whether there is an interaction between attribution style and sexual victimization experience. Learned helplessness theory suggests that individual differences in attribution style lead to susceptibility to pathology (e.g., Abramson et al., 1980; Abramson et al., 1978). The lack of a significant correlation between the victimization variables and the attribution style variables suggests that attribution style is independent of the victimization experience, but further research is needed to 
clarify this relationship.

The findings of this study support the view of coping presented by Lazarus and Launier (1978). It is worth repeating their point that "the ways people cope with stress are even more important to overall morale, social function, and health/illness than the frequency and severity of episodes of stress themselves" (p. 308). The victimized women in this research have demonstrated that how they perceive events, either the victimization experience or other events, is more important to their overall functioning than aspects the events themselves. This finding has specific implications for treatment of victimized women who experience coping problems. If their view of themselves and their experiences can be modified, then their level of distress should decrease and their self-esteen should increase.

\section{Future Directions}

Given the strong relationship found in the present study between attribution style and coping level, and the lack of relationships between victimization experience and coping level, and victimization and attribution style, several theoretical questions remain unanswered. How is the victimized woman's attribution style determined? Is it a function of her learning history prior to the abuse such as her disturbed family background, or is it modeled from her parents? In support of the 
latter view, Seligman and colleagues (Seligman, Peterson, Kaslow, Tanenbaum, Alloy \& Abramson, 1984) have found that attribution style for bad events and depressive symptoms of children were correlated with the attribution patterns and depression levels of their mothers, but not those of their fathers.

At least two approaches to pursuing these questions are possible. One is to undertake a large prospective study as previously suggested. Attribution style, social support, coping and victimization experiences could be assessed at various time periods and the relationships between subjects' responses and those of their parents could be examined over time. Of course the practicality of such a study is questionable given the amount of time required before completion and the expense involved in such large-scale research. However, it would generate a large volume of information, not only about the effects of sexual victimization, but also about many other aspects of development and family life.

A more expeditious method of exploring the causal relationships among these sets of variables would be to use causal modeling procedures (e.g., see Maruyama \& MoGarvey, 1980; Pedhazur, 1982, chap. 16). However, this procedure is not widely accepted by statisticians and as Maruyama and McGarvey (1980) point out, "although these techniques provide many advantages and advance the analysis of nonexperimental data, they are not sufficient to determine causality. Quite simply, they test the 
plausibility of competing theoretical models, with the hope of demonstrating the inadequacies of some theories" (p. 511). Thus, these techniques should be used with caution.

On a more practical level, the results of the present study have suggested that the victimized woman's relationships with her parents are important factors which are related to her adult functioning. However, this study was not able to clarify which elements of these relationships were most significantly related to adult functioning. It is important to explore several factors such as: (a) their relationships during different developmental periods; (b) the parent's behavior and the child's expectation of the parent's behavior; (c) the effect of the relationship with mother as opposed to the effect of the relationship with father; (d) the interaction between the type of abuse experienced and by whom, with the relationship between the child and her parents; and (e) whether mother was sexually victimized as a child and how this affects the child. All these areas must be examined further if we are to understand the determinants of victim coping problems, prevent coping problems in young girls who have been recently abused, and treat adult women who were abused as children and are experiencing problems.

An issue which was only briefly addressed in this study is the quality of interpersonal relationships of women who were sexually abused as children. Many women reported trust and 
intimacy difficulties. The assessment devices employed in this study, specifically the SRS, did not assess closeness of relationships as completely as is necessary to understand this area of the woman's functioning. Future research should address this issue as it has important implications for treatment of women who are experiencing problems, and it may be another factor which is related to depression and.low self-esteem.

Another important area of future research is evaluation of the effectiveness of specific interventions with this population of women. Ideally a therapist wants to find the most appropriate match between the client, his or her problem and the therapeutic approach employed. Several suggestions have been made in the present paper regarding treatment approaches which may prove useful with sexually victimized women, but the effectiveness of these approaches with this particular population has not been evaluated. 


\section{Footnotes}

1 There are a few exceptions such as Gagnon's (1965) report on a subsample $o_{\perp}$ wumen from the larger Kinsey study, Gundlach's (19/7) study of homosexual and heterosexual women, and Simari and Baskin's (1982) study of homosexual women and men. 
Abramson, L。, Garber, J., Edwards, No, \& Seligman, M. (1978). Expectancy changes in depression and schizophrenia. Journal of Abnormal Psychology, 87, 102-109.

Abramson, L॰, Garber, J., \& Seligman, M. (1980). Learned helplessness in humans: An attributional analysis. In J. Garber \& M. Seligman (Eds。), Human Helplessness: Theory and Applications (pp.3-34). New York: Academic Press. Abramson, L., \& Sackeim, H. (1977). A paradox in depression: Uncontrollability and self-blame. Psychological Bulletin, 84, 838-851.

Abramson, L., Seligman, M., \& Teasdale, J. (1978). Learned helplessness in humans: Critique and reformulation. Journal of Abnoraal Psychology, 87, 49-74.

American Psychiatric Association. (1980). The Diagnostic and Statistical Manual of Mental Disorders (3rd Edition). Washington, D.C.: APA.

Atkeson, B॰, Calhoun, $K_{\text {。 }}$, Resnick, P., \& Ellis, E. (1982). Victims of rape: Repeated assessment of depressive symptoms. Journal of Consulting and Clinical Psychology, 50, 96-102. Bailey, C. (1982, November). The victim's perspective. Paper presented at the Sexual Abuse of Children Conference, Winnipeg, Manitoba. 
Beck, A. (1972). Measuring depression: the depression inventory. In T. Williams, Mo Katz, and Jo Shields, (Edso), Recent Advances in the Biology of Depressive Illnesses (pp. 299-302). Washington: Government Printing Office.

Beck, A. (1978). Beck Inventory. Philadelphia: Center for Cognitive Therapy.

Beck, $A_{0}$, \& Beamesderfer, $A_{0}$ (1974). Assessment of depression: The depression inventory. Psychological Heasurements in Psychopharmacology. Modern Problems in Pharmacopsychiatry, 7, $151-169$.

Beck, A., Rush, A., Shaw, B., \& Emery, G. (1979). Cognitive Therapy of Depression. New York: The Guilford Press.

Becker, J., \& Abel, G. (1981). Behavioral treatment of victims of sexual abuse. In S. Turner, $K_{0}$ Calhoun, \& H. Adams (Eds。) Handbook of Clinical Behavior Therapy (pp. 347-379). New York: John Wiley and Sons.

Becker, J., Skinner, L., Abel, G., \& Treacy, E. (1982). Incidence and types of sexual dysfunctions in rape and incest victims. Journal of Sex and Marital Therapy, 8, 65-74.

Bender, L., \& Blau, A. (1937). The reaction of children to sexual relations with adults. American Journal of Orthopsychiatry, 7, 500-518.

Benward, J., \& Densen-Gerber, J. (1975). Incest as a causative factor in antisocial behavior: An exploratory study. 
Contemporary Drug Problems, 4, 323-340.

Berliner, Io (1982, November). Treatment of families where sexual abuse has occurred. Paper presented at the Sexual Abuse of Children Conference, Winnipeg, Manitoba.

Bowers, K. (1973). Situationalism in psychology: an analysis and a critique. Psychological Review, 80, 305-336.

Briere, J. (1984, April). The effects of childhood sexual abuse on later psychological functioning: Defining a post-sexual abuse syndrome. Paper presented at the Third National Conference on Sexual Victimization of Children, Children's Hospital National Medical Centre, Washington, D.C.

Bulman, Ro, \& Wortman, C. (1977). Attribution of blame and coping in the "real world": Severe accident victims react to their lot. Journal of Personality and Social Psychology, 35, 351363.

Burgess, Ao, \& Holmstrom, L. (1974). Rape trauma syndrome. American Journal of Psychiatry, 131, 981-986.

Burgess, $A_{0}$, \& Holmstrom, L. (1975). Sexual trauma of children and adolescents: Pressure, sex and secrecy. Nursing Clinics of North America, 10, 551-563.

Burgess, Ao, \& Holmstrom, Lo (1978). Recovery from rape and prior life stress. Research in Nursing and Bealth, 1, 165-174. Burgess, A., \& Holmstrom, L. (1979). Adaptive strategies and recovery from rape. American Journal of Psychiatry, 136, $1278-1282$. 
Carmen, E。, Rieker, Po, \& Mills, T。 (1984) Victims of violence and psychiatric illness. American Journal of Psychiatry, 141, 378-383.

Cobb, S. (1979). Social support and health through the life course. In M. Riley (Ed。), Aging from Birth to Death: Interdisciplinary Perspectives (pp. 93-106). Boulder, Colorado: Westview Press.

Cook, To, \& Campbell, D. (1979). Quasi-Experimentation: Design and Analysis Issues for Field Settings. Boston, Mass.: Houghton Mifflin Co.

Coyne, J., \& Gotlib, I. (1983) The role of cognition in depression: A critical appraisal. Psychological Bulletin, 94, 472-505.

Crowne, D., \& Marlowe, D. (1960). A new scale of social desirability independent of psychopathology. Journal of Consulting Psychology, 24, 349-354。

Crowne, D., \& Marlowe, D. (1964). The Approval Motive: Evaluative Dependence. New York: John Wiley \& Sons.

De Francis, V. (1971). Protecting child victims of sex crimes committed by adults. Federal Probation, 35, 15-20.

Derogatis, L॰, Lipman, R॰, Rickels, $K_{\circ}$, Uhlenhuth, E。, \& Covi, L. (1974). The Hopkins Symptom Checklist (HSCL): A self-report symptom inventory. Behavioral Science, 19, 1-15. Emslie, G., \& Rosenfeld, A. (1983) Incest reported by children 
and adolescents hospitalized for severe psychiatric problems. American Journal of Psychiatry, 140, 708-711.

Feather, No (1967). Some personality correlates of external control. Australian Journal of Psychology, 19, 253-260.

Finkelhor, D. (1979). Sezually Victimized Children. New York: The Free Press。

Freud, S. (1954). The Origins of Psychoanalysis: Letters to wilhelm Fliess. New York: Basic Books Inc.

Frieze, I. (1979). Perceptions of battered wives. In I. Frieze, D. Bar-Tal, Jo Carroll (Eds.), New Approaches to Social Problems (pp. 79-108). San Francisco: Jossey-Bass Publishers. Fritz, G., Stoll, K., \& Wagner, N. (1981). A comparison of males and females who were sexually molested as children. Journal of Sex and Marital Therapy, 7, 54-59.

Gagnon, J. (1965). Female child victims of sex offenses. Social Problems, 13, 176-192.

Garber, J., \& Hollon, S. (1980). Universal versus personal helplessness in depression: Belief in uncontrollability or incompetence. Journal of Abnormal Psychology, 89, 56-66. Golin, S., Sweeney, P., \& Shaeffer, D. (1981). The causality of causal attributions in depression: A cross-lagged panel correlation analysis. Journal of Abnormal Psychology , 90, 1422 .

Gong-Guy, E., \& Hammen, C. (1980). Causal perceptions of stressful events in depressed and nondepressed outpatients. 
Journal of Abnormal Psychology, 89, 662-669.

Gottlieb, B. (1983). Social support as a focus for integrative research in psychology. American Psychologist, 38, 278-287.

Gundlach, $R_{0}$ (1977). Sexual molestation and rape reported by homosexual and heterosexual women. Journal of Homosexuality, $2,367-384$.

Hammen, C., \& Cochran, S. (1981). Cognitive correlates of life stress and depression in college students. Journal of Abnormal Psychology, 90, 23-27.

Hammen, C., Krantz, S., \& Cochran, S. (1981). Relationships between depression and causal attributions about stressful life events. Cognitive Therapy and Research, 5, 351-358.

Harvey, D. (198I). Depression and attributional style: interpretations of important personal events. Journal of Abnormal Psychology, 90, 134-142.

Helmreich, Rop \& Stapp, J. (1974). Short form of the Texas Social Behavior Inventory (TSBI), an objective measure of selfesteem. Bulletin of the Psychonomic Society, 4, 473-475.

Herman, J. (1981). Father Daughter Incest. Cambridge, Mass。: Harvard University Press.

Herman, J., \& Hirschman, L. (1977). Father-daughter incest. Journal of Women in Culture and Society, 2, 735-756. Hudson, W., Harrison, D., \& Crosscup, D. (1981). A short-form scale to measure sexual discord in dyadic relationships. The 
Journal of Sex Research, 17, 157-174.

Husain, $A_{0}, \&$ Chapel, J. (1983) History of incest in girls admitted to a psychiatric hospital. American Journal of Psychiatry, 140, 591-593.

Ickes, W., \& Layton, M. (1978). Attributional styles. In J. Harvey, W. Ickes, $R_{0}$ Kidd (Eds。), New Directions in Attribution Research (Vol. 2) (pp. 119-152). Hillsdale, N.J.: Lawrence Erlbaum Associates. James, J., \& Meyerding, J. (1977). Early sexual experience as a factor in prostitution. Archives of Sexual Behavior, 7, 31-42. James, K. (1977). Incest: The teenager's perspective. Psychotherapy: Theory, Research and Practice, 14, 146-155. Janoff-Bulman, R. (1979). Characterological versus behavioral self-blame: Inquiries into depression and rape. Journal of Personality and Social Psychology, 37, 1798-1809.

Joe, V. (1971). Review of the internal-external control construct as a personality variable. Psychological Reports, 28, 619-640. Kaufman, I., Peck, A., \& Tagiuri, C. (1954). The family constellation and overt incestuous relations between father and daughter. American Journal of Orthopsychiatry, 24, 266179.

Kinsey, A., Pomeroy, W., Martin, C., \& Gebhard, P. (1953). Sexual Behavior in the Human Female. Philadelphia: W. B. Saunders Company . Kuiper, No (1978). Depression and causal attributions for success 
and failure. Journal of Personality and Social Psychology, 36, 236-246.

Landis, J. (1956). Experiences of 500 children with adult sexual deviation. Psychiatric Quarterly Supplement, 30, 91-109.

Lazarus, Ro, \& Launier, $R_{0}$ (1978). Stress-related transactions between person and environment. In L. Pervin \& M. Lewis, Perspectives in Interactional Psychology (pp. 287-327). New York: Plenum Press.

Lefcourt, H. (1980). Personality and locus of control. In J. Garber \& M. Seligman (Eds.), Human Helplessness: Theory and Applications (pp. 245-259). New York: Academic Press. Lewinsohn, P., Steinmetz, J., Larson, D., \& Franklin, J. (1981). Depression-related cognitions: Antecedent or consequence. Journal of Abnormal Psychology, 90, 213-219.

Libow, J., \& Doty, D. (1979). An exploratory approach to selfblame and self-derogation by rape victims. American Journal of Orthopsychiatry, 49, 670-679.

Maisch, H. (1972). Incest. New York: Stein \& Day. Marascuilo, L., \& Levin, J. (1983). Multivariate Statistics in the Social Sciences: A Researcher's Guide. Monterey, Calif.: Brooks/Cole Publishing Co.

Maruyama, Go, \& McGarvey, Bo (1980). Evaluating causal models: an application of maximum-likelihood analysis of structural equations. Psychological Bulletin, 87, 502-512. 
Masson, J. (1984, February). Freud and the seduction theory. The Atlantic Monthly, 33-60.

McFarlane, Ao, Neale, Ko, Norman, Go, Roy, Ro, \& Streiner, D. (1981). Methodological issues in developing a scale to measure social support. Schizophrenia Bulletin, 7, 90-100.

MoGuire, Io, \& Wagner, No (1978). Sexual dysfunction in women who were molested as children: One response pattern and suggestions for treatment. Journal of Sex and Marital Therapy, 4, 11-15.

Medea, $A_{0}$, \& Thompson, $A_{0}$ (1974). Against Rape. New York: Farrar, Straus \& Giroux.

Meiselman, Ko (1978). Incest: A Psychological Study of causes and Effects with Treatment Recommendations. San Francisco: JosseyBass Publishers.

Meiselman, Ko (1980). Personality characteristics of incest history psychotherapy patients: A research note. Archives of Sexual Behavior, 9, 195-197.

Metalsky, Go, \& Abramson, Io (1981). Attributional styles: Toward a framework for conceptualization and assessment. In $P_{0}$ Kendall \& S. Hollon (Eds.), Assessment strategies for Cognitive-Behavioral Interventions (pp. 13-57). New York: Academic Press.

Miller, I॰, \& Norman, W. (1979). Learned helplessness in humans: A review and attribution theory model. Psychological Bulletin 86, 93-118. 
Monroe, S. (1983). Social support and disorder: Toward an untangling of cause and effect. American Journal of Community Psychology, 11, 81-97.

Norris, Jo, \& Feldman-Summers, S. (1981). Factors related to the psychological impact of rape on the victim. Journal of Alonormal Psychology, 90, 562-567.

Notman, Mor \& Nadelson, C. (1976). The rape victim: Psychodynamic considerations. American Journal of Psychiatry, 133, 408-418. Paulson, M. (1978). Incest and sexual molestation: Clinical and legal issues. Journal of Clinical Child Psychology, 177-180. Pearlin, L., \& Schooler, C. (1978). The structure of coping. Journal of Bealth and Social Behavior, 19, 2-21.

Pedhazur, E. (1982). Multiple Regression in Behavioral Research: Explanation and Prediction (2nd ed.). New York: Holt, Rinehart and Winston.

Peterson, Co, Schwartz, So, \& Seligman, M。 (1981). Self-blame and depressive symptoms. Journal of Personality and Social Psychology, 41, 253-259.

Peterson, $C_{0}$, Semmel, $A_{0}$, von Baeyer, $C_{0}$, Abramson, $I_{0}$, Metalsky, G., \& Seligman, M. (1982). The attributional style questionnaire. Cognitive Therapy and Research, 6, 287-300. Raps, C., Peterson, C., Reinhard, K., Abramson, L., \& Seligman, M. (1982). Attributional style among depressed patients. Journal of Abnormal Psychology, 91, 102-108. 
Rizley, R。 (1978). Depression and distortion in the attribution of causality. Journal of Abnormal Psychology, 87, 32-48. Rotter, J. (1966). Generalized expectancies for internal versus external control of reinforcement. Psychological ronographs, $80,1-28$.

Sarason, I, Levine, H॰, Bashamp R॰, \& Sarason, B. (1983). Assessing social support: The social support questionnaire. Journal of Personality and Social Psychology, 44, 127-139.

Schover, L॰, Friedman, J., Weiler, S., Heiman, J., \& LoPiccolo, J. (1982). Multiaxial problem-oriented system for sexual dysfunctions: An alternative to DSM-III. Archives of General Psychiatry, 9 614-619.

Seligman, M॰, Abramson, L., Semmel, A॰, \& von Baeyer, C. (1979). Depressive attributional style. Journal of Abnormal Psychology, 88, 242-247.

Seligman, M., Peterson, C., Kaslow, No, Tanenbaum, R., Alloy, L. \& Abramson, L。 (1984). Attributional style and depressive symptoms among children. Journal of Abnormal Psychology, 93, $235-238$.

Silver, Ro, Boon, Co, \& Stones, $H_{0}$ (1983). Searching for meaning in misfortune: Making sense of incest. Journal of Social Issues, 39, 81-102.

Silver, Ro, \& Wortman, C. (1980). Coping with undesirable life events. In J. Garber \& $M_{0}$ Seligman (Eds.), Human Helplessness: Theory and Applications (pp. 279-340). New York: Academic 
Press.

Simari, Co, \& Baskin, D. (1982). Incestuous experiences within homosexual populations: A preliminary study. Archives of Sexual Behavior, 11, 329-344.

Tsai, M॰p Feldman-Summers, S。, \& Edgar, M。 (1979). Childhood molestation: Variables related to differential impacts on psychosexual functioning in adult women. Journal of Abnormal Psychology, 88, 407-417.

Tsai, M., \& Wagner, N. (1978). Therapy groups for women sexually molested as children. Archives of Sexual Behavior, 7, 417-427. Welner, B. (1972). Theories of Motivation: From Mechanism to Cognition. Chicago: Markham Publishing Co.

Weiner, I. (1962). Father-daughter incest: A clinical report. The Psychiatric Quarterly, 36, 607-632.

Wortman, C. (1976). Causal attributions and personal control. In J. Harvey, Wo Ickes, Ro Kidd (Eds。) New directions in Attribution Research (Volume 1) (pp. 23-52). Hillsdale, New Jersey: Lawrence ErIbaum Associates.

Zuroff, D. (1980). Learned helplessness in humans: An analysis of learning processes and the roles of individual and situational differences. Journal of Personality and Social Psychology, 39, $130-146$. 
APPENDIX A

Advertisement and Description of the Study 
Advertisement

Women needed to participate in research investigating the effects of early sexual experiences on adult functioning. The study is being conducted by Erica Gold, M.A., doctoral candidate in Clinical Psychology at the University of Manitoba. All responses are strictly confidential. Approximately two hours of participation is required at your convenience. Call evenings or weekends. 


\section{WOM E N}

Women 18 years of age and older are needed to participate in research which is being conducted to investigate the effects of early sexual experiences on a woman's adult functioning. The study will provide information about the psychological effects of sexual experiences during childhood which will be used to provide the best possible treatments for women in distress.

The researcher is a doctoral candidate in $\mathrm{Cl}$ inical Psychology at the University of Manitoba working under the direction of Dr. Lillian Esses and has had several years of clinical experience.

We understand that questions about your family and sexuality are very personal. All responses will be strictly confidential. You need never disclose your full name and none of the materials ask questions that might identify you indirectly. All materials will be guarded with the utmost care and no one but the researchers will have access to them. You may choose to withdraw your participation at any time throughout the study.

Approximately two hours of your time will be required to complete questionnaires and talk with the the researcher. All interviews will be conducted at the University of Western Cntario at a time which is convenient for you.

If you are interested in participating in this important research please contact Erica Gold at \$72-3305 any evening or weekend. 
APPENDIX B

Informed Consent Form and Experimental Questionnaire 


\section{Questionnaire}

\section{Dear Participant:}

We would like you to participate in this study of early sexual behavior by filling out this questionnaire.

Some of the questions here are very personal. Because they are personal, social scientists have been reluctant to investigate them in the past. But as you are certainly aware, family life has been undergoing profound changes in recent years, as have people's attitudes toward sex. If social scientists are to try to help families become healthier environments for living and growing up, if we are to attempt to answer important questions about the effects of sexual abuse, incest, rape and sexual molestation during childhood and adolescence, we need to know about these personal things.

The questionnaire includes questions about sexual attitudes and sexual experiences, as well as questions about your family and your present functioning. Some of the information that you will be providing here is not information that you would want other people to know. It may be personally embarassing or painful. It may involve people beside yourself, who would not want information divulged. Some of the things you are reporting may be against the law. This gives you an idea of how sensitive an area this is. Consider carefully whether you really want to participate.

We hope that with this in mind, and the knowledge that everything you answer here is anonymous, you will decide to participate. However, we want you to be aware that by law in ontario anyone who becomes aware of a situation of potential child abuse has a legal obligation to inform the Children's Aid Society. Therefore, although we are not asking direct questions about children who may be at risk, you should know that if you inform us of any situation in which a child is presently being sexually abused or is at risk of being sexually abused we will have to report the situation to the proper authorities. Moreover, for your own information, you may also be under a legal obligation to inform the Children's Aid Society if you have reason to believe that a child is being subject to sexual abuse. With this exception, we will keep the information that you give us confidential. 
Given the personal nature of the study, we want to tell you the steps that we are taking to safeguard your privacy.

First of all, you are under no obligation to participate. Much as we would like your cooperation, you should feel free not to fill out the questionnaire. In fact, if at any point while filling out the questionnaire you decide that you no longer wish to participate, you may stop where you are and fill out no more. Moreover, if there are any particular questions which you want to skip, you may do so.

Secondly, all questionnaires are completely anonymous. Nowhere on the questionnaire do we ask for your name and we have carefully avoided asking questions that might identify you indirectly. All questionnaires will be guarded by us with the utmost care. No one but the researchers will have access to them.

Thirdly, because of the sensitive nature of the research, it is important that we have your fully informed consent to use your questionnaire. If you choose to participate, make a check in the box below indicating your consent.

Thank you for your cooperation.

I have read the above and I agree to participate [ ]

I have read the above and decided not to participate [ ]

I heard about this study from: (circle one number)

1. An advertisement in a newspaper. Which paper?

2. My therapist. Name of agency (if appI icable)

3. My group leader. The group is run by (name of agency) in (city).

4. A notice posted on a bulletin board. Where? 
PART A

1. Your age at last birthday

2. Present marital status (circle one answer number):

1. Single

2. Married

3. Separated or divorced

4. Widowed

3. Number of times you have been married:

1. Never

2. Once

3. Twice

4. Three or more times

4. How many children do you have?

5. How many children presently live with you?

6. What is your present occupation and the occupation of your spouse?

Self

Spouse

7. What is your annual income and your spouse's annual income before taxes? Self Spouse

$\begin{array}{lll}0 & 0 & \text { Not employed } \\ 1 & 1 & \text { less than } \$ 10,000 \\ 2 & 2 & \$ 10,000 \text { to } \$ 19,999 \\ 3 & 3 & \$ 20,000 \text { to } \$ 29,999 \\ 4 & 4 & \$ 30,000 \text { to } \$ 39,999 \\ 5 & 5 & \$ 40,000 \text { to } \$ 49,999 \\ 6 & 6 & \$ 50,000 \text { and over } \\ X & x & \text { Don't know }\end{array}$

8. What is the highest level of education that you and your spouse have attained?

$\begin{array}{ccl}\text { Self } & \text { Spouse } & \\ 1 & 1 & \text { Some grade school } \\ 2 & 2 & \text { Completed grade school } \\ 3 & 3 & \text { Some high school } \\ 4 & 4 & \text { Completed high school } \\ 5 & 5 & \text { High school and some other training but not college } \\ 6 & 6 & \text { Some college } \\ 7 & 7 & \text { Completed college } \\ 8 & 8 & \text { Some graduate work } \\ 9 & 9 & \text { Graduate or professional degree }\end{array}$

We would like to gather some information about members of your family. 
9. a. Is your father:

1. Living with your mother

2. Divorced or separated from her

3. Widowed

4. Living apart for some other reason

5. Deceased

b. When you last lived with your father, how close did you feel to him?

1. Very close

2. Close

3. Somewhat close

4. Not close

5. Distant

10. Did you also have a stepfather?

1. Yes 2. No (If no, go to question 11)

a. Is your stepfather:

1. Living with your mother

2. Divorced or separated from your mother

3. Widowed

4. Living apart for some other reason

5. Deceased

b. When you last lived with him, how close did you feel to him?

1. Very close

2. Close

3. Somewhat close

4. Not close

5. Distant

11. a. Is your mother:

1. Living with your father

2. Divorced or separated from your father

3. Widowed

4. Living apart for some other reason

5. Deceased

b. When you last lived with her, how close did you feel to her?

1. Very close

2. Close

3. Somewhat close

4. Not close

5. Distant

12. Did you also have a stepmother?

1. Yes 2. No (If no, go to question 13)

a. Is she:

1. Living with your father

2. Divorced or separated from your father

3. Widowed

4. Living apart for some other reason

5. Deceased

b. When you last lived with her, how close dia you feel to her?

1. Very close

2. Close

3. Somewhat close

4. Not close

5. Distant 
13. When you were 12 did you have:

1. Many good friends

2. A few good friends

3. One or two good friends

4. No good friends

PART B

It is now generally realized that most people have sexual experiences as children and while they are still growing up. Some of these are with friends and playmates, and some with relatives and family members. Some are very upsetting and painful, and some are not. Some influence people's later lives and sexual experiences, and some are practically forgotten. Although these are often important events, very little is actually known about them.

We would like you to try to remember the sexual experiences you had while growing up. By "sexual", we mean a broad range of things, anything from playing "doctor" to sexual intercourse - anything that might have seemed sexual to you.

14. Did you have any of the following experiences before the age of 12 ? (Circle any that apply。)

a. An invitation or request to do something sexual.

b. Kissing and hugging in a sexual way.

c. Another person showing you his/her sex organs.

d. You showing your sex organs to another person.

e. Another person fondling you in a sexual way.

f. You fondling another person in a sexual way.

g. Another person touching your sex organs in a sexual way.

$\mathrm{h}$. You touching another person's sex organs in a sexual way.

i. Intercourse, but without attempting penetration.

j. Intercourse.

k. Other

Now we want to ask you to think of three sexual experiences - or however many up to three - that you had before the age of 12 with an adult or adolescent over 12 including strangers, friends or family members like cousins, aunts, uncles, brothers, sisters, mother or father. Choose the three most important to you and answer the following questions.

15. How many such experiences did you have? (If none, go to question 34 .)
With regard to the first experience:
Experience
\#1
Experience
$\# 2$
Experience
\#3

16. About how old were you at the time?

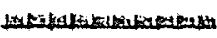

17. About how old was the other person?

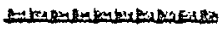

+58

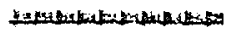

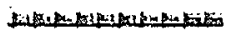


18. Was the other person:

Circle 1 for male

2 for female

1

12

1

21

2

19. Was the other person:
a stranger
a person you knew, but not a friend
a friend of yours
a friend of your parents
a cousin
an uncle or aunt
a grandparent
a brother
a sister
a father
a stepfather
a mother
a stepmother
a guardian

$\frac{1}{2}$

$\begin{array}{rrr}1 & 1 & 1 \\ 2 & 2 & 2 \\ 3 & 3 & 3 \\ 4 & 4 & 4 \\ 5 & 5 & 5 \\ 6 & 6 & 6 \\ 7 & 7 & 7 \\ 8 & 8 & 8 \\ 9 & 9 & 9 \\ 10 & 10 & 10 \\ 11 & 11 & 11 \\ 12 & 12 & 12 \\ 13 & 13 & 13 \\ 14 & 14 & 14\end{array}$

20. What happened?

a. An invitation or request to do something sexual.

b. Kissing and hugging in a sexual way.

c. Another person showing you his/her sex organs.

d. You showing your sex organs to another person.

e. Another person fondling you in a sexual way.

f. You fondling another person in a sexual way.

g. Another person touching your sex organs in a sexual way.

h. You touching another person's sex organs in a sexual way.

i. Intercourse, but without attempting penetration.

j. Intercourse.

$\mathrm{k}$. Other \# $I_{\text {. }}$

$\begin{array}{rrrrrr}\text { Yes } & \text { No } & \text { Yes } & \text { No } & \text { Yes } & \text { No } \\ 1 & 0 & 1 & 0 & 1 & 0 \\ 1 & 0 & 1 & 0 & 1 & 0 \\ 1 & 0 & 1 & 0 & 1 & 0 \\ 1 & 0 & 1 & 0 & 1 & 0 \\ 1 & 0 & 1 & 0 & 1 & 0 \\ 1 & 0 & 1 & 0 & 1 & 0 \\ 1 & 0 & 1 & 0 & 1 & 0 \\ 1 & 0 & 1 & 0 & 1 & 0 \\ 1 & 0 & 1 & 0 & 1 & 0 \\ 1 & 0 & 1 & 0 & 1 & 0\end{array}$

$\# 2$

\#3

ian

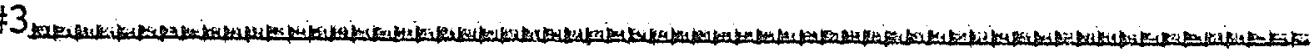

21. Who started this? I. You 2. Other person

12

12

12

22. Did the other person threaten or force you? 1. Yes 2. A little

3. No

$\begin{array}{lllllllll}1 & 2 & 3 & 1 & 2 & 3 & 1 & 2 & 3\end{array}$


23. Did you threaten or force the other person? 1. Yes 2. A little 3. No

$\begin{array}{lllllllll}1 & 2 & 3 & 1 & 2 & 3 & 1 & 2 & 3\end{array}$

24. About how many times did you have a sexual experience with this person?

$2 x+100=0$

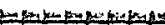

25. Over how long a time did this go on?

(Indicate number of days, months, years.)

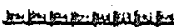

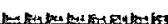

26. Which of these would best describe your reaction at the timeofthe experience?

1. Fear 2. Shock 3. Surprise

4. Interest 5. Pleasure

$12345 \quad 12345 \quad 12345$

27. Who did you tell about this experience

if anyone?

1. No one

2. Mother

3. Father

4. Brother/sister

5. Friend

6. Therapist/counselor

7. Police

8. Other adult

$\begin{array}{lll}1 & 1 & 1 \\ 2 & 2 & 2 \\ 3 & 3 & 3 \\ 4 & 4 & 4 \\ 5 & 5 & 5 \\ 6 & 6 & 6 \\ 7 & 7 & 7 \\ 8 & 8 & 8\end{array}$

28. If mother, how did she react? (If you did not tell your mother, how do you think she would have reacted?)
a. Angry at you
1. Very 2. Mildly

3. A little 4. Not at all 1234

b. Supportive of you 1. Very

2. Mildly 3. A little 4. Not at all 1234

1234

1234

1234

1234

29. If father, how did he react? (If you

did not tell your father, how do you

think he would have reacted?)

a. Angry at you 1. Very 2. Mildly

3. A little 4. Not at al

b. Supportive of you 1. Very

2. Mildly 3. A little 4. Not at all $1234 \quad 1234 \quad 1234$

30. In retrospect, would you say that this experience was

1. Positive 2. Mostly positive

3. Neutral 4. Mostly negative

5. Negative

31. Did you see the experience as

1. A challenge 2. A threat

32. Have you been able to find some meaning for this experience?

1. None 2. Some 3. Very much

$\begin{array}{lllllllll}1 & 2 & 3 & 1 & 2 & 3 & 1 & 2 & 3\end{array}$ 
35. At the time whom did you feel was mostly responsible for causing this experience? 1. You 2. The other person 3. Your mother 4. Your father 5. Someone else 123451234512345

Now go back to question 16 and answer the questions about Experience \#2.

Now go back to question 16 and answer the questions about Experience \#3

Now we would like you to think of sexual experiences that you had after the age of 12 with an adult, which you did not consent to. That is, a sexual experience which was forced on you, or done against your will, or which you didn't want to happen. This includes experiences with strangers, friends and relatives, such as cousins, uncles, aunts, brothers, sisters, grandparents, mother or father, or a guardian or close friend of a parent. (If this relationship was described in the previous section, do not repeat it.) Choose the three most important to you and answer the following questions.

34. How many such experiences did you have?

(If none, go to question 53.)

With regard to the first experience:

Experience

\#I

35. About how old were you at the time?

36. About how old was the other person?

37. Was the other person:

Circle I for male

2 for female

12
38. Was the other person:
a stranger
a person you knew but not a friend
a friend of yours
a friend of your parents
a cousin
an uncle or aunt
a grandparent
a brother
a sister
a father
a stepfather
a mother
a stepmother
a guardian

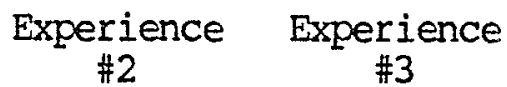

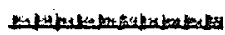

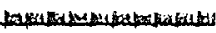

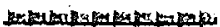

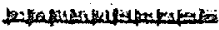

$\begin{array}{rr}1 & 1 \\ 2 & 2 \\ 3 & 3 \\ 4 & 4 \\ 5 & 5 \\ 6 & 6 \\ 7 & 7 \\ 8 & 8 \\ 9 & 9 \\ 10 & 10 \\ 11 & 11 \\ 12 & 12 \\ 13 & 13 \\ 14 & 14\end{array}$


39. What happened?

a. An invitation or request to do something sexual.

b. Kissing and hugging in a sexual way.

c. Another person showing you his/her sex organs.

d. You showing your sex organs to another person.

e. Another person fondling you in a sexual way.

f. You fondling another person in a sexual way.

g. Another person touching your sex organs in a sexual way.

h. You touching another person's sex organs in a sexual way.

i. Intercourse, but without attempting penetration.

j. Intercourse.

$\begin{array}{rrrrrr}\text { Yes } & \text { No } & \text { Yes } & \text { No } & \text { Yes } & \text { No } \\ 1 & 0 & 1 & 0 & 1 & 0 \\ 1 & 0 & 1 & 0 & 1 & 0 \\ 1 & 0 & 1 & 0 & 1 & 0 \\ 1 & 0 & 1 & 0 & 1 & 0 \\ 1 & 0 & 1 & 0 & 1 & 0 \\ 1 & 0 & 1 & 0 & 1 & 0 \\ 1 & 0 & 1 & 0 & 1 & 0 \\ 1 & 0 & 1 & 0 & 1 & 0 \\ 1 & 0 & 1 & 0 & 1 & 0 \\ 1 & 0 & 1 & 0 & 1 & 0\end{array}$

$\# 2$

\#3

40. Who started this? 1. You 2. Other person
12
12
12

41. Did the other person threaten or force you? 1. Yes 2. A little 3. No

$\begin{array}{lllllllll}1 & 2 & 3 & 1 & 2 & 3 & 1 & 2 & 3\end{array}$

42. Did you threaten or force the other person? 1. Yes 2. A little 3. No

$\begin{array}{lllllllll}1 & 2 & 3 & 1 & 2 & 3 & 1 & 2 & 3\end{array}$

43. About how many times did you have a sexual experience with this person?

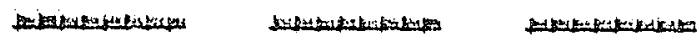

44. Over how long a time did this go on?

(Indicate number of days, months, years.)

to:

$0 \cos 20$

45. Which of these would best describe your reaction at the time of the experience?
1. Fear
2. Shock 3. Surprise
4. Interest 5. Pleasure
$12345 \quad 12345 \quad 12345$

46. Who did you tell about this experience if anyone?

1. No one

2. Mother

3. Father

4. Brother/sister

5. Friend 
6. Therapist/counselor

7. Police

8. Other adult

$\begin{array}{lll}6 & 6 & 6 \\ 7 & 7 & 7 \\ 8 & 8 & 8\end{array}$

47. If mother, how did she react? (If you

did not tell your mother, how do you

think she would have reacted?)

a. Angry at you 1. Very 2. Mildly

3. A little 4. Not at all 12344 I $234 \quad 1234$

b. Supportive of you 1. Very

2. Mildly 3. A little 4. Not at all $1234 \quad 1234 \quad 1234$

48. If father, how did he react? (If you

did not tell your father, how do you

think he would have reacted?)

a. Angry at you 1. Very 2. Mildly

3. A little 4. Not at all $12334 \quad 1234 \quad 1234$

b. Supportive of you 1. Very

2. Mildly 3. A little 4. Not at all $1234 \quad 1234 \quad 1234$

49. In retrospect, would you say that this

experience was

1. Positive 2. Mostly positive

3. Neutral 4. Mostly negative

5. Negative

$12345 \quad 12345 \quad 12345$

50. Did you see the experience as

1. A challenge 2. A threat

$\begin{array}{llllll}1 & 2 & 1 & 2 & 1 & 2\end{array}$

51. Have you been able to find some

meaning for this experience?

1. None 2. Some 3. Very much

$\begin{array}{lllllllll}1 & 2 & 3 & 1 & 2 & 3 & 1 & 2 & 3\end{array}$

52. At the time whom did you feel was mostly responsible for causing this experience?

1. You 2. The other person 3. Your

mother 4. Your father 5. Someone else 123451234512345

Now go back to question 35 and answer the questions

about Experience \#2.

Now go back to question 35 and answer the questions about Experience \#3

PART C

53. Everyone gets into conflicts with other people and sometimes these lead to physical blow such as hitting really hard, kicking, punching, stabbing throwing someone down, etc. the following items ask about how often these 
things happened to you, and how often you saw them happen to others. Try to remember these events for a year when you were around 12. Use the following code:

$0=$ Never

$1=$ Once

$2=$ Twice

$3=3-5$ times

$4=6-10$ times

$5=11-20$ times

$6=$ More than 20 times

$\mathrm{X}=$ no such person in the family

During that one year:

a. One of my brothers or sisters did this to me.

b. A brother/sister did to another brother/sister.

c. I did to a brother or sister.

d. My father did to me.

e. My father did to a brother or sister.

f. My mother did to me.

g. My mother did to a brother or sister.

h. Father did to mother.

i. Mother did to father.

$\begin{array}{llllllll}0 & 1 & 2 & 3 & 4 & 5 & 6 & X \\ 0 & 1 & 2 & 3 & 4 & 5 & 6 & X \\ 0 & 1 & 2 & 3 & 4 & 5 & 6 & X \\ 0 & 1 & 2 & 3 & 4 & 5 & 6 & X \\ 0 & 1 & 2 & 3 & 4 & 5 & 6 & X \\ 0 & 1 & 2 & 3 & 4 & 5 & 6 & X \\ 0 & 1 & 2 & 3 & 4 & 5 & 6 & X \\ 0 & 1 & 2 & 3 & 4 & 5 & 6 & X \\ 0 & 1 & 2 & 3 & 4 & 5 & 6 & X\end{array}$

54. When you were 12 years old, how often would your mother or father spank you?

$\begin{array}{ccl}\begin{array}{c}\text { Mother } \\ 1\end{array} & \begin{array}{c}\text { Father } \\ 1\end{array} & \text { Never } \\ 2 & 2 & \text { Once or twice } \\ 3 & 3 & \text { A few times each year } \\ 4 & 4 & \text { Once a month } \\ 5 & 5 & \text { Every week } \\ 6 & 6 & \text { More often than once a week } \\ \mathrm{X} & \mathrm{X} & \text { No such parent }\end{array}$

People often experience problems as they are growing up. Some of these difficulties may bring them into conflict with the law or result in a need for psychological or psychiatric help. The following questions ask about any such difficulties that you may have experienced as an adolescent or adult.

55. Use the following code to respond.

0 . Never

1. Less than once a year

2. Once a year

3. 2-3 times a year

4. Every couple of months

5. Once a month

6. 2-3 times a month

7. Once a week

8. 2-3 times a week

9. More thar 3 times a week

a. How often did you have a drink or two (but not get drunk) during your teenage years (ages 12 to 18)?

b. How often do you have a drink now?

$\begin{array}{llllllllll}0 & 1 & 2 & 3 & 4 & 5 & 6 & 7 & 8 & 9 \\ 0 & 3 & 2 & 3 & 4 & 5 & 6 & 7 & 8 & 9\end{array}$ 
c. How often did you get drunk during your teenage years?

d. How often do you get drunk now?

e. How often did you use marijuana as a teenager?

f. How often do you use marijuana now?

g. How often did you use other drugs (speed,

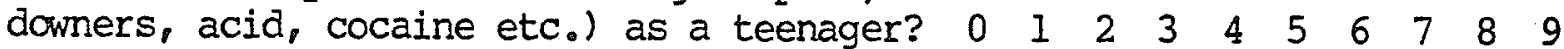

$h$. How often do you use these other drugs now? $00 \begin{array}{llllllllll} & 1 & 2 & 3 & 4 & 5 & 6 & 7 & 8 & 9\end{array}$

56. Were you ever arrested?

How many times?

0 . No 1. Yes

What was the charge?

57. Have you ever gone for counseling or therapy?

0. No

1. Yes

58. Are you currently in therapy?

If yes, is discussion of an early sexual

experience an aspect of your present therapy?

0 . No

1. Yes

0. No

1. Yes

59. Were you ever hospitalized for a psychological problem?

0 . Never

1. Once

2. Twice

3. Three or more times

PART D

The following questions ask about your sexual activities and attitudes.

60. Please indicate how you feel about each of the following statements.

a. Men often try to take advantage of women sexualiy

b. Masturabtion is unheal thy Agree Disagree

c. Sexual relations between two persons of the same sex are abnormal

d. Sex games among children are unhealthy

e. Sexual relations between brothers and sisters are unheal thy

f. Sexual relations between children and their parents are unheal thy

$\begin{array}{llll}1 & 2 & 3 & 4 \\ 1 & 2 & 3 & 4 \\ 1 & 2 & 3 & 4 \\ 1 & 2 & 3 & 4 \\ 1 & 2 & 3 & 4 \\ 1 & 2 & 3 & 4\end{array}$

61. Within the last year how many different sexual partners have you had?

1. None

2. $1-2$

3. $3-4$

4. $5-10$

5. more than 10 
62. Use the following code to respond to the next four questions.

1. More than once a day

2. Once a day

3. 3 - 4 times a week

4. Twice a week

5. Once a week

6. once every two weeks

7. Once a month

8. Less than once a month

9. Not at all

a. How often have you engaged in sexual intercourse with a person of the opposite sex during the past year?

b. How often have you engaged in sexual intercourse with a person of the same sex during the past year?

c. How often do you feel sexual desire?

d. How often do you masturbate?

63. When your partner makes sexual advances toward you, how do you usually respond?

1. Usually accept with pleasure

2. Accept reluctantly

3. Often refuse

4. Usually refuse

64. Use the following code to respond to the next six questions. 1. Nearly always, over $90 \%$ of the time

2. Usually, about 758 of the time

3. Sometimes, about $50 \%$ of the time

4. Seldom, about $25 \%$ of the time

5. Never

6 . Have never tried

a. When you have sex with your partner, do you feel sexually aroused (i.e., feeling "turned on", pleasure, excitement)?

b. When you have sex with your partner, including foreplay

and intercourse, do you notice some of these things happening: your breathing and pulse speeding up, wetness in your vagina, pleasurable sensations in your breasts and genitals?

c. When you have sex with your partner, do you have negative emotional reactions, such as fear, disgust, shame or guilt?

d. When you attempt intercourse is your vagina so "tight" or "dry" that intercourse cannot occur?

e. Do you feel pain in your genitals during intercourse?

f. If you try, is it possible for you to reach orgasm through the following means: masturbation sexual intercourse having your genitals caressed by your partner 
65. The following questions ask about your sexual relationship with your present partner. Use the following code to respond.

1 Rarely or none of the time

2 A little of the time

3 Some of the time

4 Good part of the time

5 Most or all of the time

1. I feel that my partner enjoys our sex life.

2. I feel that sex is something that has to be endured.

3. I feel that our sex life really adds a lot to our relationship.

4. I feel that my sex life is boring.

$\begin{array}{lllll}1 & 2 & 3 & 4 & 5 \\ 1 & 2 & 3 & 4 & 5 \\ 1 & 2 & 3 & 4 & 5 \\ 1 & 2 & 3 & 4 & 5\end{array}$

PART E

Below is a list of problems and complaints that people sometimes have. Read each one carefully, and select the response that best describes HOW MUCH DISCOAFORT THAT PRCBLER HAS CAISED YOU DURIMG THE PAST WEER IRCLUDING TODAY. Circle the appropriate number to the right of the problem using the code below. Do not skip any items.

$I=$ Not at all

$2=$ A little bit

3 = Quite a bit

4 = Extreme

1. Headaches..........................................1 $233^{4}$

2. Nervousness or shakiness inside........................ $22^{2} 34$

3. Repeated unpleasant thoughts that won't leave your mind........1 2 2 34

4. Faintness or dizziness.................................1 2 . 344

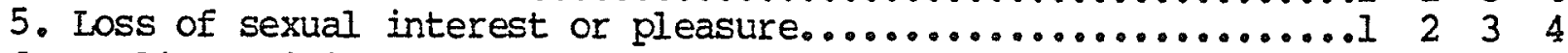

6. Feeling critical of others............................... 2 3. 4

7. Bad dreams...........................................1 $2{ }^{3} 4$

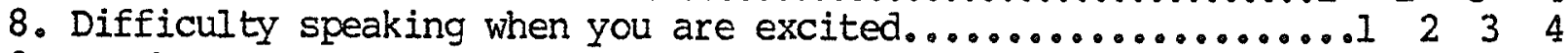

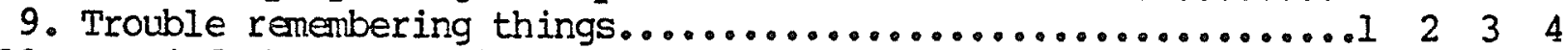

10. Worried about sloppiness or carelessness................... $22^{2} \quad 3 \quad 4$

11. Feeling easily annoyed or irritated.........................

12. Pains in the heart or chest...............................1 $23^{2} 3^{4}$

13. Itching............................................ $22^{2} 34$

14. Feeling low in energy or slowed down...................... $22^{2} 34$

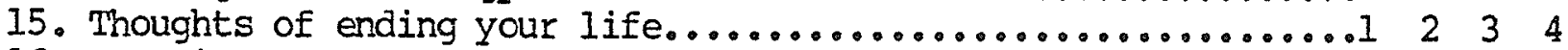

16. Sweating............................................1 $23^{2} 4$

17. Trembling......................................... $2{ }^{2} 34$

18. Feeling confused....................................1 $2{ }^{2} 34$

19. Poor appetite.......................................1 $23^{4} 4$

20. Crying easily.....................................1 $22^{2} 3^{4} 4$

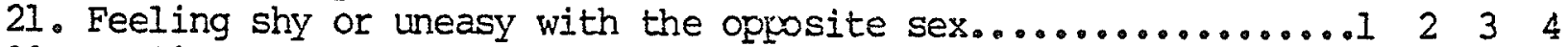

22. Feelings of being trapped or caught........................ 2 . 34

23. Suddenly scared for no reason............................... $22^{2} \quad 3 \quad 4$

24. Temper out bursts that you could not control................ $2{ }^{2} \quad 3 \quad 4$

25. Constipation........................................ $2{ }^{2} 3{ }^{4} 4$

26. Blaming yourself for things............................ $2{ }^{2} \quad 3 \quad 4$ 


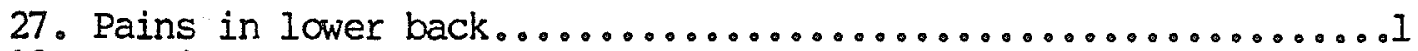

28. Feeling blocked in getting things done.....................

29. Feeling lonely .......................................

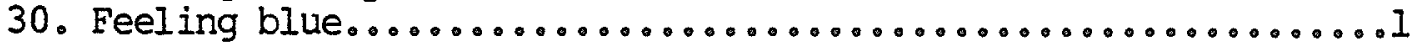

31. Worrying too much about things...........................

32. Feeling no interest in things...........................

33. Feeling fearful.....................................

34. Your feelings being easily hurt.........................

35. Having to ask others what you should do.....................

36. Feeling others do not understand you or are unsympathetic......

37. Feeling that people are unfriendly or dislike you..............

38. Having to do things very slowly to insure correctness..........

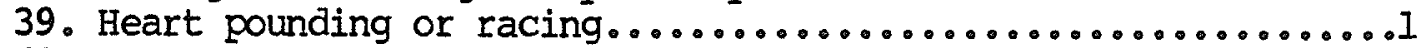

40. Nausea or upset stomach..............................1

41. Feeling inferior to others.............................

42. Soreness of your muscles................................1

43. Loose bowel movements...................................

44. Trouble falling asleep or staying asleep.................1

45. Having to check and double check what you do.................

46. Difficulty making decisions...........................1

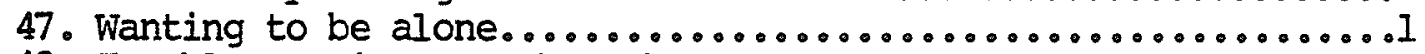

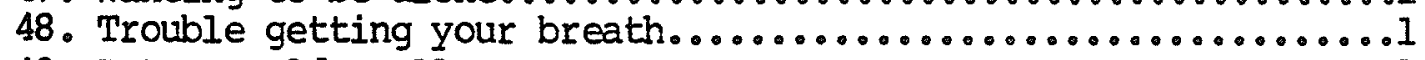

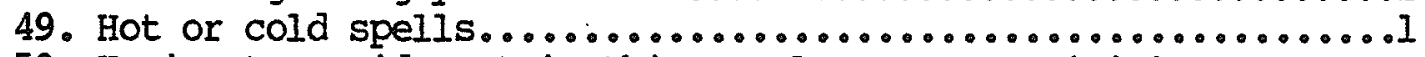

50. Having to avoid certain things, places, or activities

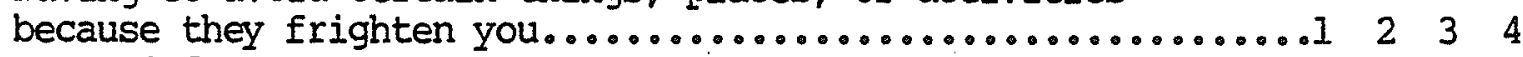

51. Your mind going blank.................................. 2 2 34

52. Numbness or tingling in parts of your body.................. 2 . 3 . 4

53. A lump in your throat.................................. $22^{2} 33^{4}$

54. Feeling hopeless about the future........................... $22^{2} 3^{4} 4$

55. Trouble concentrating..................................1 2 2 34

56. Feeling weak in parts of your body........................ $2^{2} \quad 3 \quad 4$

57. Feeling tense or keyed up................................ $22^{2} 34$

58. Heavy feelings in your arms or legs.............................. $22^{2} 3_{4} 4$

PART F

Please try to vividly imagine yourself in the situations that follow. If such a situation happened to you, what would you feel would have caused it? While events have many causes, we want you to pick only one - the major cause if this event happened to you. Please write this cause in the blank provided after each event. Next we want you to answer some questions about the cause. To summarize, we want you to:

1. Read each situation and vividly imagine it happening to you.

2. Decidew hat you feel would be the major cause of the situation if it happened to you.

3. Write one cause in the blank provided.

4. Answer three questions about the cause.

5. Go on to the next situation.

1. You meet a friend who compliments you on your appearance. a. Write down the one major cause b. Is the cause of the compliment due to something about you or to 
something about other people or circumstances? (circle one number) Totally due to other Totally due

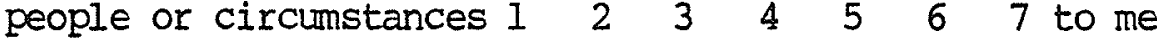

c. In the future when receiving a compliment, will this cause again be present?

Will never again

be present

$\begin{array}{llllllll} & 1 & 2 & 3 & 4 & 5 & 6 & 7 \\ \text { be present }\end{array}$

d. Is the cause something that just influences receiving compliments or does it also influence other areas of your life? Influences just this $\begin{array}{lllllllll}\text { particular situation } & 1 & 2 & 3 & 4 & 5 & 6 & 7 & \text { situations }\end{array}$

2. You have been looking for a job unsuccessfully for some time.

a. Write down the one major cause

b. Is the cause of your unsuccessful job search due to something about you or to something about other people or circumstances?

Totally due to other

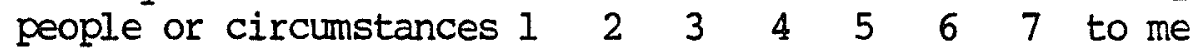

c. In the future when looking for a job, will this cause again be present? Will never again $\begin{array}{lllllllll}\text { be present } & 1 & 2 & 3 & 4 & 5 & 6 & 7 & \text { be present }\end{array}$

$d_{0}$ Is the cause something that just influences looking for a job or coes it also influence other areas of your life?

Influences just this Influences all $\begin{array}{lllllllll}\text { particular situation } & 1 & 2 & 3 & 4 & 5 & 6 & 7 & \text { situations }\end{array}$

3. You become very rich.

a. Write down the one major cause

b. Is the cause of your becoming rich due to something about you or to something about other people or circumstances? Totally due to other

Totally due

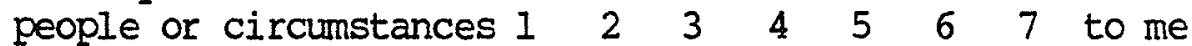

c. In the future if you become rich, will this cause again be present? Will never again

$\begin{array}{lllllllll}\text { be present } & 1 & 2 & 3 & 4 & 5 & 6 & 7 & \text { be present }\end{array}$

d. Is the cause something that just influences becoming rich or does it also influence other areas of your life?

Influences just this

$\begin{array}{lllllllll}\text { particular situation } & 1 & 2 & 3 & 4 & 5 & 6 & 7 & \text { situations }\end{array}$

4. A friend comes to you with a problem and you don't try to help.

a. Write down the one major cause

b. Is the cause of your not helping your friend due to something about you or to something about other people or circumstances?

Totally due to other

Totally due

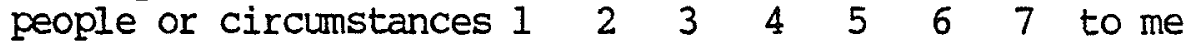

c. In the future if you don't help a friend, will this cause again be present?

Will never again $\quad$ Will always

$\begin{array}{lllllllll}\text { be present } & 1 & 2 & 3 & 4 & 5 & 6 & 7 & \text { be present }\end{array}$

d. Is the cause something that just influences your response to requests for help from friends or does it also influence other areas of your life?

Influences just this particular situation
12
3
$\begin{array}{lll}4 & 5 & 6\end{array}$
Influences all 
5. You give an important talk in front of a group and the audience reacts negatively.

a. Write down the one major cause

b. Is the cause of the audience's response due to something about you or to something about other people or circumstances? (circle one number) Totally due to other Totally due people or circumstances $1 \quad 2 \quad 3 \quad 4 \quad 5 \quad 6 \quad 7$ to me

c. In the future when an audience responds negatively, will this cause again be present?

Will never again

be present

$$
\text { Will always }
$$

$\begin{array}{llllllll}1 & 2 & 3 & 4 & 5 & 6 & 7 & \text { be present }\end{array}$

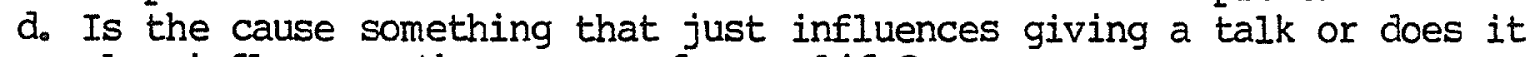
also influence other areas of your life? Influences just this particular situation
1
23
34
456

Influences all

6. You do a project that is highly praised.

a. Write down the one major cause

b. Is the cause of the praise due to something about you or to something about other people or circumstances? (circle one number)
Totally due to other
Totally due

people or circumstances $1 \quad 2 \quad 3 \quad \begin{array}{lllllll}1 & 2 & 3 & 5 & 6 & 7 & \text { to me }\end{array}$

c. In the future when you receive praise for a project will this cause again be present?

will never again

be present

$\begin{array}{llllllll}1 & 2 & 3 & 4 & 5 & 6 & 7 & \begin{array}{l}\text { Will always } \\ \text { be present }\end{array}\end{array}$

d. Is the cause something that just influences receiving praise for a project or does it also influence other areas of your life?

Influences just this

$\begin{array}{lllllllll}\text { particular situation } & 1 & 2 & 3 & 4 & 5 & 6 & 7 & \text { situations }\end{array}$

7. You meet a friend who acts hostilely toward you.

a. Write down the one major cause

b. Is the cause of the friend's reaction due to something about you or to something about other people or circumstances? (circle one number) Totally due to other Totally due

people or circumstances $1 \quad 2 \quad 3 \quad \begin{array}{lllllll}1 & 2 & 3 & 5 & 6 & 7 & \text { to me }\end{array}$

c. In the future when a friend acts hostile, will this cause again be present?

Will never again

be present

\section{$\begin{array}{llllllll}1 & 2 & 3 & 4 & 5 & 6 & 7 & \text { be present }\end{array}$}

d. Is the cause something that just influences friends' actions or does it also influence other areas of your life?

Influences just this particular situation $\quad \begin{array}{llllllll}1 & 2 & 3 & 4 & 5 & 6 & 7 & \text { situations }\end{array}$

8. You can't get all the work done that others expect of you.

a. Write down the one major cause

b. Is the cause of your inability to do all the work due to something about you or to something about other people or circumstances? Totally due to other people or circunstances $1 \quad 2 \quad 3 \quad \begin{array}{llllll}1 & 2 & 5 & 6 & 7 & \text { to me }\end{array}$

c. In the future when you are unable to get work done, will this cause again be present? 
Will never again

be present

$\begin{array}{llllllll}1 & 2 & 3 & 4 & 5 & 6 & 7 & \begin{array}{l}\text { Will always } \\ \text { be present }\end{array}\end{array}$

d. Is the cause something that just influences inability to get work done or does it also influence other areas of your life?

Influences just this

particular situation

$$
\begin{array}{llllllll}
1 & 2 & 3 & 4 & 5 & 6 & 7 & \text { situations }
\end{array}
$$

9. Your spouse (boyfriend/girlfriend) has been treating you more lovingly.

a. Write down the one major cause

b. Is the cause of your partner's behavior due to something about you or to something about other people or circumstances? (circle one number) Totally due to other people or circumstances $11 \quad 2 \quad \begin{array}{lllllll} & 3 & 4 & 5 & 6 & 7 & \text { to me }\end{array}$

c. In the future when your partner treats you lovingly will this cause again be present?

Will never again

$\begin{array}{lllllllll}\text { be present } & 1 & 2 & 3 & 4 & 5 & 6 & 7 & \text { be present }\end{array}$

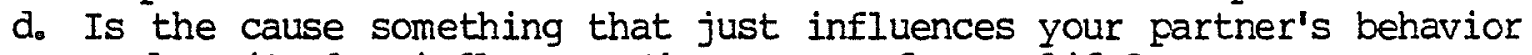
or does it also influence other areas of your life?

Influences just this

$\begin{array}{lllllllll}\text { particular situation } & 1 & 2 & 3 & 4 & 5 & 6 & 7 & \text { situations }\end{array}$

10. You apply for a position that you want very badly (e.g., important job, graduate school admission) and you get it.

a. Write down the one major cause

b. Is the cause of your success due to something about you or to something about other people or circumstances? (circle one number) Totally due to other Totally due

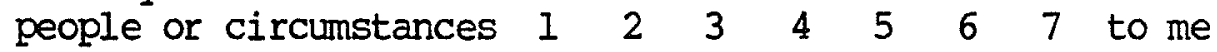

c. In the future when you get a position you want will this cause again be present?

Will never again Will always

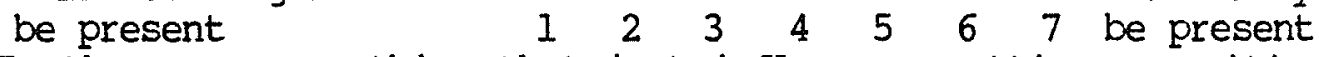

$d_{0}$. Is the cause something that just influences getting a position you want or does it also influence other areas of your life?

Influences just this

$\begin{array}{lllllllll}\text { particular situation } & 1 & 2 & 3 & 4 & 5 & 6 & 7 & \text { situations }\end{array}$

11. You go out on a date and it goes badly.

a. Write down the one major cause

b. Is the cause of your unsuccessful date due to something about you or to something about other people or circumstances? (circle one number) Totally due to other Totally due people or circumstances $11 \quad 2 \quad \begin{array}{lllllll} & 3 & 4 & 5 & 6 & 7 & \text { to me }\end{array}$

c. In the future when a date goes badly, will this cause again be present? Will never again be present $\begin{array}{llllllll}1 & 2 & 3 & 4 & 5 & 6 & 7 & \text { be present }\end{array}$

d. Is the cause something that just influences dates or does it also influence other areas of your life?

Influences just this particular situation

12. You get a raise.

a. Write down the one major cause b. Is the cause of your raise due to something about you or to something 
about other people or circumstances? (circle one number)

Totally due to other people or circumstances $11 \quad 2 \quad \begin{array}{lllllll} & 3 & 4 & 5 & 6 & 7 & \text { to me }\end{array}$

c. In the future when you get a raise, will this cause again be present? Will never again

be present

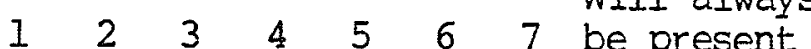

d. Is the cause something that just influences getting a raise or does it also influence other areas of your life?

Influences just this particular situation

$\begin{array}{llllllll}1 & 2 & 3 & 4 & 5 & 6 & 7 & \begin{array}{l}\text { Influences all } \\ \text { situations }\end{array}\end{array}$

\section{PART G}

This section is designed to gather background and social behavior information. Answer the questions by circling the number which corresponds to the best answer for you. Use the following code.

0 Not at all characteristic of me

1 Not very characteristic of me

2 Slightiy characteristic of me

3 Fairly characteristic of me

4 Very much characteristic of me

1. I am not likely to speak to people until they speak to me..0 12234

2. I would describe myself as self-confident.................

3. I feel confident of my appearance.........................

4. I am a good mixer..................................... $1{ }^{2}{ }^{2} 3{ }^{4}$

5. When in a group of people, I have trouble thinking of the

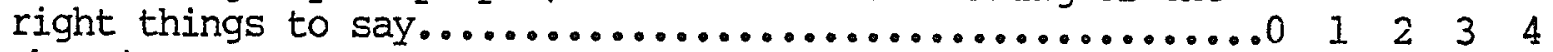

6 . When in a group of people, I usually do what the others

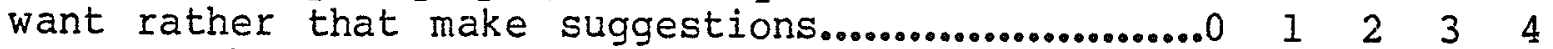

7. When I am in a disagreement with other people, my opinion usually prevails................................... I $2{ }^{2} 34$

8. I would describe myself as one who attempts to master situations..........................................0 $12^{2} 34$

9. Other people look up to me............................. $1{ }^{2}{ }^{2} \quad 3 \quad 4$

10. I enjoy social gatherings just to be with people...........

11. I make a point of looking other people in the eye.......... $1 c^{2} \quad 3 \quad 4$

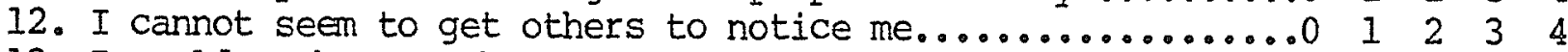

13. I would rather not have very much responsibility for other people............................................ $1{ }^{2} 34$

14. I feel comfortable being approached by someone in a

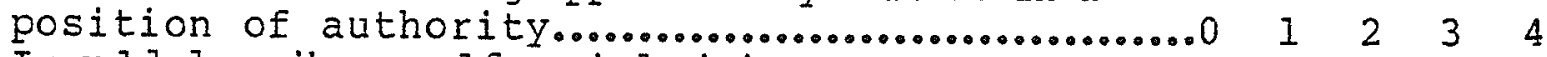

15. I would describe myself as indecisive...................... $I^{2} 23^{3} 4$

16. I have no doubt about my social competence...............

\section{PART H}

In tnis section you are asked to list the people with whom wou discuss issues related to a) home and family and b) personal and social issues. In each case, please list the people with whom you generally discuss that issue, using the first name or initials only. After each name or set of initials fill in a one or two word description of the relation each person 
has to you (e.g., spouse, parent, friend, co-worker, etc.). Then go on to circle the number which indicates the degree of helpfulness of your discussions with each person, and lastly, check off yes or no if you feel this person would come to you to discuss that issue. Don't feel that you have to fill up all the spaces provided.

a) I discuss home and family with:

\begin{tabular}{|c|c|c|c|c|c|c|c|c|c|c|}
\hline Kare or & Relation & Belpfu & Ir & hess of & E I & biscus: & sid & & Would th & \\
\hline initials & 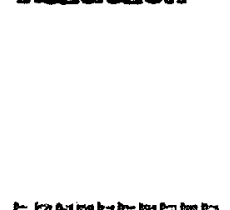 & $\begin{array}{l}\text { Makes } \\
\text { things } \\
\text { a lot } \\
\text { worse } \\
1\end{array}$ & 2 & $\begin{array}{l}\text { Makes } \\
\text { things } \\
\text { a bit } \\
\text { worse } \\
3\end{array}$ & 4 & $\begin{array}{l}\text { Helps } \\
\text { things } \\
\text { a bit }\end{array}$ & 5 & $\begin{array}{l}\text { Helps } \\
\text { things } \\
\text { a lot } \\
7\end{array}$ & $\begin{array}{l}\text { person } \\
\text { you to d } \\
\text { home and } \\
\text { Yes } \\
1\end{array}$ & $\begin{array}{l}\text { Come to } \\
\text { liscuss } \\
\text { family? } \\
\text { No } \\
0\end{array}$ \\
\hline 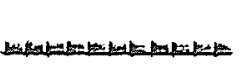 & - & 1 & 2 & 3 & 4 & 5 & 6 & 7 & 1 & 0 \\
\hline 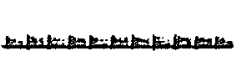 & 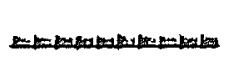 & 1 & 2 & 3 & 4 & 5 & 6 & 7 & 1 & 0 \\
\hline 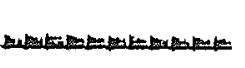 & 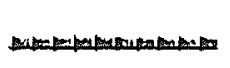 & 1 & 2 & 3 & 4 & 5 & 6 & 7 & 1 & 0 \\
\hline 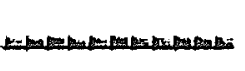 & 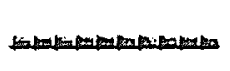 & 1 & 2 & 3 & 4 & 5 & 6 & 7 & 1 & 0 \\
\hline 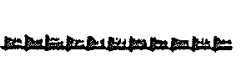 & 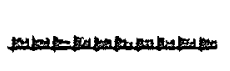 & 1 & 2 & 3 & 4 & 5 & 6 & 7 & 1 & 0 \\
\hline $5=1-1=10$ & 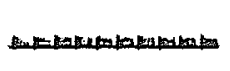 & 1 & 2 & 3 & 4 & 5 & 6 & 7 & 1 & 0 \\
\hline 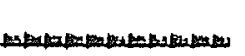 & 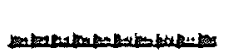 & 1 & 2 & 3 & 4 & 5 & 6 & 7 & $I$ & 0 \\
\hline
\end{tabular}

b) I discuss personal and social issues with:

Name or initials

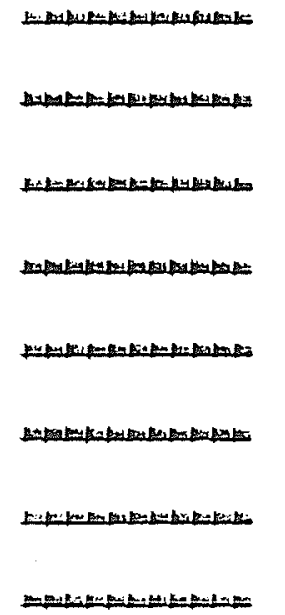

Relation

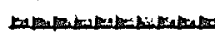

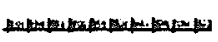

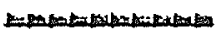

19an

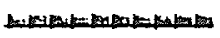

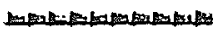

ton

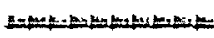

Helpfulness of Discussion Makes Makes Helps Helps things things things things a lot a bit a bit a lot worse
123

$\begin{array}{lllllll}1 & 2 & 3 & 4 & 5 & 6 & 7\end{array}$

$\begin{array}{lllllll}1 & 2 & 3 & 4 & 5 & 6 & 7\end{array}$

$\begin{array}{lllllll}1 & 2 & 3 & 4 & 5 & 6 & 7\end{array}$

$\begin{array}{lllllll}1 & 2 & 3 & 4 & 5 & 6 & 7\end{array}$

$\begin{array}{lllllll}1 & 2 & 3 & 4 & 5 & 6 & 7\end{array}$

$\begin{array}{lllllll}1 & 2 & 3 & 4 & 5 & 6 & 7\end{array}$

$\begin{array}{lllllll}1 & 2 & 3 & 4 & 5 & 6 & 7\end{array}$
Would this person come to you to discuss these issues? Yes No

1

1

1

1

1

1

1

1
No

0


c) Please list the first names or initials of the people to whom you would turn in times of crisis. Fill in a brief description of how each person is related to you and check off yes or no if you feel this person would come to you in times or crisis.

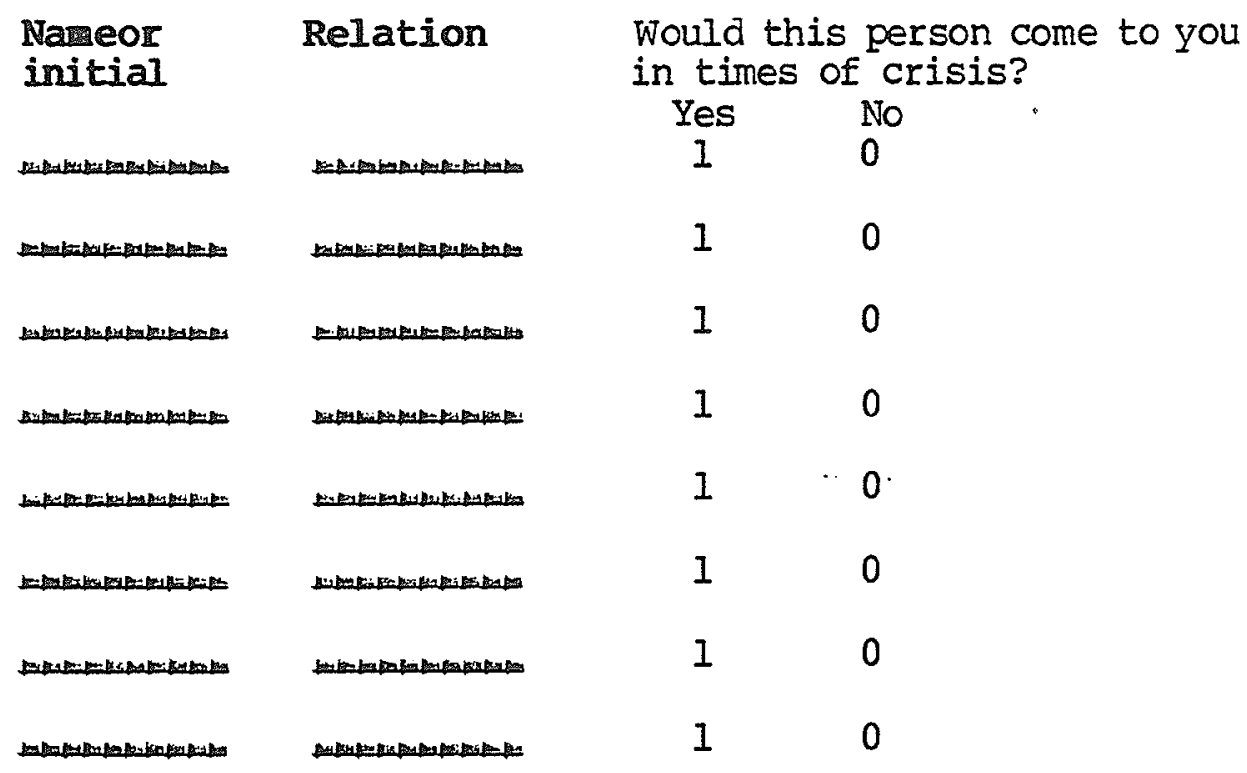

PART I

Please read each of the following four scenarios and imagine that the situation described actually happened to you, then answer the four questions that follow each situation.

1. You are driving to the store with a friend of yours in the passenger seat. It is wintertime and al though it hasn't snowed in almost two weeks, the sides of the street are still piled high with snow from previous storms. You get to an intersection which has no stop sign on either corner. Because of the snow it is hard to see around the corner, so you look up and down the street and then step on the accelerator. As you get to the middle of the intersection, you see another car heading straight for your car. It's too late; you can't stop. Your car is hit and your friend is badly hurt.

a. Given what happened, how much do you blame: all yourself............................ other people............................ the enviroment (i.e., the impersonal world).....0 chance.............................

b. Given what happened, how much do you blame yourself for the kindof person who is in an accident? $0 \begin{array}{llllll}1 & 2 & 3 & 4 & 5\end{array}$

c. Given what happened, how much do you blame yourself for your driving behavior?............

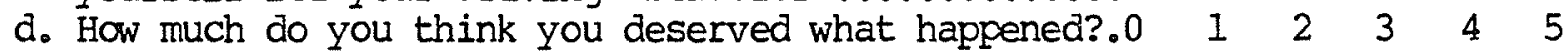


2. You meet a new "friend" at a party, and you think the two of you hit it off fairly well. You spend much of the evening talking to each other. When you leave you tell yourself you would like to stay in touch with this person, although you haven't made definite plans to do so. A week later there is a show in town; your parents have two tickets but can't make it, so they give them to you. You call your new "friend" who seems happy to hear from you, but who claims that $\mathrm{s} / \mathrm{he}$ is busy the night of the show. You express your regrets and go to the show with another friend. The next day you find out that your new "friend" really did not have prior plans as claimed. You can't help but wonder why s/he didn't want to go with you to the show.
a. Given what happened, how much do you blame: $\begin{aligned} & \text { Not at } \\ & \text { yourself }\end{aligned}$
all

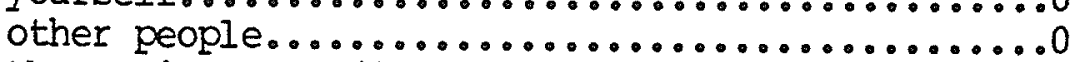 the environment (i.e., the impersonal world).....0 chance..................................
b. Given what happened, how much do you blame your- self for the kind of person who has invitations

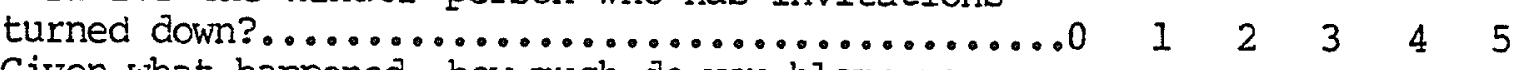
c. Given what happened, how much do you blame your- self for how you acted when you first met the person?.................................

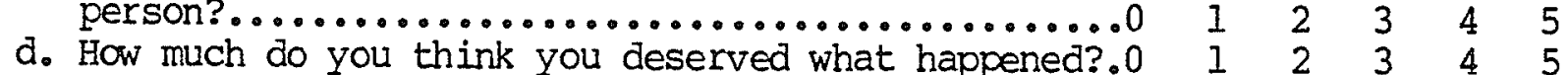

3. Your roommate is out and her boyfriend calls. He leaves a message as to his whereabouts and asks you to have your roommate call him when she gets in. It is urgent that she call as soon as possible. Al though there is a lot of commotion on both ends of the phone, you get the number down and give your roommate the message. She tries to get through, but the line is busy; when sne finally does get through, she finds that the number you gave her is the wrong number. There is no other way for your roommate to get in touch with her boyfriend.
a. Given what happened, how much do you blame: all yourself...................................0

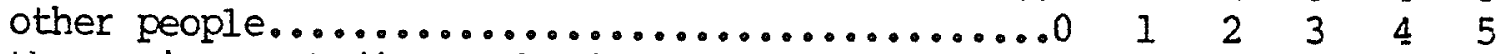

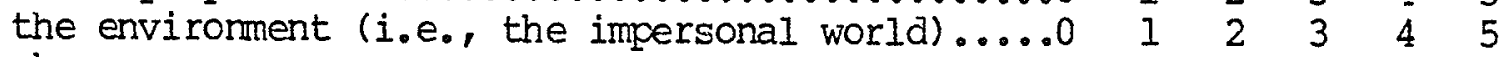 chance................................ 1 . 2345
b. Given what happened, how much do you blame your- self for the kindof person who causes

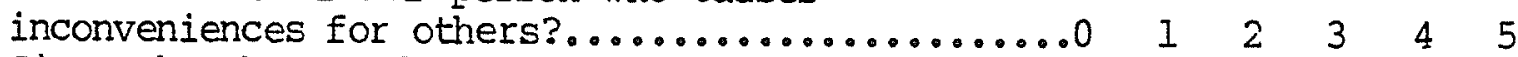
c. Given what happened, how much do you blame yourself for how you acted when taking down the
$\begin{array}{lllllll}\text { telephone number?................................. } & 1 & 2 & 3 & 4 & 5 \\ \text { d. How much do you think you deserved what happened?.0 } & 1 & 2 & 3 & 4 & 5\end{array}$

4. You are involved in an intense love relationship that lasts about two years. Your relationship has "normal" ups and downs, but you still care very much about this person. out of the blue, it seems, your boyfriend leaves you and immediately becomes involved with another person. You are alone and miss him terribly because, despite the problems, you still love him very much. 


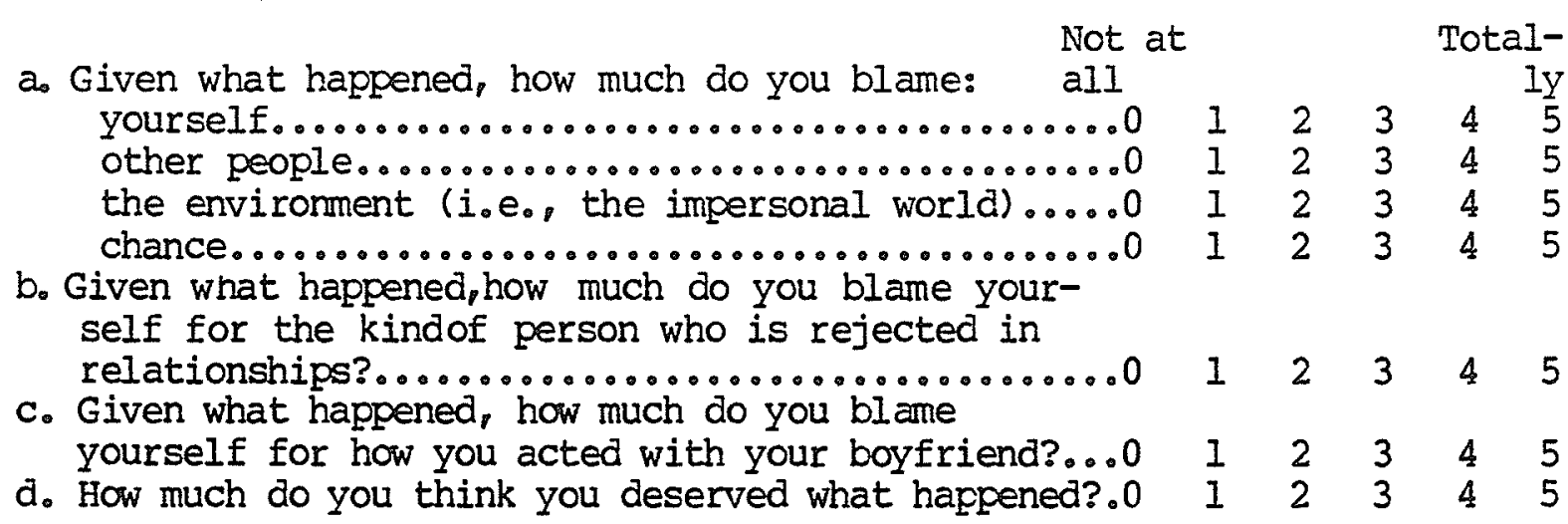

PART J

These questions are designed to find out the way in which certain important events in our society affect different people. Each item consists of a pair of alternatives lettered $a$ or $b$. Please select the one statement of each pair (and only one) which you more strongly believe to be the cause as far as you are concerned. Be sure to select the one that you actually believe to be more true rather than the one you think you should choose or the one you would like to be true. This is a measure of personal belief; obviously there are no right or wrong answers.

Please answer these items carefully but do not spend too much time on any one item. Be sure to find an answer for every choice. In some instances you may discover that you believe both statements or neither one. In such cases be sure to select the one you more strongly believe to be the case as far as you are concerned. Also try to respond to each item independently when making your choice; do not be influenced by your previous choices.

1a. Children get into trouble because their parents punish them too much.

b. The trouble with most children nowadays is that their parents are to easy with them.

2a. Many of the unhappy things in people's lives are partly due to bad luck

b. People's misfortunes result from the mistakes they make.

3a. One of the major reasons why we have wars is because people don't take enough interest in politics.

b. There will always be wars, no matter how hard people try to prevent them.

4a. In the long run people get the respect they deserve in this world.

b. Unfortunately, an individual's worth often goes unrecognized no matter how hard he tries.

5a. The idea that teachers are unfair to students is nonsense.

b. Most students don't realize the extent to which their grades are influenced by accidental happenings.

6a. Without the right breaks one cannot be an effective leader.

b. Capable people who fail to become leaders have not taken advantage of their opportunities. 
7a. No matter how hard you try some people just don't like you.

b. People who can't get others to like them don't understand how to get along with others.

8a. Heredity plays the major role in determining one's personality.

b. It is one's experiences in life which determine what they're like.

9a. I have often found that what is going to happen will happen.

b. Trusting to fate has never turned out as well for me as making a decision to take a definite course of action.

10a. In the case of the well prepared student there is rarely if ever such a thing as an unfair test.

b. Many times exam questions tend to be so unrelated to course work that stuodying is really useless.

1la. Becoming a success is a matter of hard work, luck has little or nothing to do with it.

b. Getting a good job depends mainly on being in the right place at the right time.

12a. The average citizen can have influence in government decisions.

b. This world is run by the few people in power, and there is not much the little guy can do about it.

13a. When I make plans, I am almost certain that I can make them work.

b. It is not always wise to plan too far ahead because many things turn out to be a matter of good or bad fortune anyhow.

14a. There are certain people who are just no good.

b. There is some good in everybody.

15a. In my case getting what I want has little or nothing to do with luck.

b. Many times we might just as well decide what to do by flipping a coin.

16a. Who gets to be the boss often depends on who was lucky enough to be in the right place first.

b. Getting people to do the right thing depends upon ability, luck has little or nothing to do with it.

17a. As far as world atfairs are concerned, most of us are the victims of we can neither understand, nor control.

b. By taking an active part in political and social affairs the people can control world events.

18a. Most people don't realize the extent to which their lives are controlled by accicental happenings.

b. There is really no such thing as "luck".

19a. One should always be willing to admit mistakes.

b. It is usually best to cover up one's mistakes.

20a. It is hard to know whether or not a person really likes you.

b. How many friends you have depends upon how nice a person you are. 
21a. In the long run the bad things that happen to us are balanced by the good ones.

b. Most misfortunes are the result of lack of ability, ignorance, laziness, or all three.

22a. With enough etfort we can wipe out political corruption.

b. It is difficult for people to have much control over the things politicians do in office.

23a. Sometimes I can't understand how teachers arrive at the grades they give.

b. There is a direct connection between how hard I study and the grades I get.

24a. A good leader expects people to decide for themselves what they should do.

b. A good leader makes it clear to everyone what their jobs are.

25a. Many times I feel that I have little influence over the things that happen to me.

b. It is impossible for me to believe that chance or luck plays an important role in my life.

26a. People are lonely because they don't try to be friendly.

b. There's not much use in trying too hard to please people, if they like you, they like you.

27a. There is too much emphasis on athletics in high school.

b. Team sports are an excellent way to build character.

28a. What happens to me is my own doing.

b. Sometimes I feel that I don't have enough control over the direction my life is taking.

29a. Most of the time I can't understand why politicians behave the way they do.

b. In the long run the people are responsible for bad governement on a national as well as on a local level.

\section{PART K}

For each of the following questions circle the number of the statement that best describes how you have been feeling auring the past week.

1. 0 I do not feel sad.

I I feel saá.

2 I am sad all of the time and I can't snap out of it.

3 I am so sad or unhappy that I can't stand it.

2. 0 I am not particularly discouraged about the future.

I I feel discouraged about the future.

2 I feel I have nothing to look forward to.

3 I feel that the future is hopeless and that things cannot improve. 
3. 0 I do not feel like a failure.

I I feel I have failed more than the average person.

2 As I look back on my life, all I can see is a lot of failures.

3 I feel I am a complete failure as a person.

4. 0 I don't feel particularly guilty.

1 I feel guilty a good part of the time.

2 I feel quite guilty most of the time.

3 I feel guilty all of the time.

5. 0 I don't feel I am being punished.

I I feel I may be punished.

2 I expect to be punished.

3 I feel I am being punished.

6. 0 I don't feel disappointed in mvself.

1 I am disappointed in myself.

2 I am disgusted with myself.

3 I hate myself.

7. 0 I don't feel I am any worse than anybody else.

1 I am critical of myself for my weaknesses or mistakes.

2 I blame myself all the time for my faults.

3 I blame myself for everything bad that happens.

8. 0 I don't have any thoughts of killing myself.

1 I have thoughts of killing myself; but I would not carry them out.

2 I would like to kill myself.

3 I would $k i l$ myself if I had the chance.

9. 0 I don't cry any more than usual.

I I cry more now than I used to.

2 I cry all the time now.

3 I used to be able to cry, but now I can't even though I want to.

10. 0 I am no more irritated now than I ever am.

1 I get annoyed or irritated more easily than I used to.

2 I feel irritated all the time now.

3 I don't get irritated at all by the things that used to irritate me.

11. 0 I have not lost interest in other people.

I I am less interested in other people than I used to be.

2 I have lost most of my interest in other people.

3 I have lost all of my interest in other people.

12. 0 I make decisions about as well as I ever could.

1 I put off making decisions more than I used to.

2 I have greater difficulty in making decisions than before.

3 I can't make decisions at all any more.

13. 0 I don't feel I look any worse than I used to.

I I am worried that I am looking old or unattractive.

2 I feel that there are permanent changes in my appearance that make me look unattractive.

3 I believe that I look ugly. 
14. 0 I can work about as well as before.

1 It takes an extra effort to get started at doing something.

2 I have to push myself very hard to do anything.

3 I can't do any work at all.

15. 0 I can sleep as well as usual.

I I don't sleep as well as I used to.

2 I wake up 1-2 hours earlier than usual and find it hard to get back to sleep.

3 I wake up several hours earlier than I used to and cannot get back to sleep.

16. 0 I don't get more tired than usual.

1 I get tired more easily than I used to.

2 I get tired from doing almost anything.

3 I am too tired to do anything.

17. O I haven't lost much weight, if any, lately.

I I have lost more than 5 pounds.

2 I have lost more than 10 pounds.

3 I have lost more than 15 pounds.

I am purposely trying to lose weight by eating less.

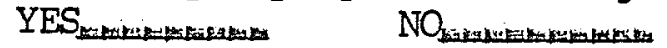

18. O I am no more worried about my health than usual.

I I am worried about physical problems such as aches or pains, or upset stomach or constipation.

2 I am very worried about physical problems and it's hard to think of much else.

3 I am so worried about my physical problems that I can't think about anything else.

19. O I have not noticed any recent change in my interest in sex.

1 I am less interested in sex than I used to be.

2 I am much less interested in sex now.

3 I have lost interest in sex completely.

20. 0 I get as much satisfaction out of things as I used to.

I I don't enjoy things the way I used to.

2 I don't get real satisfaction out of anything any more.

3 I am dissatisfied or bored with everything.

21. O My appetite is no worse than usual.

I My appetite is not as good as it used to be.

2 My appetite is much worse now.

3 I have no appetite at all anymore. 


\section{PART L}

Listed below are a number of statements concerning personal attitudes and traits. Read each item and decide whether the statement is true or false a it pertains to you personally.

1. Betore voting I thoroughly investigate the qualifications of

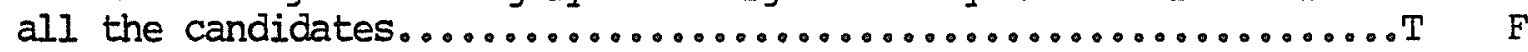

2. I never hesitate to go out of $\mathrm{my}$ way to help someone in trouble...T $\mathrm{F}$

3. It is sometimes hard for me to go on with my work if I am not

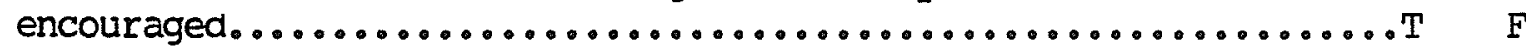

4. I have never intensely disliked anyone..................... F F

5. On occasion I have had doubts about my ability to succeed in Iife.T $F$

6. I scmetimes feel resentful when I don't get my way............T F

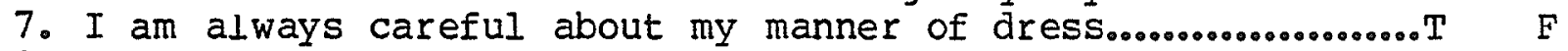

8. My table manners at home are as good as when I eat out in a restaurant .................................... $\quad F$

9. If I could get into a movie without paying and be sure I was

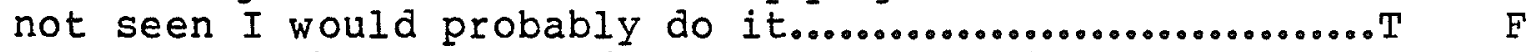

10. On a few occasions, I have given up doing something because

I thought too little of my ability............................ T F

11. I like to gossip at times............................ F

12. There have been times when I felt like rebelling against people in authority even though I knew they were right............T $F$

13. No matter who I'm talking to, I'm always a good Iistener.........T F

14. I can remember "playing sick" to get out of something........... F F

15. There have been occasions when I took advantage of someone......T F

16. I'm always willing to admit when I make a mistake............. F F

17. I always practice what I preach....................... $\quad$ F

18. I don't find it particularly difficult to get along with loud mouthed, obnoxious people................................T F

19. I sometimes try to get even rather than to forgive and forget....T $F$

20. When I don't know something I don't at all mind admitting it.....T $F$

21. I am always courteous, even to people who are disagreeable.......T F

22. At times I have really insisted on having things my own way......T F

23. There have been occasions when I felt like smashing things........T $\mathrm{F}$

24. I would never think of letting someone else be punished

for my wrongdoings.................................

25. I never resent being asked to return a favor................. F F

26. I have never been irked when people expressed ideas very

different from my own.................................... T F

27. I never make a long trip without checking the safety of my car...T F

28. There have been times when I was quite jealous of the good fortune of others................................... T F

29. I have almost never felt the urge to tell someone off..........T F

30. I am sometimes irritated by people who ask favors of me.........T F

31. I have never felt that I was punished without cause...........T F

32. I sometimes think when people have a misfortune they only got what they deserved....................................T F

33. I have never deliberately said something that hurt someone's feelings..................................... 
APPENDIX C

Open-ended Questions About Sexual Victimization Experiences 
Discussion Questions for Victims

la. How did your sexual experience(s) as a child affect you at the time it occurred?

b. How did your sexual experience(s) affect you as an adult?

2. Which aspects of your sexual experience(s) most affected how you responded to the situation?

3a. How well do you think you have coped with this experience generally, and compared to other women who have had similar experiences?

b. What helped you to cope?

c. What factors, if any, interfered with your ability to cope?

4. If a girl came to you and told you that she had had a similar experience to yours, what advice would you give her to help her to cope?

5a. If you have received therapy, what aspects of it helped you the most?

b. What aspects of therapy were not helpful? 
APPENDIX D

Table of Means and Standard Deviations from Multivariate Analysis of Covariance 
Table of Means and Standard Deviations from Multivariate Analysis of Covariance

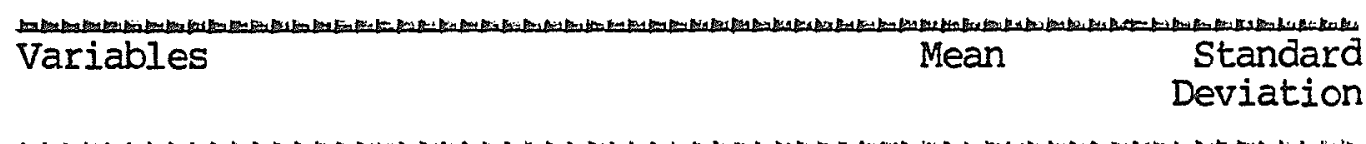

Global - Bad Events (ASQ)

Victims

Nonvictims

Internal, Stable, Global-Bad (ASQ)

Victims

Nonvictims

Characterological Blame

Victims

Nonvictims

Internal - Good Events (ASQ)

Victims

Nonvictims

Other Blame

Victims

7.96

4.14

Nonvictims

Behavioral Blame

Victims

Nonvictims
4.41

1.24

3.71

1.16

4.57 .84

4.21 .72
9.39

6.51

5.66

4.70

1.15

5.03 .80
9.64 4.00

10.63

4.63

8.91

5.46

(table continues) 


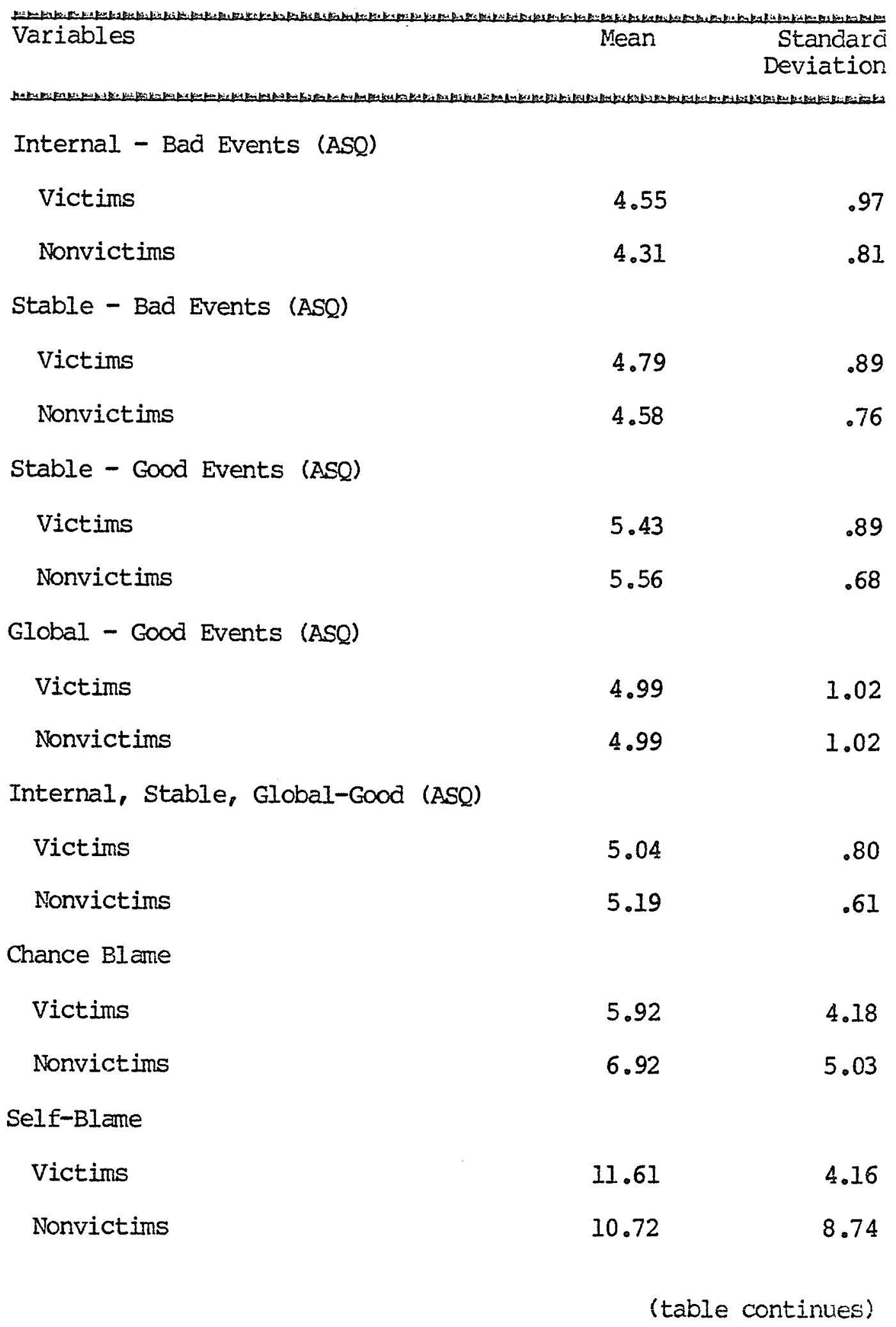




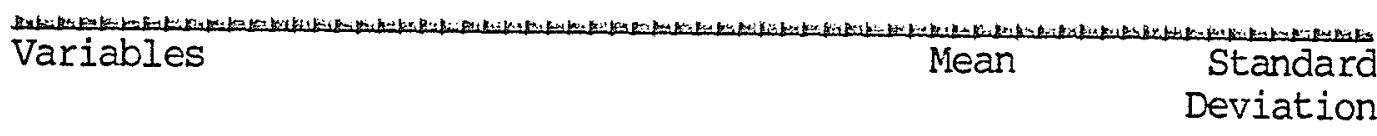

Jiz

Envi ronment-Blame

Victims

6.86

4.07

Nonvictims

7.39

4.81

Deservingness

Victıms

6.14

4.94

Nonvictims

5.76

10.29

Locus of Control

Viccims

10.90

3.91

Nonvictims

10.17

4.70

Depression (BDI)

Victims

11.59

9.10

Nonvictims

5.85

5.05

Psychological Symptoms (HSCL)

Victims

22.88

9.38

Nonvictims

17.41

8.19

Incensicy of Symptoms (HSCL)

Victims

79.41

21.56

Nonvictims

67.64

14.75

Negative Sexual Symptoms

Victims

12.29

3.09

Nonvictims

13.83

2.19

(table continues) 


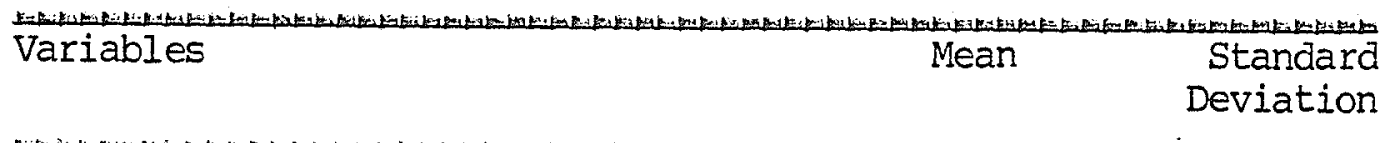

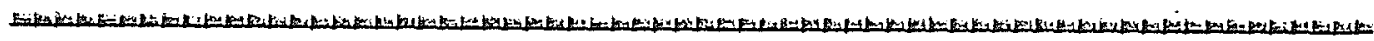

Sexual Responsiveness

Victıms

Nonvictims

1.12

.63

Self-Esteem (TSBI)

Victims

36.96

9.53

Nonvictims

41.24

7.52

Sexua」 Satisfaction

Victims

12.56

7.81

Nonvictims

15.25

6.67

Heterosexual Behavior

Victims

5.79

2.46

Nonvictims

5.43

2.29

Homosexual Behavior

Victıms

8.50

1.28

Nonvictims

8.75

1.22

Sexual Desire

Victims

4.47

1.97

Nonvictims

3.92

1.77

Masturbation

Viccıms

5.83

2.31

Nonvictims

6.39

2.08

(table continues) 


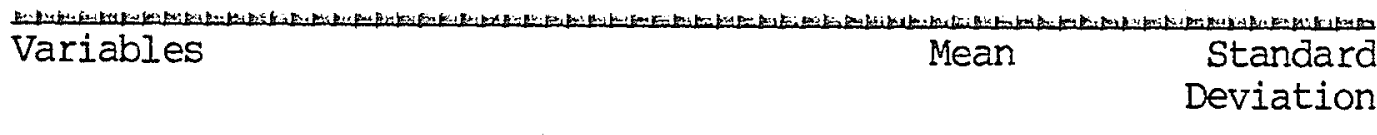

10

Sexual Arousal

Victims

4.00

2.50

Nonvictims

3.47

2.78

Orgasmic Ability

Victıms

7.59

3.48

Nonvictims

7.85

3.98

Number of Sex Partners

Viccims

2.09

.94

Nonvictims

2.09

.71

Crıminal Benavior

Victims

.16

Nonvictims

.08

.27

Alcohol and Drug Use

Vicrims

19.13

12.43

Nonvictims

17.93

12.32

Psychological Help received

Vicrıms

1.56

1.32

Nonvictins

.72

.97

Number of Friends (age 12)

Vicrims

2.72

.72

Nonvictims

2.21

.85

(table continues) 


\begin{tabular}{|c|c|c|}
\hline Variables & Mean & $\begin{array}{l}\text { Standard } \\
\text { Deviation }\end{array}$ \\
\hline \multicolumn{3}{|c|}{ 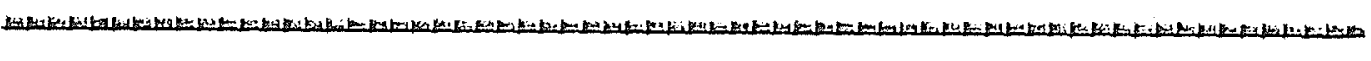 } \\
\hline \multicolumn{3}{|c|}{ Closeness to Mother } \\
\hline Victims & 2.93 & 1.42 \\
\hline Nonvictims & 2.18 & 1.03 \\
\hline \multicolumn{3}{|c|}{ Closeness to Father } \\
\hline Vicrims & 3.34 & 1.39 \\
\hline Nonvictims & 2.68 & 1.29 \\
\hline \multicolumn{3}{|c|}{ Reciprocity of Sccial Supports (SRS) } \\
\hline Victims & .84 & .14 \\
\hline Nonvictims & .86 & .15 \\
\hline \multicolumn{3}{|c|}{ Helpfulness of Social Supports (SRS) } \\
\hline Victıms & 5.56 & .71 \\
\hline Nonvictims & 5.66 & .86 \\
\hline \multicolumn{3}{|c|}{ Number of Social Supports (SRS) } \\
\hline Victıms & 14.16 & 5.60 \\
\hline Nonvictims & 15.03 & 4.79 \\
\hline \multicolumn{3}{|c|}{ Spanking by Mother } \\
\hline Vicrims & 2.13 & 1.62 \\
\hline Nonvictims & 1.51 & .89 \\
\hline \multicolumn{3}{|c|}{ Overall Family Violence } \\
\hline Victims & 11.81 & 12.74 \\
\hline Nonvictims & 6.41 & 10.92 \\
\hline
\end{tabular}


Variables Mean

Standard

Deviation

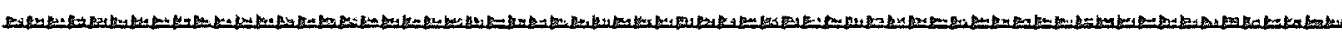

Spanking by Father

Victims

1.96

1.43

Nonvictims

1.42

.80

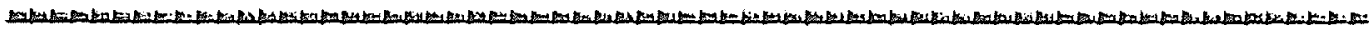

$\mathrm{n}=92$ for victims

$\mathrm{n}=75$ for nonvictims 